\title{
Bimodal Remapping of Visual Grids
}

2 Xiaoyang Long ${ }^{1}$, Jing $\mathrm{Cai}^{1}$, Bin Deng ${ }^{1}$, Zhe Sage Chen ${ }^{2, *} \&$ Sheng-Jia Zhang ${ }^{1, *}$

$3{ }^{1}$ Department of Neurosurgery, Xinqiao Hospital, Army Medical University, Chongqing 400037, China

$4 \quad{ }^{2}$ Department of Psychiatry, Department of Neuroscience \& Physiology, Neuroscience Institute, New

5 York University School of Medicine, New York, NY 10016, USA

6 *To whom correspondence should be addressed:

7 zhe.chen@ nyulangone.org (Z.S.C.) or sheng-jia.zhang@ outlook.com

8 ORCID: 0000-0002-6483-6056 (Z.S. Chen)

\section{Highlights}

10 - Bistable V2 grid cells display bimodal or bistable remapping

11 - V2 grid cell firing patterns are not disrupted in darkness

12 - V2 grid cells preserve theta frequency modulation during remapping

\section{Keywords}

14 grid cells, secondary visual cortex, remapping, bimodal grid patterns 


\section{Abstract}

16 Spatially modulated neurons from the rat secondary visual cortex (V2) show grid-like firing patterns

17 during freely foraging in open-field enclosures. However, the remapping of the V2 grid cells is not well

18 understood. Here we report two classes of V2 grid cell populations with distinct remapping properties:

19 one regular class with invariant grid field patterns, and the other bimodal class that has remapping

20 induced by environmental manipulations such as changes in enclosure shape, size, orientation and

21 lighting in a familiar environment. The bimodal V2 grid cell pattern remains stable regardless of the

22 follow-up manipulations, but restores to the original firing pattern upon animal's re-entry into the

23 familiar environment on the next day or from the novel environment. The bimodal V2 grid cells are

24 modulated with theta frequency during the course of remapping and stabilize quickly. We also found

25 conjunctive bistable V2 grid cells with invariant head directional tuning. Overall, our results suggest a

26 new grid cell mechanism in V2 that is different from the medial entorhinal cortex (MEC) grid cells. 


\section{Introduction}

28 Remapping of neuronal receptive fields reflects neural plasticity in response to changes in local or global environment, task context or stimulus cue (Latuske et al., 2017). Grid cells in the medial entorhinal cortex (MEC) is known to display spatial firing fields with a grid-like pattern (Hafting et al., 2005). Grid cells may change their firing patterns following environmental changes, which often involve translation and rotation of fields, but not much in rate-remapping fashion as reported in hippocampal place cells (Hafting et al., 2005, Fyhn et al., 2007, Barry et al., 2007, Jeffery, 2011, Barry et al., 2012, Marozzi et al., 2015). In humans, grid-like responses have been reported outside of the hippocampal formation in fMRI experiments [for a review, see (Raithel and Gottfried, 2021)], including the orbitofrontal cortex (OFC) (Constantinescu et al., 2016), prefrontal cortex (PFC) (Bao et al., 2019, Doeller et al., 2010) and anterior cingulate cortex (ACC) (Jacobs et al., 2013). Until very recently, grid cells have been discovered in the primary somatosensory cortex (S1) (Long and Zhang, 2021) and the secondary visual cortex (V2) from freely foraging rats in two-dimensional environmental enclosures (Long et al., 2021). However, the remapping of those sensory grid cells have not been systematically investigated, the potential circuit mechanisms of underlying the partial or global remapping of grid cells remains elusive.

Here we report two distinct subclasses of recorded V2 grid cells, which displayed two different stability in remapping patterns during environment changes in enclosure, one showing invariant grid field patterns and the other displaying translation and rotation in grid field patterns. Importantly, this bimodal remapping of V2 grid cells was not shown in the grid cells of rat MEC or S1, and was not found in other simultaneously recorded V2 spatially tuned cells (such as V2 place cells, V2 head-direction cells and V2 border cells). Additionally, unlike MEC grid cells that have disrupted firing patterns in the absence of visual input (Chen et al., 2016), the bimodal V2 grid cells have stable firing field independent of the visual input. MEC grid cells are reported to have modular grid scales and theta (6-12 Hz) modulation (Barry et al., 2012, Stensola et al., 2012, Deshmukh et al., 2010, Hafting et al., 2008). We found similar theta modulation among V2 grid cells, but did not observe any modular grid structure that might be due to sparse sampling. Moreover, theta frequency did not change during darkness where the visual input was absent. Thus, we first identify V2 bimodal/bistable grid patterns, which are distinct from firing properties of MEC grid cells. 


\section{Results}

\section{Bimodal remapping of $\mathrm{V} 2$ grid cells}

57 From a total of $70 \mathrm{~V} 2$ grid cells of freely foraging rats identified in our previous study (Long et al., 2021), 58 we began by asking whether V2 grid cells retained their spatial firing patterns in a similar manner as 59 MEC grid cells did when animals responded to manipulations of distinct environments (Hafting et al., 60 2005, Fyhn et al., 2007, Barry et al., 2007, Barry et al., 2012). In our experimental design, we recorded 61 and calculated only 40 out of 70 identified V2 gird cells ( $n=6$ rats) systematically for at least 20 min 62 from freely foraging rats in open two-dimensional enclosures. The recordings were continued for four 63 consecutive days consisting of several different sessions daily, each with unique experimental 64 manipulation and separated by an overnight sleep in a home cage (Fig. 1a). Surprisingly, contrary to the 65 context-invariant property of classical MEC grid cells, we observed that a proportion of V2 grid cells $(15 / 40=37.5 \%)$ switched to another distinct spatial firing pattern upon entry into manipulations of the changed environment, continued to retain its switched spatial firing patterns and did not revert back to its original spatial firing pattern across a series of environmental feature manipulations (Fig. 1). We therefore named this class of V2 grid cell as the bimodal V2 grid cell.

For the first manipulation of environmental shape, we compared the spatial firing patterns of V2 bimodal grid cells across square (S)-circle (C)-square (S')-circle (C')-square (S') boxes in five 30-min recording sessions. The first, third and fifth session were within a familiar square enclosure and the second and forth were within a novel circular enclosure in the same recording room (Fig. 1b). Specifically, bimodal remapping was evoked by replacing the square box with the circle one (Fig. 1b). Like MEC grid cells, the spatial firing pattern of the representative V2 bimodal grid cell was realigned by the circular arena (second row in Fig. 1b). However, the V2 grid pattern did not revert to the original spatial structure (S) from the novel circle (C) back to the familiar square (S') box, in contrast with the retained stable spatial alignment for MEC grid cells (Fyhn et al., 2007). When V2 grid cells were subsequently recorded in the circle $\left(C^{\prime}\right)$ and square $\left(S^{\prime}\right)$ arenas, the grid pattern still retained its bimodal firing pattern. After the completion of five consecutive recording sessions on day 1 , recorded animals were returned to the home cage for sleep. 
83 patterns of V2 bimodal grid cells reverted back to its original firing pattern observed during the first recording on day 1 (the first row in Fig. 1c). However, the switched grid patterns emerged again in the total darkness (D) and remained constantly stable during consecutive light-darkness-light (L-D-L') sessions in the same familiar recording room. These results indicated that this bimodal grid pattern was not disrupted in the absence of visual inputs.

Again, the shifted grid spatial firing patterns changed back to its original firing structure on the first recording session on day 3 . We further examined whether rotating the cue card can evoked bimodal remapping of V2 grid cells (Fig. 1d). The clockwise $90^{\circ}$ rotation (R) of the cue card evoked bimodal switch from the baseline (B), and the remapped grid structure did not reverse to its original firing pattern once back to the baseline condition (B'), in contrast to the MEC grid cell remapping during the similar cue-rotation manipulation (Fyhn et al., 2007). Similarly, after counterclockwise $90^{\circ}$ rotation (R') of the cue card, the bimodal grid vertices remained similar between rotation $\left(R^{\prime}\right)$ and baseline $\left(B^{\prime}\right)$.

On day 4, we examined whether bimodal remapping could be induced in a larger environment from the baseline trial (the first row in Fig. 1e). Again, we found similar remapping patterns in the recorded V2 grid cells in a $1.5 \times 1.5 \mathrm{~m}^{2}$ novel square box (L) and remained stable when back to the standard $1 \times 1 \mathrm{~m}^{2}$ recording enclosure $(S)$. The bimodal grid structure stayed unaltered although the size of the running boxes was reduced back to $1 \times 1 \mathrm{~m}^{2}\left(\mathrm{~S}^{\prime}\right)$ again.

100 In contrast to the bimodal V2 grid cells, the majority of recorded V2 grid cells $(25 / 40=62.5 \%)$ did not 101 switch their spatial firing patterns after environmental change in the same familiar room (Fig. S1), and 102 we called this subpopulation as the regular V2 grid cells. To compare the bimodal with regular V2 grid 103 cells, we calculated the mean displacement of the peak of the spatial cross-correlogram between the 104 original baseline (B) and the baseline (B') after environmental change. We found that the mean 105 displacement of regular V2 grid cells was centered on the origin with the mean displacement being 5.25 $106 \pm 0.11 \mathrm{~cm}$ (mean \pm s.e.m.), which was significantly smaller than that for bimodal V2 grid cells (Fig. S1f, $107 Z=4.88, P=1 \times 10^{-6}$, two-tailed Mann-Whitney $\mathrm{U}$ test, $n=15$ and 25$)$. In turn, the spatial correlation 108 coefficient was significantly higher in V2 regular grid cells than in V2 bimodal grid cells (Fig. S1g, $Z=$ $\left.1094.57, P=5.0 \times 10^{-6}\right)$.

110 As a comparison, we independently recorded 15 MEC grid cells from two new implanted rats under the 
111 same familiar environment (Fig. S2). However, we found that the MEC grid cell did not exhibit bimodal 112 remapping patterns. Both spatial correlation coefficient (Fig. $\mathbf{S 2 g}, Z=4.13, P=3.7 \times 10^{-5}$, two-tailed 113 Mann-Whitney U test, $n=15$ and 15) and displacement of peaks of cross-correlogram (Fig. S1f, $Z=$ $1144.34, P=1.5 \times 10^{-5}$ ) were significantly different from those of V2 bimodal grid cells.

115 To quantify the displacement of bimodal grid patterns in V2, we computed the cross-correlograms 116 between three baseline sessions. The peak of the cross-correlograms $\left(\mathrm{B} \times \mathrm{B}^{\prime}\right)$ was offset from the origin 117 (first row of Fig. 1e), and the mean displacement was $22.72 \pm 2.54 \mathrm{~cm}$ (red dots in Fig. 1g). However, 118 when comparing B' and B" sessions, the peak of the cross-correlograms was significantly smaller (two119 sided Wilcoxon signed-rank tes, $Z=3.41$, *** $P=0.001, n=15$ ), centered on the origin (the second row 120 in Fig. 1e) with the mean displacement being $6.05 \pm 0.78 \mathrm{~cm}$ (black dots in Fig. 1f). This observation 121 indicated that V2 grid cells re-aligned after bimodal remapping of spatial firing patterns. Moreover, the 122 spatial correlation in $\mathrm{B}^{\prime} \times \mathrm{B}^{\prime}$ " was significantly higher than that in $\mathrm{B} \times \mathrm{B}^{\prime}$ (Fig. 1g, $Z=3.41, * * * P=0.001$, $123 n=15$ ). Additionally, spatial stability was preserved among three baseline conditions (Fig. 1h, t, B-B': $124 Z=1.02, P=0.31$; B'-B' $: Z=0.8, P=0.43$; B-B', $Z=1.65, P=0.1)$. We further compared the grid 125 firing properties of V2 bimodal grid cells, gridness score, mean firing rate and grid scale among three 126 baseline sessions (Figs. 1i-k) and found no significant difference between them (two-sided Wilcoxon 127 signed-rank test, gridness score: B-B': $Z=0.17, P=0.86$; B'-B' ': $Z=1.53, P=0.13$; B-B',$Z=0.34$, $128 P=0.73$; mean firing rate: $\mathrm{B}-\mathrm{B}^{\prime}: Z=0.68, P=0.5 ; \mathrm{B}^{\prime}-\mathrm{B}^{\prime}{ }^{\prime}: Z=0.45, P=0.65$; $\mathrm{B}-\mathrm{B}{ }^{\prime}, Z=0.68, P=0.5$; 129 grid radius: $\mathrm{B}-\mathrm{B}^{\prime}: Z=0.06, P=0.96$; B'-B' ': $Z=0.85, P=0.39$; $\mathrm{B}-\mathrm{B}$ ', $, Z=0.17, P=0.87$ ). Together, 130 these results suggested that V2 grid cells exhibited intrinsic bimodal firing patterns; the environmental 131 manipulation in the familiar recording room could evoked bimodal remapping in a subpopulation of V2 132 grid cells; and the V2 grid-like firing structure became stabilized after remapping. 
bioRxiv preprint doi: https://doi.org/10.1101/2021.10.30.466568; this version posted November 2, 2021. The copyright holder for this preprint (which was not certified by peer review) is the author/funder, who has granted bioRxiv a license to display the preprint in perpetuity. It is made available under aCC-BY-NC-ND 4.0 International license.

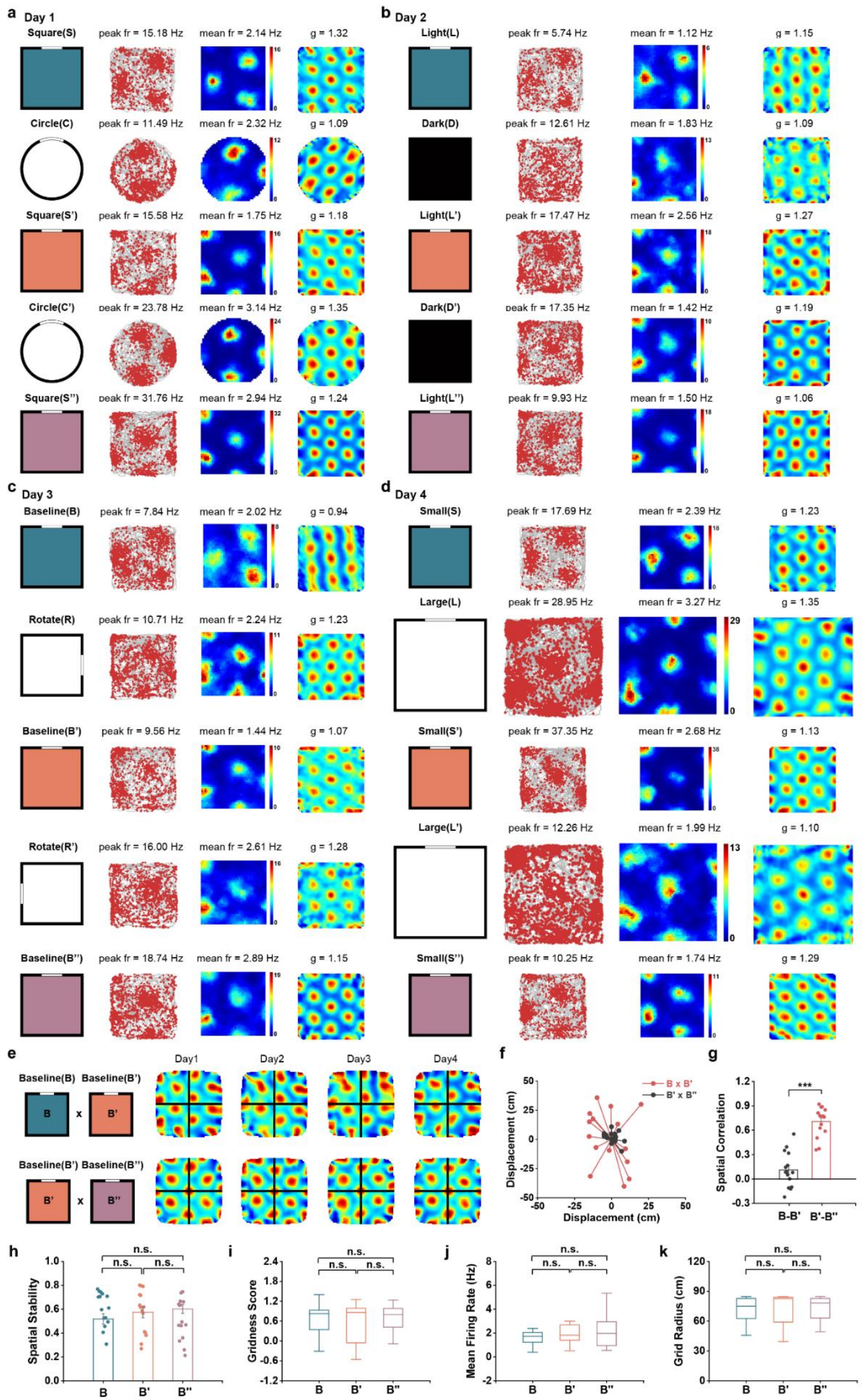


134 Figure 1. Bimodal remapping of firing patterns in V2 grid cells triggered by experimental 135 manipulations

136 (a) Remapping of V2 grid firing patterns in different shapes of running boxes.

137 (b) Remapping of V2 grid firing patterns after total darkness.

138 (c) Cue triggered bimodal remapping of V2 grid firing patterns.

139 (d) Remapping of grid firing patterns in different sizes of running boxes.

140 (e) Cross-correlogram for the same cell during the same baseline condition after remapping (B versus

141 B') or after stabilization (B' versus B'). The peaks of the cross-correlogram were offset from the origin 142 after environment change.

143 (f) Vector diagram showing the grid displacement from the center of the cross-correlogram to the nearest 144 peak.

145 (g) Spatial correlation between two baselines after environmental manipulation (B-B') and after the 146 switch of grid firing patterns (B'-B'').

147 (h) Grid firing patterns were stable.

148 (i-k) Gridness score, mean firing rate and grid scale showed no significant change during bimodal 149 remapping.

150 Restoration of $\mathbf{V 2}$ bimodal grid patterns upon re-entry into the familiar 151 environment

152 We further investigated whether bimodal remapping of V2 grid cells are reversible in their firing patterns, 153 and recorded another bimodal V2 grid cell (with conjunctive head-direction tuning) in both familiar and 154 novel environments across multiple days (Fig. 2). We first triggered the bimodal remapping of the V2 155 grid cell from the original firing pattern in the standard square (S) box to a new firing pattern in the circle 156 (C) box in the same familiar room (Fig. 2a). To reset grid firing pattern, we then conducted a series of 157 recordings starting from the familiar room $\left(\mathrm{S}^{\prime}\right)$ to another novel room with distinct distal landmarks (the 158 fourth row in Fig. 2a). Consistent with the substantial realignment of grid cells in MEC, V2 bimodal 159 grid cells showed a significant shift in grid structure in the novel environment. However, the grid pattern 160 reversed back to its original firing structure upon animal's re-entry into the square box (S") in the 161 familiar room. Interestingly, the bimodal firing pattern can be repeatedly induced upon changes in two 162 different environmental geometries (C' and S'" enclosures in Fig. 2a). Notably, the head directional 
163 tuning of the conjunctive V2 bimodal grid cell switched both directional tuning and bimodal grid pattern 164 in the novel room (the fourth rows in Fig. 2a and Fig. 2b), indicating that the conjunctive V2 bimodal 165 grid cells maintained a coherent ensemble for both head directionality and grid structure in response to 166 manipulations of environmental feature.

167 Could bimodal grid patterns reset after returning to the home cage, equivalent to a possible reset of the 168 path integrator? To address this possibility, we recorded the same V2 bimodal grid cell from the home 169 cage on day 2 and found that the original grid pattern emerged again (the first row in Fig. 2b). Subsequent 170 box shape-change caused the appearance of the bimodal grid patterns between the circle $(\mathrm{C})$ and the 171 familiar square running box (S'). The bimodal grid pattern was maintained despite further environmental 172 manipulations (C' and S" in Fig. 2b). In all box-shape manipulations within the same familiar recording 173 room, the directionality of the recorded conjunctive V2 grid cell remained similar head directional tuning 174 (the fifth columns in Fig. 2b and Fig. 2d).

175 We next asked if the original grid pattern of the bimodal grid cell was stable in the darkness without any 176 change in the box-shape. As expected, the grid-like firing pattern was stable between two repeated light177 on baseline sessions (the first and the second rows in Fig. 2c). However, the light-off caused the sudden 178 shift in the grid structure (the third row in Fig. 2c), and darkness-induced bimodal grid structure 179 remained stable in the following light condition (L') in the familiar square enclosure. Notably, the 180 bimodal grid pattern was switched again to a distinct grid structure in another novel recording room (the 181 fifth row in Fig. 2c), with its conjunctive head directional tuning rotated (the fifth columns in Fig. 2c). 182 Interestingly, the novel environment-induced grid firing pattern was completely reversed back to its 183 original firing mode after re-entry into the familiar room (the sixth row in Fig. 2c).

184 On day 4, we further verified the bimodal remapping in a larger environment (Fig. 2d). As predicted, 185 the bimodal grid pattern was evoked upon animal's entry into a larger enclosure (L) from the small box 186 (S). After returning to the small recording box (S'), the grid pattern was transformed into another firing 187 mode (the third row in Fig. 2d). Further manipulation of the local cue in the standard running box (R) 188 imposed no difference in terms of its grid mode (the fourth row in Fig. 2d). The grid mode was preserved 189 despite the cue card being rotated to its original orientation (the fifth row in Fig. 2d), suggesting that 190 once the bimodal pattern was switched, further environmental change could not induce any substantial 191 shift in its grid structure. We found that the peaks of the cross-correlograms for sessions before and after 
192 environmental change $(\mathrm{F} \times \mathrm{C})$ were offset from the origin (the first row in Fig. 2e). However, on session

193 before and after re-entry to the home cage, the peaks of the cross-correlograms $(\mathrm{F} \times \mathrm{H})$ remained in the 194 center (the second row in Fig. 2e) with the mean displacement being $4.92 \pm 0.76 \mathrm{~cm}$ (black dots in Fig.

195 2f). Accordingly, the peaks of the cross-correlograms $(\mathrm{F} \times \mathrm{H})$ were also centered on the origin before and 196 after re-entry from the novel room (the third row in Fig. 2e) with the mean displacement being $3.07 \pm$ $1970.68 \mathrm{~cm}$ (red dots in Fig. 2f).

198 Furthermore, the spatial correlation between two baselines after re-entry either from the home cage or a 199 novel room showed no significant difference (Fig. 2g, two-tailed Mann-Whitney U test, $Z=1.27, P=$ $2000.23, n=12$ and 7). Additionally, spatial stability after re-entry either from the home cage or a novel 201 room was preserved (Fig. $2 \mathrm{~h}, Z=1.44, P=0.17$ ). To compare the grid feature of V2 bimodal grid cells 202 during the reset, we calculated the gridness score, mean firing rate and grid scale among three baseline 203 sessions and found no significant difference during reset (two-sided Wilcoxon signed-rank test, Fig. 2i, 204 mean firing rate: Familiar-Home: $Z=1.18, P=0.24$; Familiar-Novel: $Z=0.34, P=0.74$; Fig. 2j, gridness 205 score: Familiar-Cage: $Z=1.33, P=0.18$; Familiar-Novel: $Z=1.01, P=0.31$; Fig. 2k, grid radius: 206 Familiar-Home: $Z=0, P=1.00$; Familiar-Novel: $Z=0, P=1.00)$. Importantly, the bimodal remapping 207 of grid firing patterns was not induced or accompanied by shift of cluster diagram or spike waveform 208 (Fig. S10). Of note, we found no significant change in either the separation of clusters (Figs. S10c-d), 209 spike amplitudes (Figs. S10e-f) or spike widths (Figs. S10g-h) in various comparisons. Together, the 210 bimodal V2 grid firing patterns can be restored upon reentry into the same environment. 
bioRxiv preprint doi: https://doi.org/10.1101/2021.10.30.466568; this version posted November 2, 2021. The copyright holder for this preprint (which was not certified by peer review) is the author/funder, who has granted bioRxiv a license to display the preprint in perpetuity. It is made available under aCC-BY-NC-ND 4.0 International license.

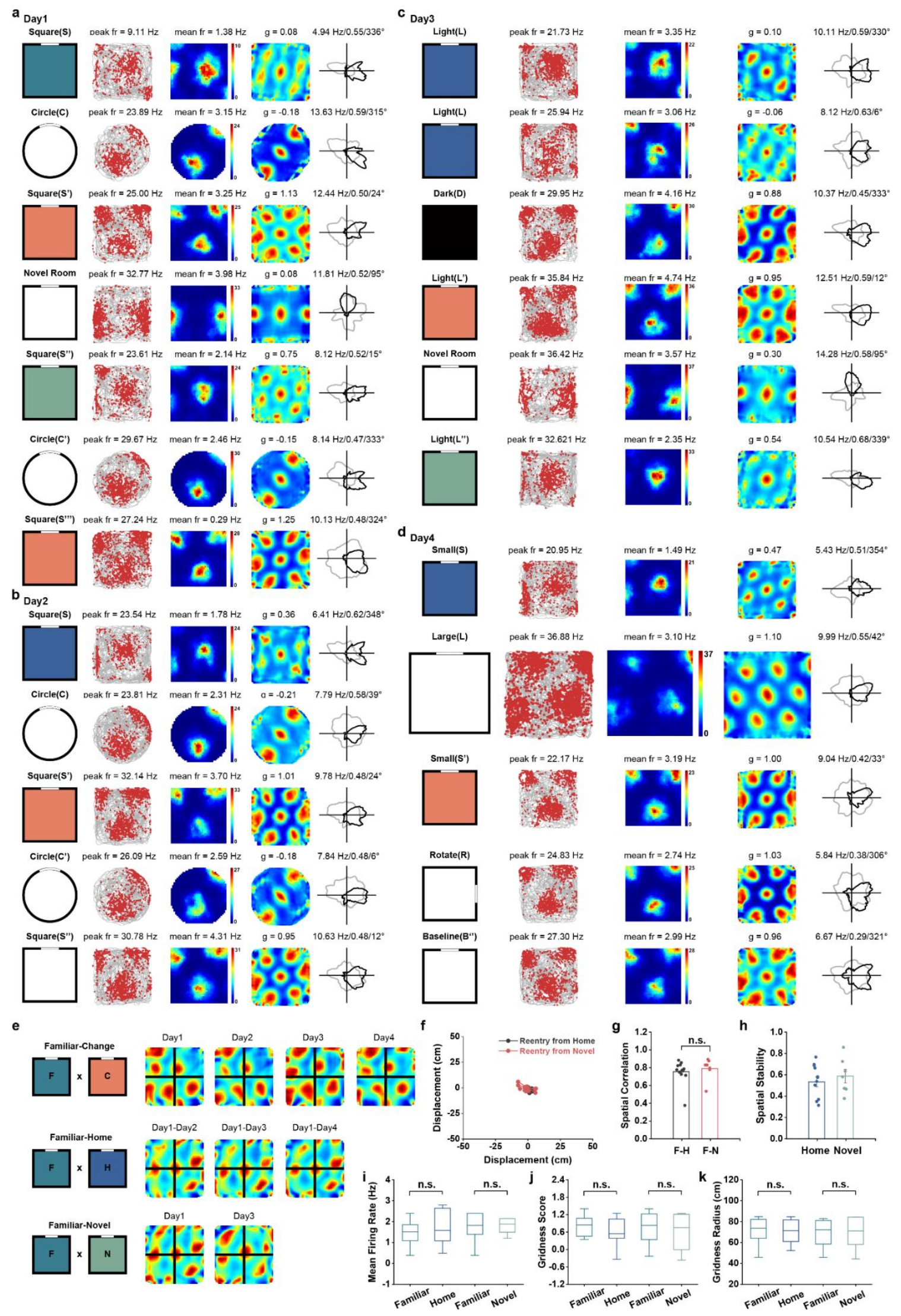


212 Fig.2 V2 grid cell grid firing pattern stabilized after bimodal remapping and restored upon 213 animal's re-entry into the same familiar environment.

214 (a) Spatial responses of a representative V2 conjunctive grid cell showing bimodal remapping of firing 215 pattern after environmental change and restoration of grid firing pattern upon animal's re-entry from 216 another room into the same familiar environment.

217 (b) The same grid cell showing stabilization of grid firing pattern after bimodal remapping and did not 218 change firing pattern in a different shape of running boxes, which led to bimodal remapping of firing 219 patterns in the first place.

220 (c) The firing patterns of grid cell remained stable when the environment was not changed and reset of 221 grid pattern after animal's re-entry from another novel environment.

222 (d) The firing pattern of the same grid cell was reset after being brought from home cage into the familiar 223 room.

224 (e) Cross-correlogram for the same cell between the baseline condition in the familiar environment and 225 the same baseline condition after environmental change (upper row), the same baseline condition after 226 re-entry into the familiar room from home cage (middle row) and the same baseline condition after 227 animal's re-entry into the familiar room from a novel environment (bottom row). The peaks of the cross228 correlogram were centered at the origin after re-entry.

229 (f) Vector diagram showing the grid displacement from the center of the cross-correlogram to the nearest 230 peak.

231 (g) Distribution of spatial correlation coefficients between two baselines after re-entry either from the 232 home cage or a novel room.

233 (h) Spatial stability between the baseline condition in the familiar environment and the same baseline 234 condition after re-entry into the familiar room from home cage and the same baseline condition after re235 entry into the familiar room from a novel environment.

236 (i-k) Gridness score, mean firing rate and grid scale were stable before and after animal's re-entry into 237 the same familiar environment.

\section{Characterization of rotation and deformation in $\mathbf{V} 2$ bimodal grid patterns}

239 What is the difference between two distinct modes of V2 grid firing pattern? Consistent with MEC grid 240 cells (Krupic et al., 2015, Stensola et al., 2015), the inner six fields of the auto-correlogram of V2 grid 
241 cells formed an ellipse (Fig. 3a) instead of a perfect circle. To quantify the change in spatial firing pattern

242 for V2 bimodal grid cells, we fitted an ellipse to the inner hexagon of auto-correlogram (Fig. 3b) and

243 defined semi-major and semi-minor axes (Fig. 3c). The orientation of the fitted ellipse was defined as

244 the angle between the horizontal axis and semi-major axis. We compared the elliptification and

245 orientation of spatial patterns under three conditions: in the familiar room $(\mathrm{F})$, after the environmental

246 change (C), and re-entry into the same familiar room (R). As shown in two V2 grid cell examples, the

247 grid pattern was deformed and rotated after the environmental change (Figs. 3a-b), with almost complete

248 overlapping between familiar and re-entry trials. We further found significant difference in elliptic

249 orientation (Fig. 3e, two-sided Wilcoxon signed-rank test, $Z=3.07$, $* * P=0.002, n=15$ ), reflecting a

250 clear deformation of grid patterns after environmental change. Additionally, grid orientation also varied

251 significantly after bimodal remapping (Fig. 3f, $Z=2.73$, **P=0.006). However, the degree of

252 elliptification (“ellipiticity") was preserved (Figs. 3g-h, Familiar-Change: $Z=0.63, P=0.53$; Change-

253 Re-entry: $Z=0.97, P=0.33$; Familiar-Re-entry: $Z=0.34, P=0.73$ ), suggesting that the distortion of

254 the hexagonal symmetry of grid patterns maintained and underwent non-coaxial rotation between two

255 distinct V2 grid cell firing modes. 
a
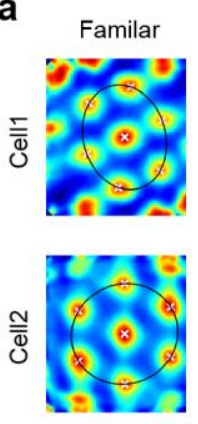

d

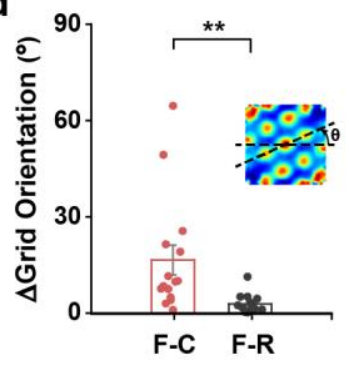

g

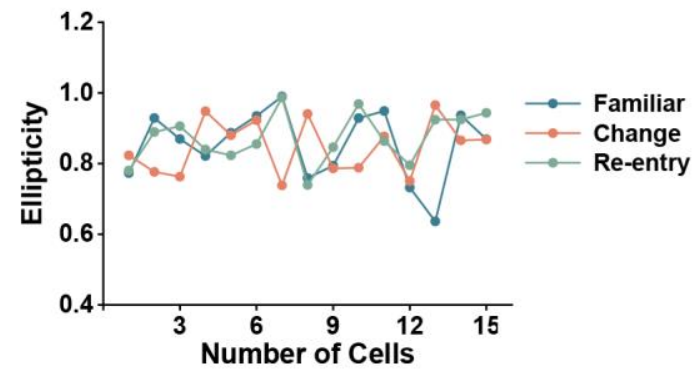

b Ellipse Fiting
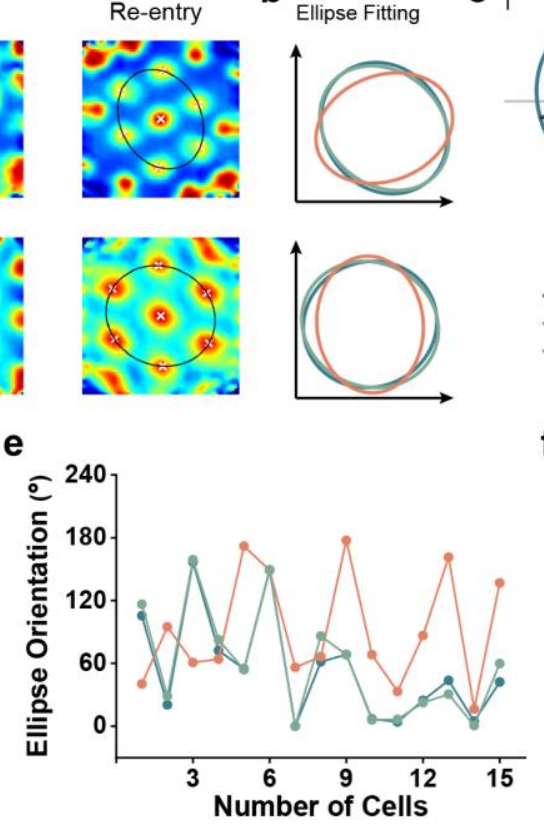

h

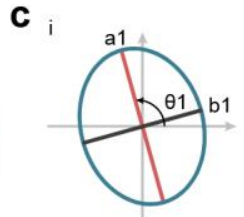

ii

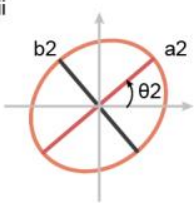

iii

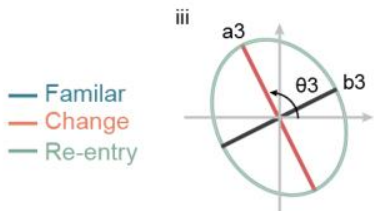

f

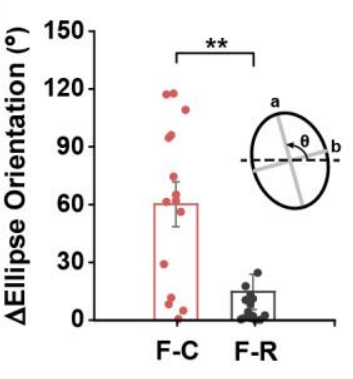

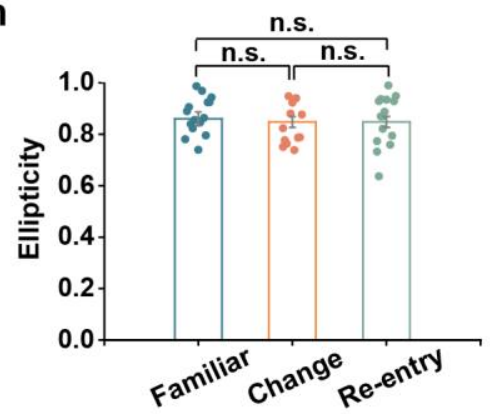

257 Fig. 3 Grid realignment by bimodal switch reflects shearing.

258 (a) Representative ellipse fitting of auto-correlogram of two visual grid cells in the familiar environment

259 (left panels), back to the same baseline condition after environmental change (middle panels) and re-

260 entry into the same familiar environment (right panels).

261 (b) Deformation of grid firing patterns during transformation between the bimodal firing patterns. The

262 ellipse deformation restored after re-entry to the same familiar environment.

263 (c) Diagram illustrating the calculation of ellipse orientation and the axes used to calculate ellipticity in

264 the three conditions above.

265 (d) Differences in grid orientation between a familiar environment and environmental change (F-C) were

266 significantly higher than that between a familiar environment and re-entry to the same environment (F267 R).

268 (e) Distribution of the horizontal orientations of the fitted ellipses for the three conditions above. 
269 (f) Orientation difference between a familiar environment and environmental change (F-C) was 270 significantly higher than that between first entry and re-entry to the same environment (F-R).

271 (g) Distribution of the ellipticity of the fitted ellipses for the three conditions.

272 (h) Ellipticity of the grid patterns showed no significant difference by bimodal remapping.

273 Since elliptification of the grid cells reflects shearing along the environmental boundaries, we next 274 sought to identify the angular offset of the grid axes to the box axes. In a perfect hexagonal grid cell, a 275 rotation of $7.5^{\circ}, 22.5^{\circ}$, or $37.5^{\circ}$ would result in asymmetrical distribution from the environmental 276 boundary (Fig. 4a). To quantify the degree of the rotational offset, we identified three grid axes with the 277 minimal angular deviation from the nearest wall (Fig. 4b). The minimal value of the angular offset of 278 grid axes from the walls for MEC grid cells was near $7.5^{\circ}$, which reflected the possible shear force 279 arising from anchoring to the geometrical borders and thus minimized symmetry with the environmental 280 boundaries (Stensola et al., 2015). Therefore, we further investigated if the asymmetrical relationship to 281 the environment boundaries had been reshaped during the transition to bimodal remapping. We found 282 that despite obvious deformation of grid patterns during bimodal remapping, the minimal angular 283 deviation of the grid axes from the walls was maintained (Fig. 4c). The minimal angular offset exhibited 284 a similar distribution after bimodal remapping (Fig. 4d), and the mean absolute angular offset was not 285 significantly different (Fig. 4e, two-sided Wilcoxon signed-rank test, Familiar-Change: $Z=0.97, P=$ 286 0.33; Change-Reentry: $Z=0.54, P=0.59$; Familiar-Reentry: $Z=1.16, P=0.25, n=15)$. The mean 287 absolute angular deviation was $9.95 \pm 1.74^{\circ}$ in familiar environment, $7.26 \pm 1.58^{\circ}$ after remapping and $2888.96 \pm 1.92^{\circ}$ back to the same familiar room, not far from the $7.5^{\circ}$ angular offset that would have 289 minimized symmetry or overlap with the cardinal and diagonal axes of the environment. In summary, 290 the rotational offset of grid patterns remained consistent despite dramatic rotation and distortion during 291 bimodal V2 grid cell remapping, suggesting that the asymmetric relationship with the environmental 292 boundary was preserved in the two distinct V2 grid cell firing modes. 
a

Familar

peak $\mathrm{fr}=6.07 \mathrm{~Hz}$
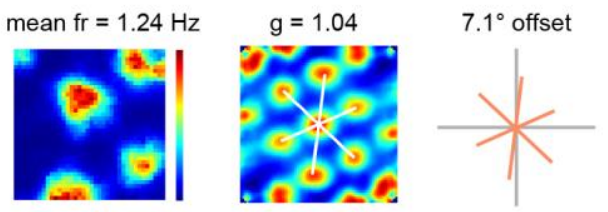

Change

peak $\mathrm{fr}=12.20 \mathrm{~Hz}$
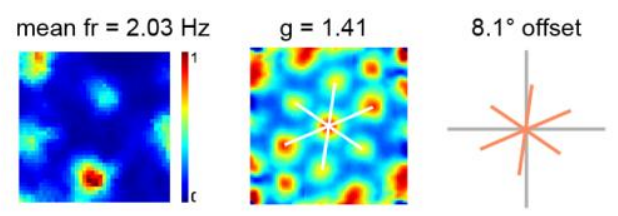

Re-entry

peak $\mathrm{fr}=14.12 \mathrm{~Hz}$

mean $\mathrm{fr}=1.25 \mathrm{~Hz}$
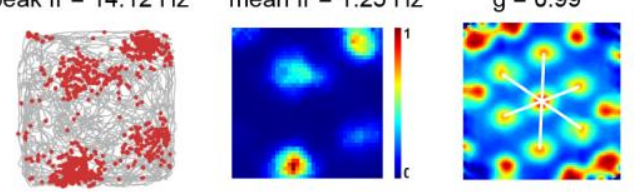

$2.5^{\circ}$ offset

b

C

angulat offset from nearst wall
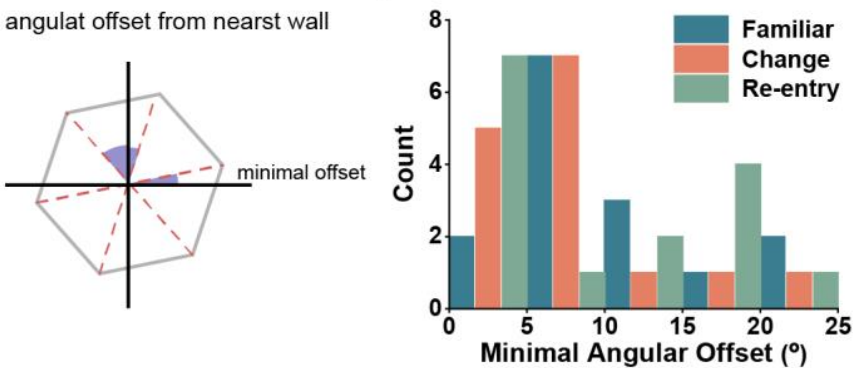

d

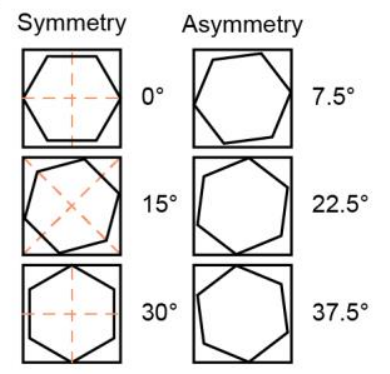

e

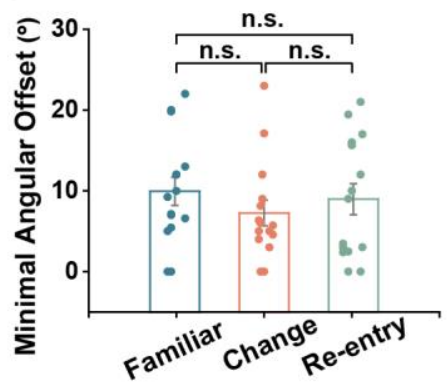

294 Fig. 4 Grid alignment after stabilization remained asymmetric with respect to the cardinal and 295 diagonal axes of the environment.

296 (a) Representative grid cells in a familiar environment (upper panels), after environmental change

297 (middle panels) and re-entry (bottom panels). For each condition, three grid axes were plotted in the 298 right.

299 (b) Schematic illustrating the definition of angular offset from the boundaries of the environment. 
300 (c) Distribution of the smallest angular offset of grid axes from the nearest wall. Under the three 301 conditions, the orientations of grid axis with minimal offset from the box walls were centered around $3027.5^{\circ}$ (red vertical line).

303 (d) Diagram illustrating the rotation of grid firing pattern in different angles resulting the symmetric and asymmetric alignment of the external environment. Red dashed line showing the axes of symmetry. (e) Minimal angular deviation of grid axes from the nearest wall did not differ significantly among three conditions.

\section{V2 bimodal grid patterns only switch in the familiar environment}

We further determined whether bimodal remapping of V2 grid cells also occurred in a novel environment after recording in the familiar room first. To do so, we recorded the spatial responses of the representative bimodal grid cell from Fig.1 in two novel rooms, each with distinct distal landmarks (Fig. S3). The bimodal grid cell was first recorded between small-large-small (S-L-S') running box sessions on day 1 (Fig. S3a), and the firing patterns between two small boxes remained the same. On day 2, the grid cell

313 was recorded across square-circle-square (S-C-S') sessions (Fig. S3b), with the grid structure 314 maintained between two square boxes. To further validate the unchanged property of V2 bimodal grid 315 cells in the novel environment, on day 3 we recorded the same grid cell in another novel room and found 316 that the V2 grid cell firing pattern did not shift in response to environmental changes across square317 circle-square (S-C-S') trials (Fig. S3c). This observation was confirmed by cross-correlogram between 318 two baseline sessions $\left(\mathrm{B} \times \mathrm{B}^{\prime}\right)$ with peaks almost centered at the origin (Fig. S3d). The finding suggested 319 that V2 bimodal grid cells seemed to measure geometric changes only in the familiar environment.

\section{Preservation of theta modulation during remapping of $\mathrm{V} 2$ bimodal grid patterns}

321 Theta oscillation (4-8 Hz) of hippocampal or cortical local field potentials (LFPs) is vital for formation 322 of grid cells (Buzsáki and Moser, 2013). To explore the influence of the temporal oscillation on the 323 spatial firing patterns of V2 bimodal grid cells, we measured the LFP and spikes simultaneously from 324 the freely-foraging animals. Running was remarkably associated with strong theta rhythmicity in V2, 325 and the majority of V2 bimodal grid cells $(12 / 15=80 \%)$ displayed clear theta-modulation in their spike 326 auto-correlogram (Figs. S4a-d). We observed continuous theta rhythmicity during the transition of grid 327 bimodal firing patterns, and found no significant difference in both theta modulation index [Fig. S4e, 
two-sided Wilcoxon signed-rank test, $Z=0, P=1.00$ (B-B'), $Z=1.82, P=0.07$ (B-B'’) and $Z=1.39$, $P=0.16\left(\mathrm{~B}^{\prime}-\mathrm{B}\right.$ ') $\left.), n=15\right]$, and peak theta frequency [Fig. S4f, $Z=0.34, P=0.73$ (B-B'), $Z=0.79, P=$

0.43 (B-B') and $Z=1.73, P=0.08$ (B'-B'")]. These results suggested that the majority of V2 bimodal grid cells preserved temporal periodicity and theta modulation during the transformation of spatial firing patterns. Strong theta modulation was also observed during the re-entry into the same familiar environment which caused restoration of the original grid structures (Figs. S5a-d). We found no significant change in both theta modulation index (Familiar-Home: $Z=0.63, P=0.53$; Familiar-Novel: $Z=1.018, P=0.31$, two-sided Wilcoxon signed-rank test, $n=5$ and 3) and peak theta frequency (Familiar-Home: $Z=1.75, P=0.08$; Familiar-Novel: $Z=0.94, P=0.35$ ).

\section{V2 bimodal grid patterns stabilize rapidly upon changes in the familiar environment}

338 Does the bimodal grid structure stabilize rapidly or change gradually after the environmental change? 339 To investigate this question, we split the 30-min recording session into three 10-min epochs, and found 340 that the bimodal grid pattern was expressed instantly after the environment change (Fig. S6a). Firing 341 fields appeared to be stable from the onset of the running session. The development of bimodal firing structures was estimated by correlating for each V2 bimodal grid cell and the whole session with five 2min incremental blocks throughout the whole session. Notably, the spatial firing patterns were highly correlated during the course of recording time (Fig. S6b, Friedman's test, $P=0.05$ ), and the normalized mean firing rate was also stable during the course of recording (Fig. S6c, Friedman's test, $P=0.27$ ). Therefore, the bimodal remapping of V2 grid cells took place rapidly in response to manipulations in the familiar environment.

\section{Bimodal remapping of V2 grid firing patterns without disturbing head directionality}

349 Due to the presence of diverse spatially-modulated V2 neurons (Long et al., 2021), one may wonder if the V2 bimodal grid cells arose from the local environment content or visual input, what had happened to other spatial cell types in V2 under the same experimental manipulations. Among 15 recorded V2

352 bimodal grid cells, we detected four V2 grid cells with conjunctive head direction tuning (Fig. S7). As

353 expected, the grid firing pattern of the conjunctive bimodal grid cells preserved when there was no 354 change in the familiar environment between the first and second baseline (L) sessions on day 1 (the first 355 and second rows in Fig. S7a). Under the darkness (D) session, the spatial firing pattern was switched to 356 another firing mode (the third row in Fig. S7a). The grid structure was stabilized when returning to light 
357 (L') conditions (the fourth row in Fig. S7a) and did not change anymore in another follow-up baseline

358 (L') session (the fifth row in Fig. S7a). However, the head directionality of both conjunctive bimodal

359 V2 grid cell and simultaneously recorded V2 head-direction cell was almost invariant throughout the

360 whole recording session (the fifth columns in Fig. S7a).

361 To further validate the invariant head directionality of conjunctive bimodal grid cells, we recorded the 362 same pair of V2 cells across square-circle-square (S-C-S') sessions on day 2. Consistent with those 363 switched grid patterns and preserved head directionality on day 1, we found different shapes of running 364 boxes triggered the remapping of bimodal grid patterns (the first to the third rows in Fig. S7a) without perturbation of its head directionality (the fifth columns in Fig. S7b). In addition, the animal's re-entry into the same familiar room from a novel environment (the fourth row in Fig. S7a) restored the grid firing pattern (the fifth row in Fig. S7b). To quantify the head directional tuning accompanying the bimodal remapping of V2 grid pattern, we measured the peak direction of head directional tuning of both conjunctive bimodal grid cells and co-recorded head-direction cells under three baseline conditions: in the familiar environment (B), after the environmental change (B') and re-entry into the same environment (B"), we detected no significant change in the peak direction of head direction tuning (Fig. S7c, Rayleigh test for uniformity: B-B': median offset $=2.98^{\circ}, r=0.93, P=1.43 \times 10^{-5}$; B'-B': median offset $=2.98^{\circ}, r=0.96, P=3.68 \times 10^{-6}$; B-B": median offset $\left.=5.95^{\circ}, r=0.90, P=4.37 \times 10^{-5}\right)$. Additionally, there was no significant difference in peak angular rate [Fig. S7d, two-sided Wilcoxon signed-rank test, B-B': $Z=0.76, P=0.45$; B'-B'": $Z=1.38, P=0.17$; B-B' $: Z=0.56, P=0.58]$ and mean vector length [Fig. S7e, B-B': $Z=0.36, P=0.72$; B'-B": $Z=0.36, P=0.72$; B-B": $Z=0.71, P=$ 0.48]. It might be possible that V2 bimodal grid pattern and head directional tuning originate from different computational mechanisms. In other examples of simultaneously recorded units that included a V2 bimodal grid cell (Fig. S9, i-iii), we found a similar trend with bimodal mapping of grid patterns accompanying with invariant place or border spatial firing patterns during environmental changes.

381 Finally, we compared the grid structure of simultaneously recorded bimodal grid cells during the environmental manipulations and determined whether ensembles of V2 bimodal grid cells remained coherent in remapping. Remarkably, two pairs of co-recorded bimodal V2 grid cells (one nonconjunctive grid cell and the other conjunctive grid cell) co-varied when the familiar environment changed, and then co-restored their original firing modes upon animal's re-entry into the same familiar environment (Fig. S6). 


\section{Discussion}

388 The extrastriate (V2) cortex is the second major area in the visual cortex and the first region within the 389 visual association area. V2 receives a primary feedforward input from V1 and lateral geniculate nuclei 390 (LGN) and processes specific features of visual information (such as contour and shape); V2 projects topographically back to V1, and sends strong feedforward input to the upstreams of the visual cortex (V3, V4 and MT). In addition to the projections within the visual cortex, V2 also projects to three visual areas in the parietal cortex---the medial superior temporal (MST), parieto-occipital (PO) and ventral intraparietal (VIP) areas. Projections from the peripheral field representation of V2 of parietal areas could provide a direct route for rapid activation of circuits serving spatial vision and spatial attention (Gattass et al., 1997). The ventral visual-to-hippocampal stream is important for visual memory (Bussey and Saksida, 2007). Multiple lines of evidence have suggested that V2 plays an important role in object recognition memory (Lopez-Aranda et al., 2009). In the monkey, V2 neurons have V1-like (typical Gabor-shaped filter) receptive fields (Liu et al., 2016). Furthermore, mouse V2 neurons have remarkably fine stimulus selectivity, and the majority of response properties in V2 were not different from those in V1 (Van den Bergh et al., 2010). Among the orientation-selective cells in V1 and V2, V1-V2 corticocortical connectivity has two types of orientation networks, a tightly synchronized, orientationpreserving network and a less-synchronized orientation diverse network (Roe and Ts'o, 2015), suggesting that V2 neurons may have two distinct functional populations for feature integration.

In our previous study (Long et al., 2021), we have reported visual grid cells in the V2M area from freely foraging rats. This finding, along with the grid-like firing neurons as well as other spatial firing neurons in the S1 (Long and Zhang, 2021, Long et al., 2021, Long et al., 2020), are the first evidence of grid cells in the sensory cortex outside of the MEC from freely foraging rats. The remapping of V2 grid cells has several distinct characteristics from the traditional MEC grid cells. First, MEC grid cells remap in the presence of large changes of the environment (such as a novel room) by causing both translation and rotation, while small changes (changing the enclosure but not the room) do not cause remapping (Hafting

412 et al., 2005, Fyhn et al., 2007). In contrast, V2 grid cells have two distinct subpopulations in terms of 413 the remapping property. Second, the MEC grid cell firing is disrupted in darkness when the visual inputs 414 are removed, even when head-direction cell signaling is preserved (Chen et al., 2016). Moreover, the 415 absence of visual input alters movement velocity modulation of theta frequency. In contrast, the grid- 
416 like firing patterns of V2 grid cells are stable. The head directional tuning of V2 grid cells does not 417 change in darkness (Fig. 2c).

418 Two fundamental questions remain: how do the grid-like receptive fields emerge in V2 and what are 419 their functions beyond visual processing? A complete answer to these two questions requires systematic 420 circuit dissection of V2 circuitry and its cell types (Niell, 2015), our findings in the current study provide 421 the first necessary step towards that direction. We will speculate some answers and provide some 422 experimentally testable hypotheses below. The V2 spatial modulation may originate from V1, which 423 may encode rich spatial information (Ji and Wilson, 2007, Haggerty and Ji, 2015, Saleem et al., 2018). 424 Additionally, the source of spatial signal may also arise from the projection from the visual association 425 cortex that has dense projections to the prostrhinal cortex (Burwell and Amaral, 1998), which may 426 transform an animal's immediate sensory perception of its environment into a spatial map (LaChance et 427 al., 2019). Furthermore, in the visual cortex of macaque monkey, there is an occipito-parietal connection 428 to the posterior parietal cortex (PPC) that has a special role in spatial cognition (Husain and Nachev, 429 2007, Bicanski and Burgess, 2020). In fMRI imaging, grid-like firing patterns have been reported in 430 multiple areas of human cortices outside the traditional hippocampal formation (Constantinescu et al., 431 2016, Bao et al., 2019, Doeller et al., 2010, Jacobs et al., 2013). Further, grid-like representations can 432 contribute to mental stimulation in the absence of imagined movement (Bellmund et al., 2016). In animal 433 experiments, grid cells have been reported in the S1 from freely foraging rats (Long and Zhang, 2021).

434 Based on these data, it is reasonable to believe that grid-like firing patterns are broadly distributed across 435 the brain. One new theory for the sensory grid cells is to employ grid cell-like mechanisms to navigate 436 in an abstract "concept" space and learn the structure of the world (objects) (Hawkins et al., 2018), in 437 which the abstract concepts are represented via reference frames. According to Hawkin's theory, grid438 like computation can be implemented in cortical columns in the visual (or somatosensory) cortex to track 439 the location of visual (or tactile) features relative to the objects being viewed (or touched). Together, the 440 neocortex represents object compositionality and learns complete models of objects in different 441 modalities. In V2, there is evidence of column-like compartment that divides neurons with similar 442 receptive field properties (Horton and Adams, 2005). Experimentally, it has also been shown that some $443 \mathrm{~V} 1$ and V2 neurons fire only if a visual feature is present at object-centric location on object (Zhou et 444 al., 2000, Williford and von der Heydt, 2016). For instance, V2 neurons in behaving macaques have 445 been showed to encode the side to which the border belongs---the so-called "border ownership coding" 
446 during visual processing of complex natural scenes (Zhou et al., 2000). This is reminiscent of the

447 allocentric representation of space in the traditional MEC grid cells. Vision supports the brain's

448 allocentric spatial navigation (Morris, 1981), it is likely the brain uses both visual and spatial cues to

449 construct a "cognitive map" of the world. The grid-like mechanisms of V2 visual cortex may support

450 the hypothesis that allocentric locations may be used as a basis of visuospatial perception. Together with

451 MEC grid cells and S1 grid cells, V2 grid cells can play the role of location-processing units in

452 navigating complex and sensory cue-rich environments. Recently, it has been shown that the role of

453 MEC grid cells is beyond simple mnemonic coding for space, and can encode behaviorally relevant

454 information such as the reward or goal locality (Boccara et al., 2019, Butler et al., 2019). Very likely,

455 the V2 grid cells may also encode additional spatio-visual information with mixed selectivity for 456 performing a complex task.

457 Sensory (visual, somatosensory and spatial) cues and velocity signals may contribute to path integration

458 by connecting the "locations" in the sensory space by movements. However, sensory cues and self459 motion do not necessarily provide a coherent visuo-spatial or spatio-visual representation. In a recent 460 virtual reality study, visual environmental inputs were dissociated from physical motion inputs, MEC 461 grid cells recorded from mice navigating in virtual open areas showed a greater influence of physical 462 motion, whereas hippocampal place cell firing patterns predominantly reflected visual inputs (Chen et 463 al., 2019). However, it remains unknown whether V2 grid-like patterns are disrupted if the downstream 464 V1 input or the hippocampus is inhibited (e.g., by optogenetic inactivation) during natural navigation. 465 Additionally, unlike MEC grid cells (Stensola et al., 2012), the V2 grid cells are sparsely distributed and 466 show no modular structure between the deep and superficial layers. It is also important to note that there 467 are heterogeneous spatial tunings in V2, as seen by simultaneously recorded V2 grid cells, head-direction 468 cells, place cells and border cells.

469 Remapping is a property of neural plasticity in response to changes in environment and sensory cues. 470 Grid firing patterns of traditional MEC grid cells can remap (such as grid rotation and rescaling) in the 471 response to not only the environmental change (Fyhn et al., 2007), but also the task learning (Butler et 472 al., 2019). In our study, rats are freely foraging in the environmental enclosure without performing an 473 explicit task. The remapping of bistable V2 grid fields predominantly preserved their firing rates, 474 gridness scores and grid radius, but changed the fields by rotation and translation. Conjunctive head- 
475 direction tuning of bistable V2 grid cells was also remapped (Fig. 2). Notably, the bistable remapping in

476 V2 grid cells has not been found in other simultaneously recorded V2 spatially tuned cells, neither in the

477 MEC grid cells or S1 grid cells. Therefore, the functional significance of the bistable remapping

478 mechanism of V2 grid cells remains mysterious, as we did not find any significant differences in grid

479 cell characteristics (such as the gridness score, grid radius, spatial frequency, and theta modulation index)

480 between the V2 bimodal and regular grid cell populations. However, we cannot exclude the possibility

481 this may be a sampling issue.

482 To understand the computational mechanism of neuronal representations, grid cell's receptive field can 483 be closely approximated by a two-dimensional cosine function with a specific spatial frequency. 484 Therefore, grid cells can perform discrete Fourier transform-like computation (Kubie and Fox, 2015, 485 Rodriguez-Dominguez and Caplan, 2019). Changes by rotation and translation may be interpreted as an 486 angular modulation in the frequency domain. Several computational models and theories have been 487 proposed for the MEC grid cells and remapping (Hardcastle et al., 2017, Stachenfeld et al., 2017, 488 Mosheiff and Burak, 2019, Agmon and Burak, 2020, Anselmi et al., 2020, D'Albis and Kempter, 2020); 489 for a review, see (Giocomo et al., 2011, Zilli, 2012). The "oscillatory interference" model explains the 490 theta phase precession (Burgess et al., 2007), whereas the continuous attractor models can generate grid 491 firing patterns (Burak and Fiete, 2009, Bush and Burgess, 2014). The underlying computational model 492 explaining the remapping bistability for V2 grid cells needs further exploration.

\section{Supplemental information}

494 Supplemental information includes ten figures. 


\section{References}

496

497

498

499

500

501

502

503

504

505

506

507

508

509

510

511

512

513

514

515

516

517

518

519

520

521

522

523

524

525

526

527

528

529

530

531

532

533

534

535

536

537

1. Latuske, P., et al., Hippocampal Remapping and Its Entorhinal Origin. Front Behav Neurosci, 2017. 11: 253.

2. Hafting, T., et al., Microstructure of a spatial map in the entorhinal cortex. Nature, 2005. 436(7052): 801-806.

3. Fyhn, M., et al., Hippocampal remapping and grid realignment in entorhinal cortex. Nature, 2007. 446(7132): 190-194.

4. Barry, C., et al., Experience-dependent rescaling of entorhinal grids. Nat Neurosci, 2007. 10(6): 682-684.

5. Jeffery, K.J., Place cells, grid cells, attractors, and remapping. Neural Plast, 2011. 2011: 182602.

6. Barry, C., et al., Grid cell firing patterns signal environmental novelty by expansion. Proc Natl Acad Sci U S A, 2012. 109(43): 17687-17692.

7. Marozzi, E., et al., Purely Translational Realignment in Grid Cell Firing Patterns Following Nonmetric Context Change. Cereb Cortex, 2015. 25(11): 4619-4627.

8. Raithel, C.U. and J.A. Gottfried, What are grid-like responses doing in the orbitofrontal cortex? Behav Neurosci, 2021. 135(2): 218-225.

9. Constantinescu, A.O., J.X. O'Reilly, and T.E.J. Behrens, Organizing conceptual knowledge in humans with a gridlike code. Science, 2016. 352(6292): 1464-1468.

10. Bao, X., et al., Grid-like Neural Representations Support Olfactory Navigation of a TwoDimensional Odor Space. Neuron, 2019. 102(5): 1066-1075 e5.

11. Doeller, C.F., C. Barry, and N. Burgess, Evidence for grid cells in a human memory network. Nature, 2010. 463(7281): 657-661.

12. Jacobs, J., et al., Direct recordings of grid-like neuronal activity in human spatial navigation. Nat Neurosci, 2013. 16(9): 1188-1190.

13. Long, X. and S.J. Zhang, A novel somatosensory spatial navigation system outside the hippocampal formation. Cell Res, 2021. 31(6):649-663.

14. Long, X., et al., A compact spatial map in V2 visual cortex. bioRxiv, 2021. doi: 10.1101/2021.02.11.430687.

15. Chen, G., et al., Absence of Visual Input Results in the Disruption of Grid Cell Firing in the Mouse. Curr Biol, 2016. 26(17): 2335-2342.

16. Stensola, H., et al., The entorhinal grid map is discretized. Nature, 2012. 492(7427): 72-78.

17. Deshmukh, S.S., et al., Theta modulation in the medial and the lateral entorhinal cortices. $J$ Neurophysiol, 2010. 104(2): 994-1006.

18. Hafting, T., et al., Hippocampus-independent phase precession in entorhinal grid cells. Nature, 2008. 453(7199): 1248-1252.

19. Krupic, J., et al., Grid cell symmetry is shaped by environmental geometry. Nature, 2015. 518(7538): 232-235.

20. Stensola, T., et al., Shearing-induced asymmetry in entorhinal grid cells. Nature, 2015. 518(7538): 207-212.

21. Buzsáki, G. and E.I. Moser, Memory, navigation and theta rhythm in the hippocampal-entorhinal system. Nat Neurosci, 2013. 16(2): 130-138.

22. Gattass, R., et al., Cortical projections of area V2 in the macaque. Cereb Cortex, 1997. 7(2): 110129. 
23. Bussey, T.J. and L.M. Saksida, Memory, perception, and the ventral visual-perirhinalhippocampal stream: thinking outside of the boxes. Hippocampus, 2007. 17(9): 898-908.

24. Lopez-Aranda, M.F., et al., Role of layer 6 of V2 visual cortex in object-recognition memory. Science, 2009. 325(5936): 87-89.

25. Liu, L., et al., Spatial structure of neuronal receptive field in awake monkey secondary visual cortex (V2). Proc Natl Acad Sci U S A, 2016. 113(7): 1913-1918.

26. Van den Bergh, G., et al., Receptive-field properties of V1 and V2 neurons in mice and macaque monkeys. J Comp Neurol, 2010. 518(11): 2051-2070.

27. Roe, A.W. and D.Y. Ts'o, Specificity of V1-V2 orientation networks in the primate visual cortex. Cortex, 2015. 72: 168-178.

28. Long, X., et al., Egocentric Asymmetric Coding in Sensory Cortical Border Cells. bioRxiv, 2021. doi: 10.1101/2021.03.11.434952.

29. Long, X., C.K. Young, and S.-J. Zhang, Sharp tuning of head direction by somatosensory fastspiking interneurons. bioRxiv, 2020. doi: 10.1101/2020.02.03.933143.

30. Niell, C.M., Cell types, circuits, and receptive fields in the mouse visual cortex. Annu Rev Neurosci, 2015. 38: 413-431.

31. Ji, D. and M.A. Wilson, Coordinated memory replay in the visual cortex and hippocampus during sleep. Nat Neurosci, 2007. 10(1): 100-107.

32. Haggerty, D.C. and D. Ji, Activities of visual cortical and hippocampal neurons co-fluctuate in freely moving rats during spatial behavior. Elife, 2015. 4.

33. Saleem, A.B., et al., Coherent encoding of subjective spatial position in visual cortex and hippocampus. Nature, 2018. 562(7725): 124-127.

34. Burwell, R.D. and D.G. Amaral, Cortical afferents of the perirhinal, postrhinal, and entorhinal cortices of the rat. J Comp Neurol, 1998. 398(2): 179-205.

35. LaChance, P.A., T.P. Todd, and J.S. Taube, A sense of space in postrhinal cortex. Science, 2019. 365(6449): eaax4192.

36. Husain, M. and P. Nachev, Space and the parietal cortex. Trends Cogn Sci, 2007. 11(1): 30-36.

37. Bicanski, A. and N. Burgess, Neuronal vector coding in spatial cognition. Nat Rev Neurosci, 2020. 21(9): 453-470.

38. Bellmund, J.L., et al., Grid-cell representations in mental simulation. Elife, 2016. 5.

39. Hawkins, J., et al., A Framework for Intelligence and Cortical Function Based on Grid Cells in the Neocortex. Front Neural Circuits, 2018. 12: 121.

40. Horton, J.C. and D.L. Adams, The cortical column: a structure without a function. Philos Trans $R$ Soc Lond B Biol Sci, 2005. 360(1456): 837-862.

41. Zhou, H., H.S. Friedman, and R. von der Heydt, Coding of border ownership in monkey visual cortex. J Neurosci, 2000. 20(17): 6594-6611.

42. Williford, J.R. and R. von der Heydt, Figure-Ground Organization in Visual Cortex for Natural Scenes. eNeuro, 2016. 3(6).

43. Morris, R.G.M., Spatial localization does not require the presence of local cues. Learning and Motivation, 1981. 12(2): 239-260.

44. Boccara, C.N., et al., The entorhinal cognitive map is attracted to goals. Science, 2019. 363(6434): 1443-1447.

45. Butler, W.N., K. Hardcastle, and L.M. Giocomo, Remembered reward locations restructure entorhinal spatial maps. Science, 2019. 363(6434): 1447-1452.

46. Chen, G., et al., Differential influences of environment and self-motion on place and grid cell firing. Nat Commun, 2019. 10(1): 630. 
47. Kubie, J.L. and S.E. Fox, Do the spatial frequencies of grid cells mold the firing fields of place cells? Proc Natl Acad Sci U S A, 2015. 112(13): 3860-3861.

48. Rodriguez-Dominguez, U. and J.B. Caplan, A hexagonal Fourier model of grid cells. Hippocampus, 2019. 29(1): 37-45.

49. Hardcastle, K., et al., A Multiplexed, Heterogeneous, and Adaptive Code for Navigation in Medial Entorhinal Cortex. Neuron, 2017. 94(2): 375-387 e7.

50. Stachenfeld, K.L., M.M. Botvinick, and S.J. Gershman, The hippocampus as a predictive map. Nat Neurosci, 2017. 20(11): 1643-1653.

51. Mosheiff, N. and Y. Burak, Velocity coupling of grid cell modules enables stable embedding of a low dimensional variable in a high dimensional neural attractor. Elife, 2019. 8.

52. Agmon, H. and Y. Burak, A theory of joint attractor dynamics in the hippocampus and the entorhinal cortex accounts for artificial remapping and grid cell field-to-field variability. Elife, 2020. 9.

53. Anselmi, F., M.M. Murray, and B. Franceschiello, A computational model for grid maps in neural populations. J Comput Neurosci, 2020. 48(2): 149-159.

54. D'Albis, T. and R. Kempter, Recurrent amplification of grid-cell activity. Hippocampus, 2020. 30(12): 1268-1297.

55. Giocomo, L.M., M.B. Moser, and E.I. Moser, Computational models of grid cells. Neuron, 2011. 71(4): 589-603.

56. Zilli, E.A., Models of grid cell spatial firing published 2005-2011. Front Neural Circuits, 2012. 6 : 16.

57. Burgess, N., C. Barry, and J. O'Keefe, An oscillatory interference model of grid cell firing. Hippocampus, 2007. 17(9): 801-812.

58. Burak, Y. and I.R. Fiete, Accurate path integration in continuous attractor network models of grid cells. PLoS Comput Biol, 2009. 5(2): e1000291.

610

59. Bush, D. and N. Burgess, A hybrid oscillatory interference/continuous attractor network model of grid cell firing. J Neurosci, 2014. 34(14): 5065-5079. 
611 Acknowledgments: We thank Edvard Moser, May-Britt Moser, Daniel Bush and Neil Burgess for

612 sharing their analytical codes with us. S.-J.Z. is supported by the National Natural Science Foundation

613 of China (Grant\# 31872775). Z.S.C. is partly supported by the US National Institutes of Health (R01-

614 MH118928).

615 Author contributions: S.-J.Z. conceived the project. X.L. and S.-J.Z. designed the study, performed

616 the surgery and analyzed the data. J.C., B.D. and X.L. conducted the experiments and acquired the 617 recordings. B.D. and Z.S.C. provided the feedback. X.L. developed the codes and made the figures.

618 Z.S.C., X.L. and S.-J.Z. wrote the manuscript.

619 Competing interests: The authors declare no competing interests. 


\section{MATERIALS AND METHODS}

\section{Experimental subjects}

622 Eight experimentally naïve male adult Long-Evans rats (2 to 4 months old, 250 to 450 grams at the time 623 of implantation, six rats for V2 implanting and two rats for MEC implanting) were used in this study. 624 Prior to surgery, rats were group-housed with four male littermates per cage. After chronic implantation, 625 animals were housed singly in transparent cages ( $35 \mathrm{~cm} \mathrm{x} 45 \mathrm{~cm}$ x $45 \mathrm{~cm}, \mathrm{~W}$ x L x H) and kept on a 12626 hour light/12-hour dark cycle (lights on at 9 p.m. and off at 9 a.m.). Rats were maintained in a 627 temperature- $\left(19-22^{\circ} \mathrm{C}\right)$, humidity- (55-65\%) controlled vivarium. One week after postoperative 628 recovery, animals were food-deprived 8-24 hours before behavioral training or experimental recording 629 trials and were kept at $\sim 90 \%$ of free-feeding body weight with free access to water. Experimental training 630 and recording were performed during the dark phase of the cycle. All animal experiments were 631 conducted according to the pre-approved protocol by the Animal Care and Use Committee from both 632 Army Medical University and Xinqiao Hospital in accordance with the National Animal Welfare Act.

\section{Surgery and electrodes}

634 Rats were given intramuscular injection of buprenorphine $(0.001 \mathrm{mg}$ per $\mathrm{kg})$ just right before chronic 635 surgery. Animals were anaesthetized under 1.5-3\% of isoflurane in $\mathrm{O}_{2}$, immobilized in a stereotaxic 636 frame (David Kopf Instruments, California, USA) and maintained on a feedback-controlled heating plate 637 at $37^{\circ} \mathrm{C}$. Four tetrode bundles based on 16-channel microdrives (Axona, St. Albans, UK) were 638 constructed with $17 \mu \mathrm{m}$ Platinum/Iridium wires (\#100167, California Fine Wire Company, USA). The 639 electrode tips were cut and platinum-electroplated to reduce their target impedance to 150 to $300 \mathrm{k} \Omega$ 640 measured at $1 \mathrm{kHz}$ using an electroplating plater (nanoZ; White Matter LLC, Seattle, Washington, USA). 641 Microdrives were implanted to target the mediolateral (V2ML) and mediomedial (V2MM) regions of 642 the second visual cortex (V2) with the stereotaxic coordinate centered at $\sim 2.5 \mathrm{~mm}$ lateral to the midline 643 (ML), -4.5 mm anterior-posterior (AP) from bregma, 0.4-2.0 mm dorsal-ventral (DV) below the dura 644 and at an angle of $10^{\circ}$ from the medial-to-lateral direction in the coronal plane. Implanted microdrives 645 were anchored to jeweler's screws in the skull and secured with multiple rounds of application of dental 646 cement. The electrode was grounded via a reference electrode connected with one jeweler's screw fixed 647 to the skull.

\section{Behavioral and recording procedures}


649 Animals were allowed at least one week for postsurgical recovery in their home cages. During the 650 behavioral training, rats were handled three times a day to get familiar with the testing arena and 651 experimenter. Animals were trained to run in different shapes or sizes of open field enclosures. Implanted 652 animals were individually transferred to the experimental recording room with a covered carrying 653 container. Rats rested in the flowerpot on a holding platform outside the recording box before and after 654 each recording session. Rats were mildly disoriented and then placed back to the open filed enclosure 655 box from a random entry direction during each recording trial. Microdrives mounted on animals' heads 656 were connected to the recording device (Axona Ltd, St Albans, UK) and equipped with a headstage and 657 5-m lightweight cable. A white cue card (297 mm x $210 \mathrm{~mm})$ was used as a single polarizing cue and 658 taped to the interior enclosure wall. Each daily recording session lasted at least 20 min to facilitate full 659 coverage of the testing enclosure while they actively foraged for food pellets scattered into the enclosure.

660 Tetrodes were advanced towards deep layers of the second visual cortex in rats during each recording 661 session. Electrodes were lowered in steps of 25 or $50 \mu \mathrm{m}$ per day until well-isolated single units can be 662 identified. Unit signals were acquired by the DacqUSB system (Axona Ltd., St. Albans, U.K.) digitized 663 at $48 \mathrm{kHz}$, band-pass filtered between $800 \mathrm{~Hz}$ and $6.7 \mathrm{kHz}$ and a gain of x5-18k. Local field potentials 664 were recorded from one of the electrodes with a low-pass filter $(500 \mathrm{~Hz})$.

\section{Spike sorting and cell classification}

666 Spike sorting was manually performed offline with graphical cluster-cutting software TINT (Neil 667 Burgess and Axona Ltd, St. Albans, U.K.), and the clustering was primarily based on features of the 668 spike waveform (peak-to-trough amplitude and spike width), together with additional autocorrelations 669 and cross-correlation. To make sure that the same neuron was not counted twice, signal units with similar 670 or identical waveform shapes were counted only once during our manual cluster cutting, whenever 671 similar or identical individual neurons were recorded and tracked across successive recording sessions.

672 To confirm the quality of cluster separation, we calculated L-ratio as well as isolation distance between 673 clusters. Two small infrared light-emitting diodes (LEDs) were attached to the rat's head to track the rats' 674 speed, head position and orientation using an overhead video camera and tracking hardware/software. 675 Only spikes with instantaneous running speeds $>2.5 \mathrm{~cm} / \mathrm{s}$ were excluded for further analysis in order to 676 exclude confounding behavioral effects such as immobility, grooming and rearing. To construct firing 677 fields and firing rate distributions, the position data were divided into $2.5-\mathrm{cm} \times 2.5-\mathrm{cm}$ location bins, 678 and the path was smoothed with a 21 -sample boxcar window filter (400 ms; 10 samples on each side). 
679 Cells with $>100$ spikes per session and with a coverage of $>80 \%$ were included for further analyses.

680 Maps for the number of spikes and dwell time were smoothed with a quasi-Gaussian kernel over the 681 surrounding 5 x 5 bins. Spatial firing rates were calculated by dividing the number of spikes with dwell 682 time. The peak firing rate was constructed as the highest rate in the corresponding bin from the spatial 683 firing rate map. Mean firing rates were measured from the whole recording session data.

\section{Analysis of place cells}

685 Spatial information is a quantification used to determine the extent to which a neuron's spatial firing 686 pattern can predict the actual position of freely moving animals and is expressed in bits/spike. The spatial 687 information was calculated as:

$$
\text { spatial information }=\sum_{i} p_{i} \frac{\lambda_{i}}{\lambda} \log _{2} \frac{\lambda_{i}}{\lambda}
$$

where $\lambda_{i}$ is the mean firing rate of the given cell in the $i$-th bin, $\lambda$ is the overall mean firing rate of the cell in the whole recording trial, and $p_{i}$ is the probability for the rat being at the spatial location of the $i$-th bin.

Adaptive smoothing (Skaggs et al., 1996) was used to optimize the trade-off between sampling error and spatial resolution before the calculation of spatial information. The position data were first sorted into $2.5-\mathrm{cm} \times 2.5-\mathrm{cm}$ bins, and to calculate the firing rate for a specific bin, circle centered on the given bin is expanded gradually until

$$
\gamma \geq \frac{\alpha}{n \sqrt{s}}
$$
where $\gamma$ is the circle's radius in bins, $n$ and $s$ are the total number of occupancy samples and spikes 698 within the circle, respectively, and $\alpha=10,000$. With a video sampling frequency at $50 \mathrm{~Hz}$, the firing rate of the bin was then set to $50 \cdot s / n$.

700 A place cell was defined with its spatial information above the chance level, which was computed by a 701 random shuffling procedure using the total sample of recorded cells. For each round of the permutation 702 process, the entire sequence of spike trains was time-shifted along the animal's trajectory by a random 703 amount of time between $20 \mathrm{~s}$ and the total trial duration minus $20 \mathrm{~s}$, with the end of the spike train 
wrapped to the beginning of the trial. A spatial firing map was then constructed, and for each shuffled map, spatial information was calculated. This permutation process was repeated 100 times for each cell, leading to a total of 136,400 permutations for the 1364 visual neurons. This shuffling procedure aimed to preserve the temporal firing patterns while perturbing the spatial structure at the same time.

708 The threshold for classifying cells into place cells was defined as the spatial information scores exceeding the $99^{\text {th }}$ percentile of the entire shuffled data.

\section{Analysis of grid cells}

711 Visual grid cells were identified by calculating the 6-fold symmetry in their spatial autocorrelations with 712 smoothed rate maps (Boccara et al., 2010, Sargolini et al., 2006, Zhang et al., 2013).

713 With $\lambda(x, y)$ representing the mean firing rate of a given cell at coordinate $(x, y)$, the autocorrelation 714 between the firing field itself and the firing field with spatial lags of $\tau_{x}$ and $\tau_{y}$ was determined as:

$$
\mathrm{r}\left(\tau_{x}, \tau_{y}\right)=\frac{\mathrm{n} \sum \lambda(x, y) \lambda\left(x-\tau_{x}, y-\tau_{y}\right)-\sum \lambda(x, y) \sum \lambda\left(x-\tau_{x}, y-\tau_{y}\right)}{\sqrt{n \sum \lambda(x, y)^{2}-\left[\sum \lambda(x, y)\right]^{2}} \sqrt{n \sum \lambda\left(x-\tau_{x}, y-\tau_{y}\right)^{2}-\left[\sum \lambda\left(x-\tau_{x}, y-\tau_{y}\right)\right]^{2}}}
$$

where the summation is over total $\mathrm{n}$ pixels in $\lambda(x, y)$ for which firing rate was estimated for both $\lambda(x, y)$ and $\lambda\left(x-\tau_{x}, y-\tau_{y}\right)$. Autocorrelations were not calculated for spatial offsets when total number of overlapping pixels was smaller than 20. The degree of spatial regularity ("gridness" or "grid score") was estimated for every single unit by using an annular sample surrounding the central peak of the autocorrelogram but excluding the central peak itself, and by comparing rotated versions of this annular sample (Boccara et al., 2010, Sargolini et al., 2006). The Pearson's correlations between this annular sample and its rotated versions were obtained, with the angles of shift being $60^{\circ}$ and $120^{\circ}$ in the first group, and rotation degree of $30^{\circ}, 90^{\circ}$ and $150^{\circ}$ in the second group. Gridness or the neuron's grid score was characterized as the minimal difference between any of the correlation coefficients in the first rotation group and any of the correlation coefficients in the rotation second group. Shuffling was performed in the same way used for defining place cells. For each permutation, a randomized grid score was obtained. Grid cells were categorized as cells with grid scores exceeding the $99^{\text {th }}$ percentile of all

728 randomized grid scores from shuffled data over the entire population of identified visual cells. Grid 
730 vertices among six adjacent spatial firing fields in the autocorrelogram of the spatial firing map. Since

731 such analysis is rather sensitive to noise in the autocorrelogram, grid spacing was determined only when

732 the median distance to the six surrounding vertices for the cell was comparable to the grid radius, which

733 was defined as the radius of the circle resulting in the highest grid score. Thus, the grid radius was also

734 defined as the grid field size.

735 The orientation of the gird cell was calculated by first defining the camera-based horizontal reference

736 line of being $0^{\circ}$. The vector from the central peak to the nearest surrounding vertices of the 737 autocorrelogram in the counterclockwise direction was defined as grid orientation.

\section{Analysis of head-direction cells}

739 The rat's head direction was quantified by the relative position of the two diodes differentiated through

740 their sizes (Boccara et al., 2010, Sargolini et al., 2006, Zhang et al., 2013). The directional tuning curve

741 for a given cell was drawn by calculating the firing rate of the cell as a function of the rat's heading

742 direction, which is divided into angular bins of 3 degrees and subsequently smoothed with a 15-degree

743 mean window filter. To avoid possible bias, recorded data were only used if all head directional bins

744 contain spikes.

745 The strength of directionality was estimated by computing the mean vector length from the polar plot of 746 angular firing rates. The chance values or the threshold for defining head-direction cells were determined

747 by a shuffling procedure in a similar way as for place cells, with the entire sequence of spike trains 748 shifted between $20 \mathrm{~s}$ and the total trail length minus $20 \mathrm{~s}$ along the animal's path. Cells were classified 749 as head-direction cells if their mean vector lengths surpass the $99^{\text {th }}$ percentile of the mean vector lengths 750 of the entire shuffled distribution.

\section{$751 \quad$ Analysis of border cells}

752 Putative border or boundary vector cells were identified by computing the border score, which is defined

753 as the difference between the maximum coverage of a given wall by any single spatial firing field of the 754 recorded cell and the average firing distance of all the pixels of the firing field to the nearest wall, 755 normalized by the sum of those two values (Boccara et al., 2010, Zhang et al., 2013, Solstad et al., 2008).

756 Border scores ranged from $-1 \sim+1$, with -1 representing perfect central firing fields and +1 representing 757 spatial firing fields exactly lining up with at least one entire wall. Firing fields were defined as total 
number of neighboring pixels with firing rates exceeding 0.3 times the highest firing rate that covered a total area more than $200 \mathrm{~cm}^{2}$.

760 The definition of border cell was in a similar way as for place cells, head-direction cells and grid cells.

761 For each permutation process, the whole sequence of spike trains was shifted along the animal's path by 762 a random interval between a period of $20 \mathrm{~s}$ and the total time of the entire trial minus $20 \mathrm{~s}$, with the end 763 of the spike train wrapped to the start of the trial. A spatial firing rate map was then derived, and a border 764 score was estimated.

765 The distribution of border scores was obtained for the entire set of shuffling trials from the whole 766 population, and the $99^{\text {th }}$ percentile was then determined as the classifying threshold. Border cells were 767 defined with observed border score higher than the threshold value.

\section{Histology and identification of tetrode trajectory}

769 At the completion of the last recording session for each implanted animal, rats were deeply anesthetized 770 by giving an overdose of sodium pentobarbital. Rats underwent transcardial perfusion first with 771 phosphate-buffered saline (PBS) followed by 4\% paraformaldehyde (PFA). Brains were extracted and 772 post-fixed in 4\% PFA overnight. The individual brain was then transferred in 10, 20 and $30 \%$ 773 sucrose/PFA solution sequentially across 72 hours. After brains sank, they were sectioned at $30 \mu \mathrm{m}$ 774 intervals through the tetrode implant region with a cyrotome. Coronal sections were mounted on gelatin775 coated glass slides and stained with Cresyl violet (Sigma-Aldrich). The final tetrode trajectories through 776 V2 subregion were identified through 3D reconstruction of digitized images of the Cresyl violet-stained 777 coronal sections acquired with the Olympus Slideview VS200 Digital Slide Scanner. Tetrode trajectories 778 of each individual recordings were measured from the deepest tetrode location, daily advancement for 779 tetrode lowering and adjusted tissue shrinkage correction by dividing the distance between the initial 780 brain surface and the final electrode tip by the last advanced depth of the recording electrodes. Electrode 781 traces were confirmed to be located within the secondary visual cortex in rats according to The Rat Brain 782 in Stereotaxic Coordinates (Paxinos and Watson, 2013). 
60. Skaggs, W.E., et al., Theta phase precession in hippocampal neuronal populations and the compression of temporal sequences. Hippocampus, 1996. 6(2): 149-172.

786

61. Boccara, C.N., et al., Grid cells in pre- and parasubiculum. Nat Neurosci, 2010. 13(8): 987-994.

62. Sargolini, F., et al., Conjunctive representation of position, direction, and velocity in entorhinal

63. Zhang, S.J., et al., Optogenetic dissection of entorhinal-hippocampal functional connectivity. Science, 2013. 340(6128): 1232627.

64. Solstad, T., et al., Representation of geometric borders in the entorhinal cortex. Science, 2008. 322(5909): 1865-1868.

65. Paxinos, G. and C. Watson, The Rat Brain in Stereotaxic Coordinates 7th Edition (seventh edition). 2013, New York: Academic Press. 
bioRxiv preprint doi: https://doi.org/10.1101/2021.10.30.466568; this version posted November 2, 2021. The copyright holder for this preprint (which was not certified by peer review) is the author/funder, who has granted bioRxiv a license to display the preprint in perpetuity. It is made available under aCC-BY-NC-ND 4.0 International license.

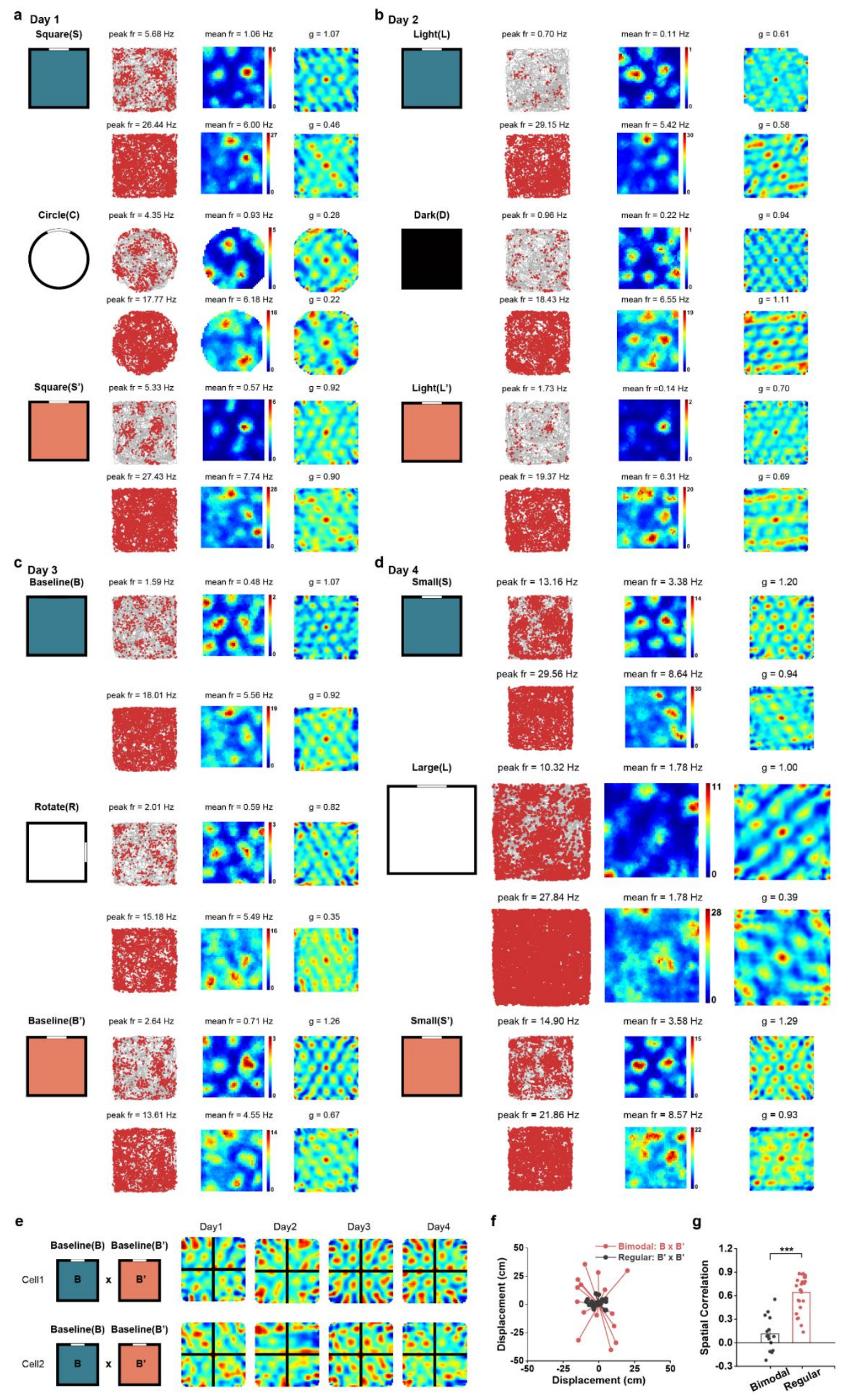


795 Fig. S1 V2 regular grid cells did not switch firing patterns during change in the familiar

796 environment. Spatial responses of co-recorded V2 regular grid cells.

797 (a) Grid firing patterns in different shapes of running boxes.

798 (b) Grid firing patterns maintained under total darkness.

799 (c) Grid firing patterns were consistent after cue card manipulation.

800 (d) Grid firing patterns remain unaltered in different sizes of running boxes.

801 (e) Cross-correlogram for the same cell in the same baseline condition after environmental change (B

802 versus B'). Note the peak of the cross-correlogram was nearly centered on the origin.

803 (f) Vector diagram showing the grid displacement from the center of the cross-correlogram to the nearest

804 peak. The mean displacement for regular grid cells was significantly higher than that for bimodal grid 805 cells.

806 (g) Comparison of spatial correlation coefficients between two baselines after environmental

807 manipulation (B versus B'), with significantly higher correlation for regular grid cells than bimodal grid 808 cells. 
bioRxiv preprint doi: https://doi.org/10.1101/2021.10.30.466568; this version posted November 2, 2021. The copyright holder for this preprint (which was not certified by peer review) is the author/funder, who has granted bioRxiv a license to display the preprint in perpetuity. It is made available under aCC-BY-NC-ND 4.0 International license.

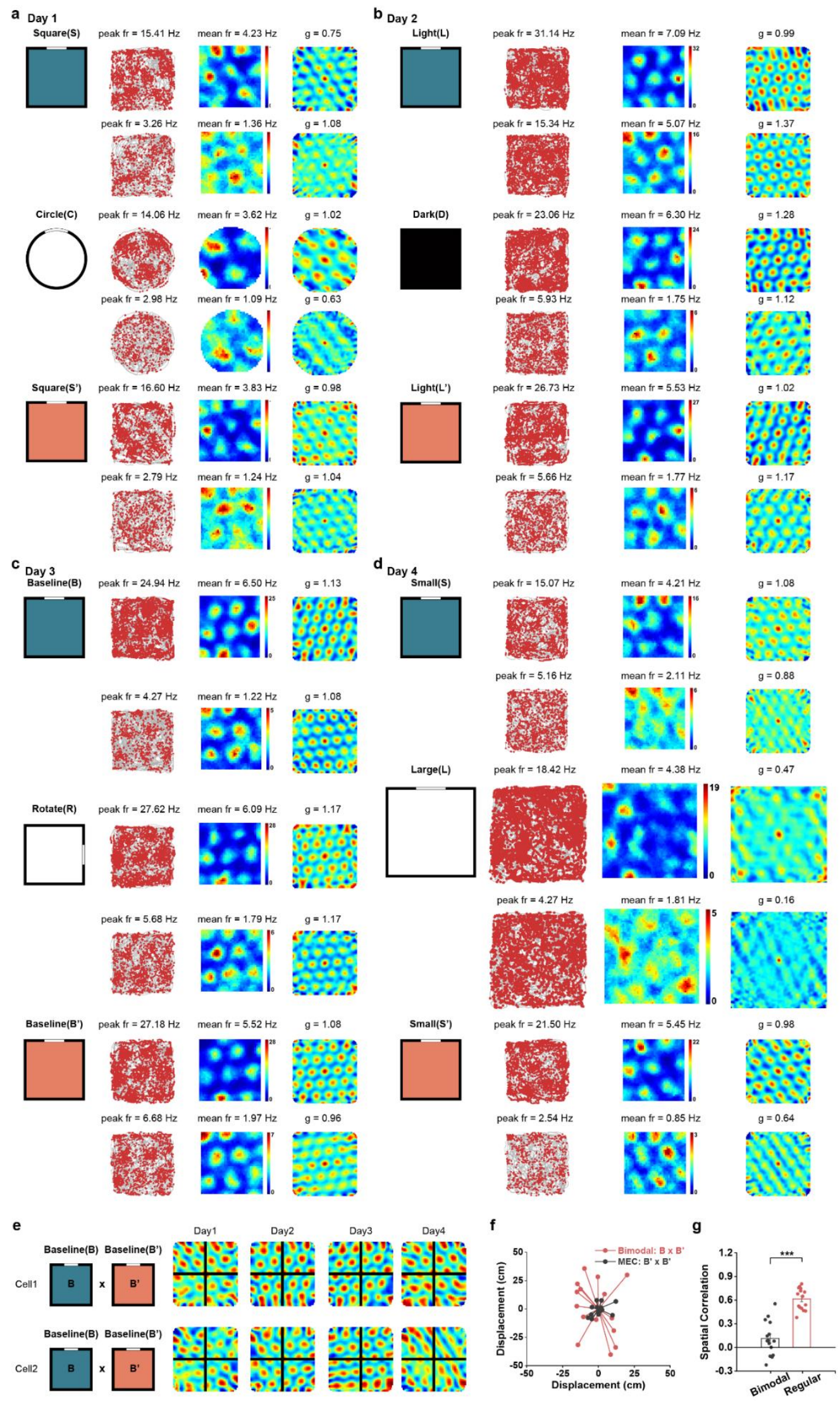


810 Fig. S2 MEC grid cells did not switch firing patterns during two baseline sessions after change in

811 the familiar environment. Spatial responses of co-recorded one pair of MEC grid cell.

812 (a) Grid firing patterns in different shapes of running boxes.

813 (b) Grid firing patterns maintained under total darkness.

814 (c) Grid firing patterns were consistent after cue card manipulation.

815 (d) Grid firing patterns remain unaltered in different sizes of running boxes.

816 (e) Cross-correlogram for the same cell in the same baseline condition after environmental change (B

817 versus B'). Note the peak of the cross-correlogram was nearly centered on the origin.

818 (f) Vector diagram showing the grid displacement from the center of the cross-correlogram to the nearest

819 peak. The mean displacement for regular grid cells was significantly higher than that for bimodal grid 820 cells.

821 (g) Comparison of spatial correlation coefficients between two baselines after environmental 822 manipulation (B versus B'), with significantly higher correlation for MEC grid cells than V2 bimodal 823 grid cells. 


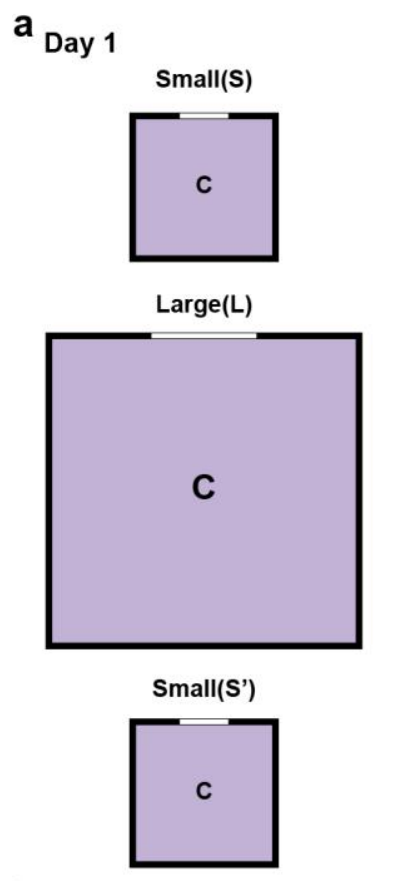

b Day 2

Square(S) peak $\mathrm{fr}=6.87 \mathrm{~Hz}$
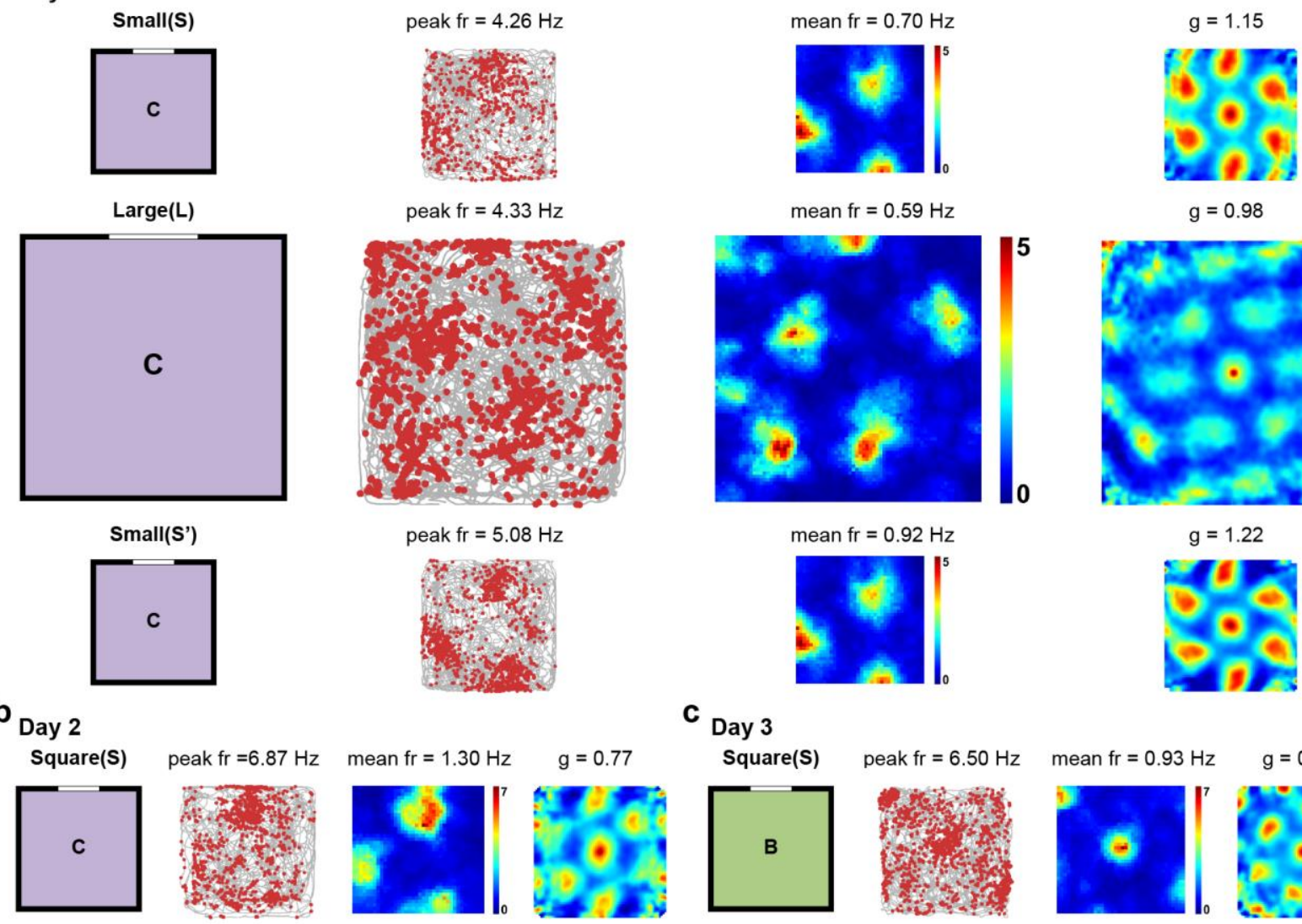

peak $\mathrm{fr}=4.33 \mathrm{~Hz}$

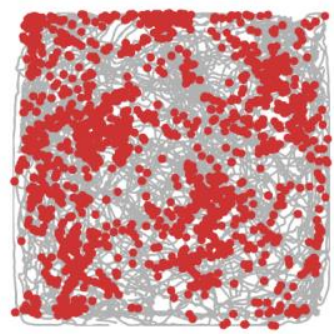

mean $\mathrm{fr}=0.59 \mathrm{~Hz}$

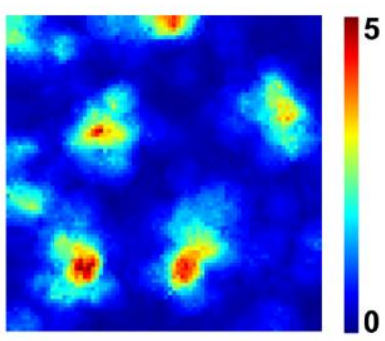

\section{$\mathrm{g}=0.98$}

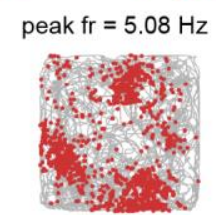

mean $\mathrm{fr}=0.92 \mathrm{~Hz}$
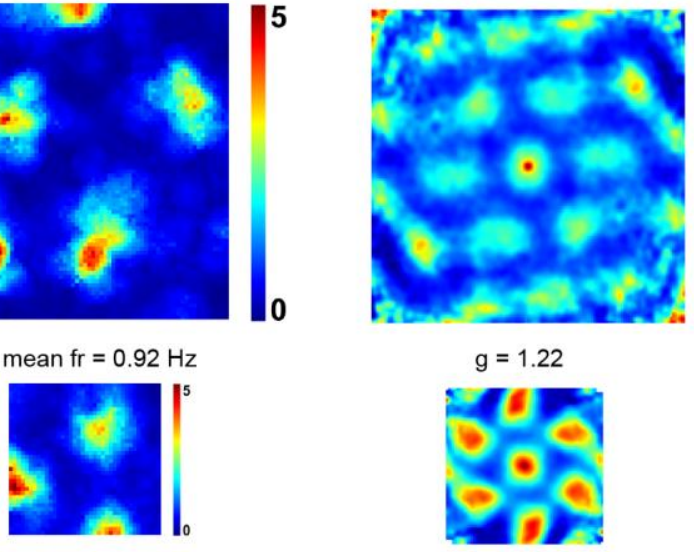

C Day 3

Square(S) peak fr $=6.50 \mathrm{~Hz} \quad$ mean $\mathrm{fr}=0.93 \mathrm{~Hz} \quad \mathrm{~g}=0.71$

Circle(C) peak fr $=7.82 \mathrm{~Hz}$

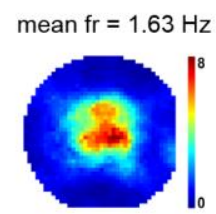

$g=0.77$
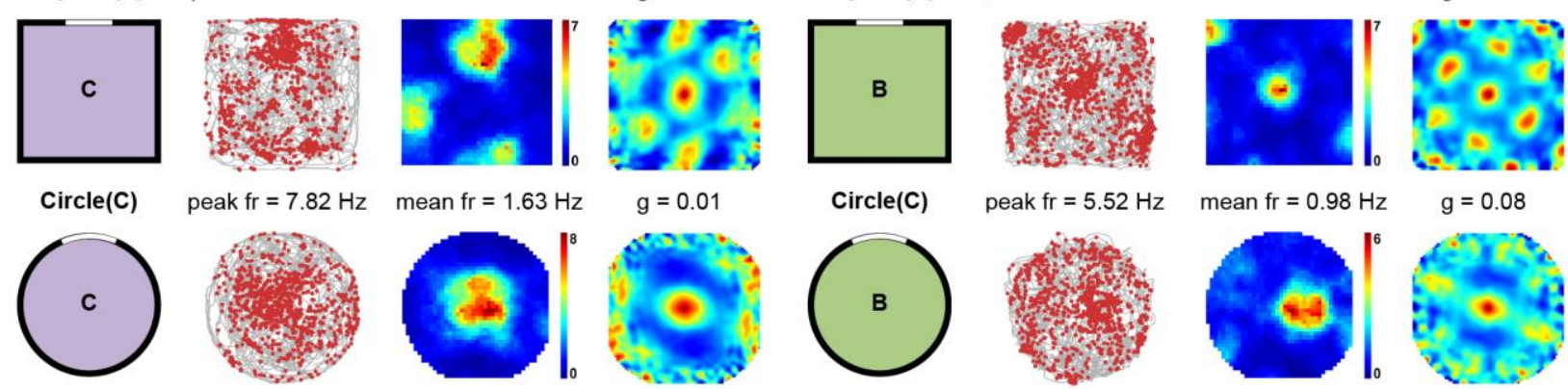

Circle(C)

peak $\mathrm{fr}=5.52 \mathrm{~Hz}$

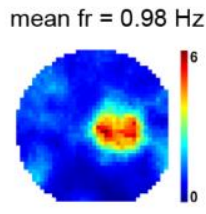

$g=0.08$
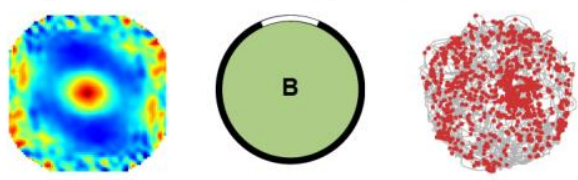

$g=0.65$

Square(')

peak $\mathrm{fr}=6.38 \mathrm{~Hz}$

mean $\mathrm{fr}=1.56 \mathrm{~Hz}$
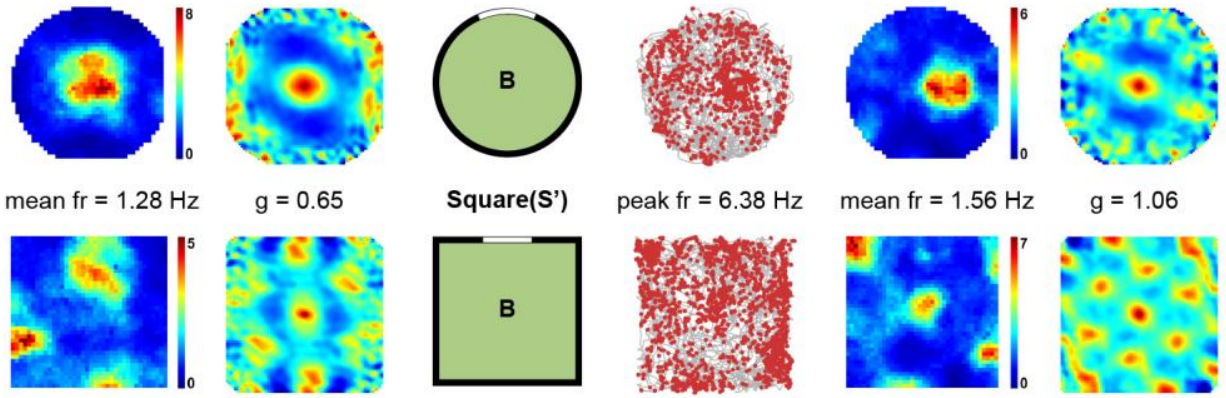

$g=1.06$
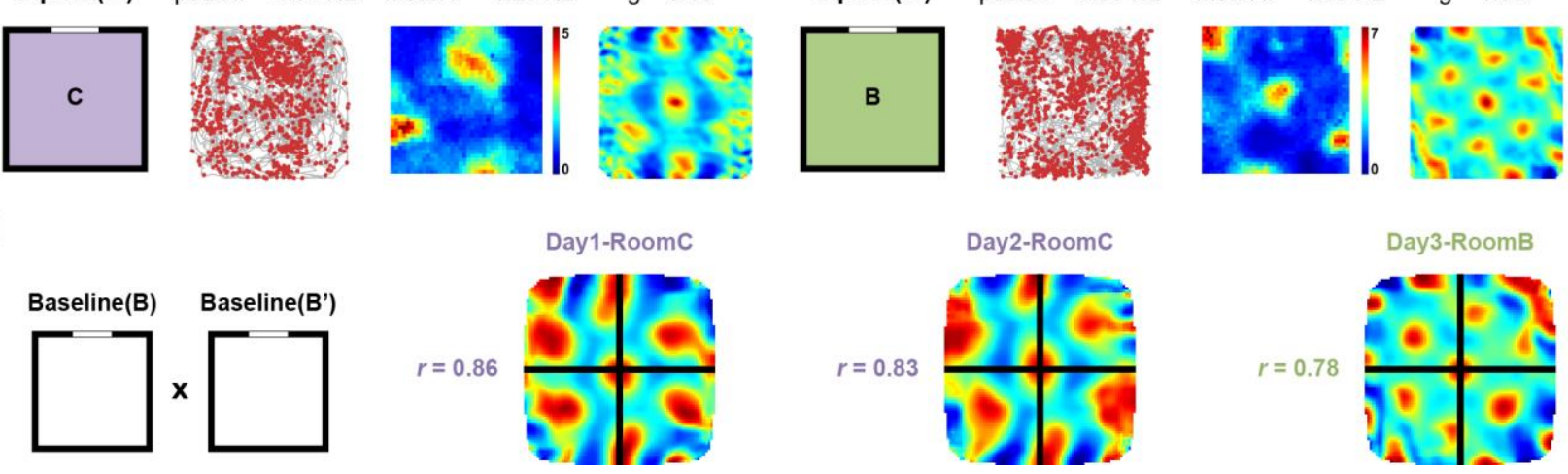

d

825 Fig. S3 Bimodal grid cells did not switch firing patterns in the novel environment. Spatial responses

826 of the same cell as in Figure 1 except in two novel environments.

827 (a) Grid firing patterns in different shapes of running boxes in novel room $\mathrm{C}$. 
828 (b) Grid firing patterns remain unaltered in different sizes of running boxes in novel room C.

829 (c) Grid firing patterns did not switch in different shapes of running boxes in novel room B.

830 (d) Cross-correlogram for the same cell in the same baseline condition after environmental change (B

831 versus B'). Pearson correlation coefficients $(r)$ of the cross-correlation between spatial maps of the two

832 baseline sessions are indicated. Note the peak of the cross-correlogram was nearly centered on the origin. 
a

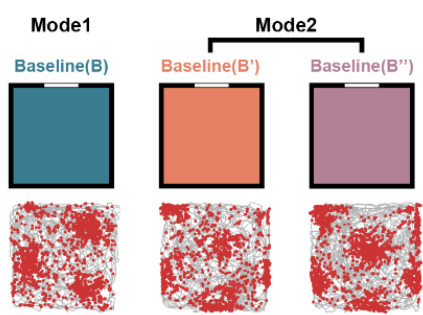

b

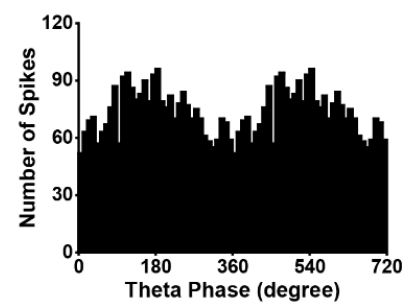

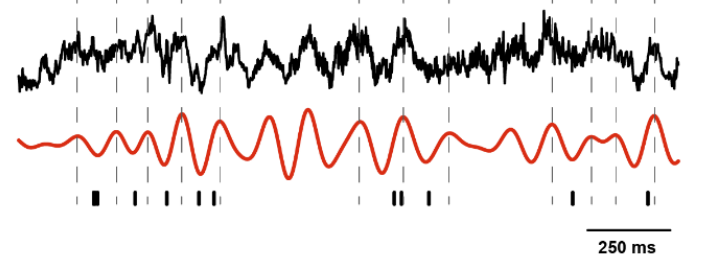

$\mathbf{d}_{\text {Day } 1}$

$e_{\text {Day } 2}$

$f_{\text {Day } 3}$

gay 4
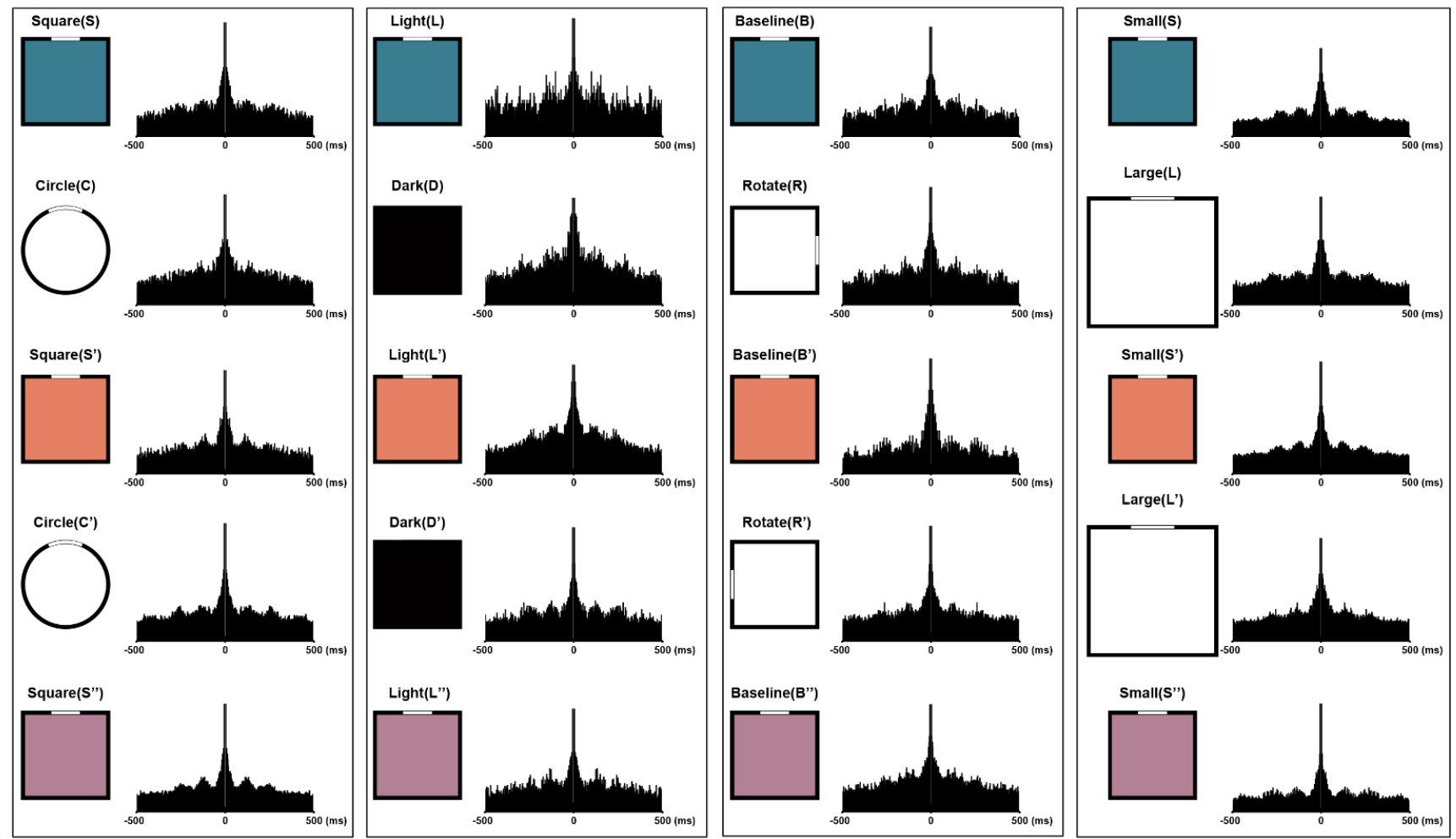

Large(L)
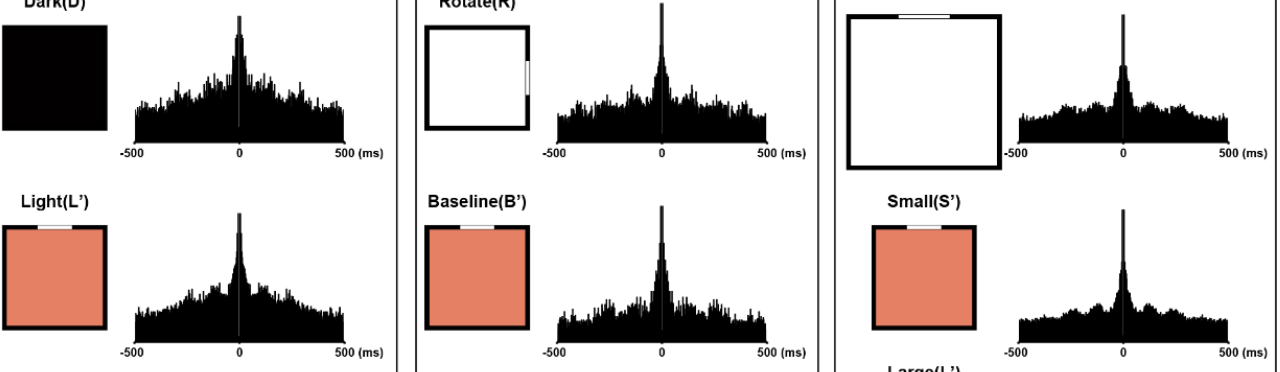

Small(S')

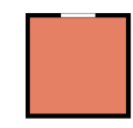

Large(L')

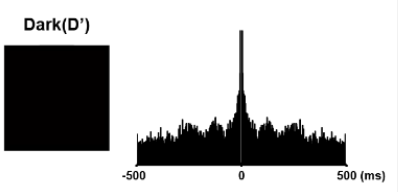

Rotate(R')
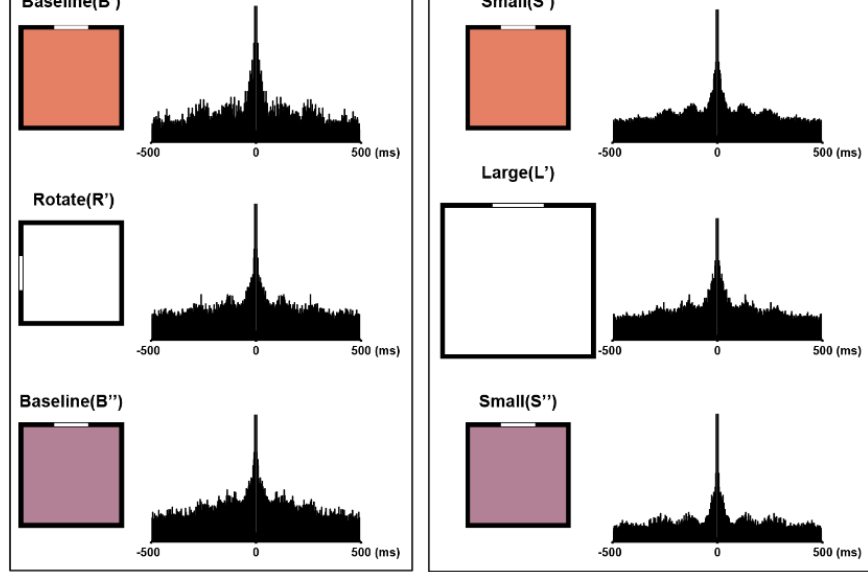

Light(L”)
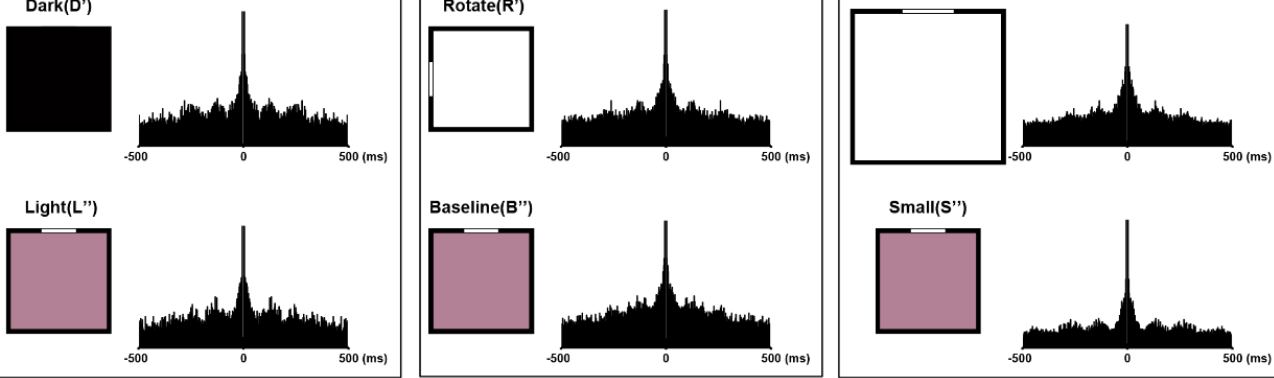

h
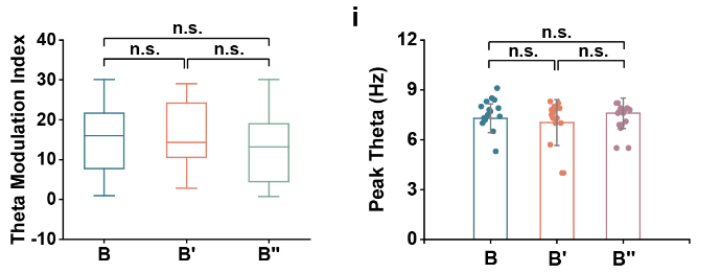

834 Fig. S4 Theta modulation preserved during bimodal switch of firing patterns of grid cells by

835 environmental change.

836 (a) Bimodal firing fields of the same grid cell in Fig. 1.

837 (b) Distribution of firing rate within two theta cycles (peak of local theta rhythm set as $0^{\circ}$ ). 
838 (c) LFP signals with spike times for the grid cell during $2 \mathrm{~s}$ of active running. Top, unfiltered EEG trace;

839 middle, theta $(6-12 \mathrm{~Hz})$ filtered trace; bottom, individual spikes. Gray dashed lines indicate $0^{\circ}$ of theta

840 phase.

841 (d-g) Theta modulation of the same grid cell as in Fig. 1 during bimodal switch of spatial firing patterns

842 in responses to different environmental changes.

843 (h) Comparison of theta modulation index in the baseline condition (B), after environmental

844 manipulation and back to the baseline condition (B') and after another environmental change and back

845 to the baseline condition again (B'"). n.s., not significant.

846 (i) Same as (h) except for theta peak frequency. 
a

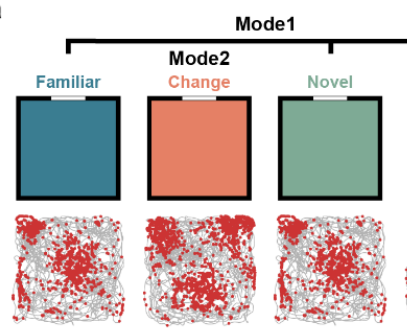

b

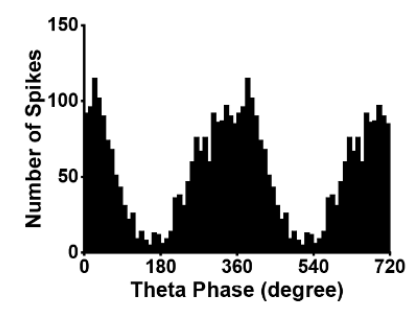

c

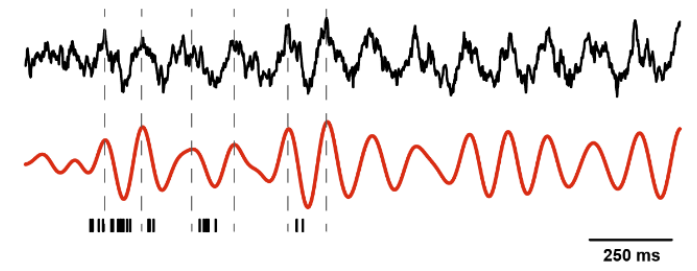

$\mathrm{d}_{\text {Day1 }}$
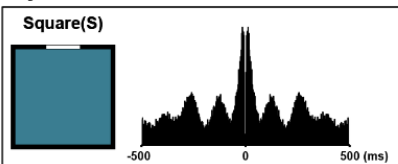

$\mathbf{e}_{\text {Day2 }}$
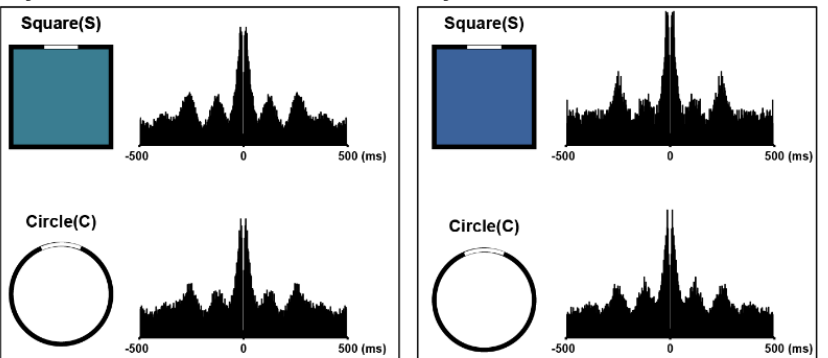

Square(S')
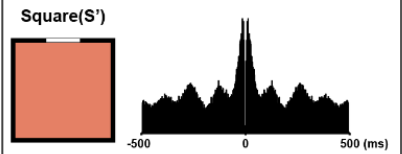

Novel Room
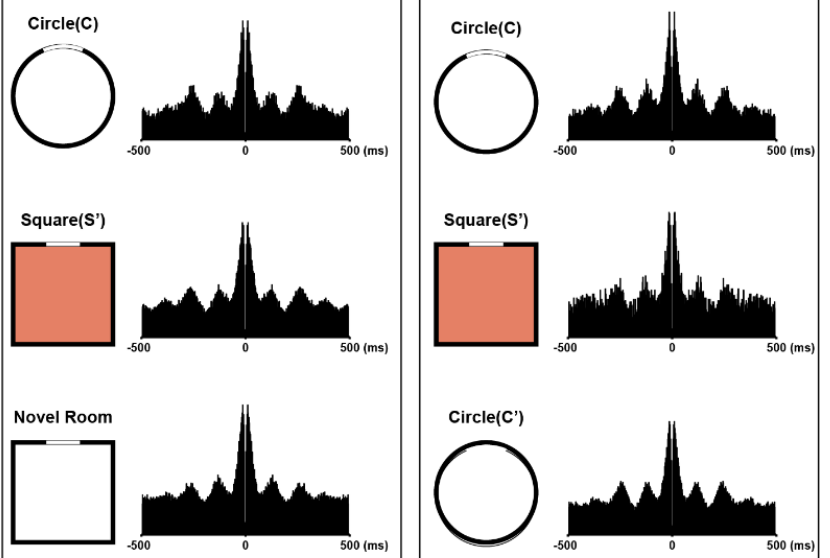

Square(S")
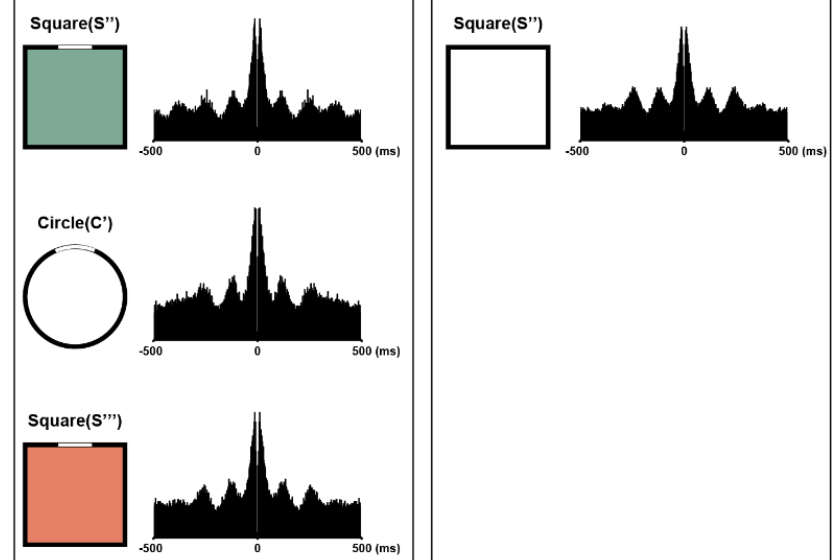

h

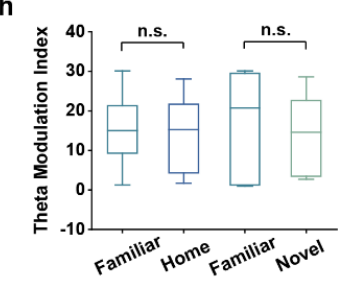$$
\text { Familiar }{ }_{\text {Hom }}^{i}
$$

$f_{\text {Day3 }}$

$g_{\text {Day4 }}$
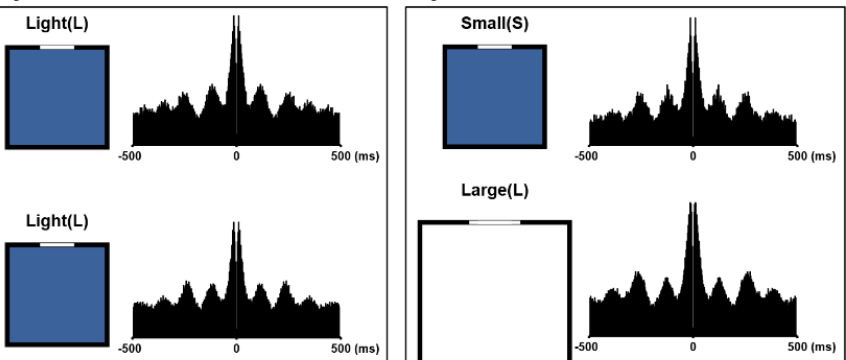

Large(L)
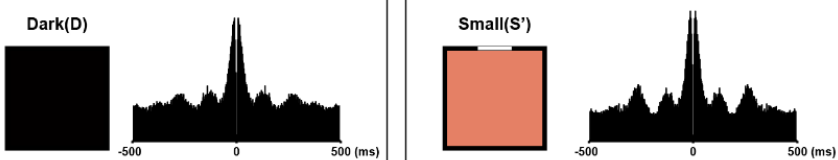

Light(L')
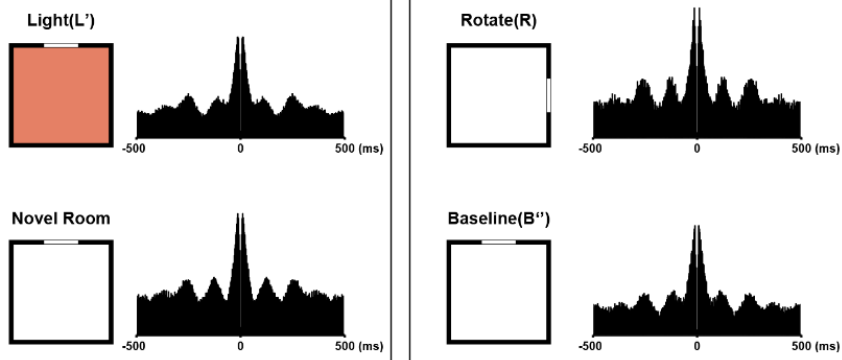

Light(L”)
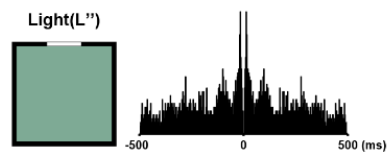

848 Fig. S5 Theta modulation persisted during re-entry into the same familiar environment. 
849 (a) Bimodal firing fields of the same grid cell in Fig. 2.

850 (b) Distribution of gird firing rate within two theta cycles (peak of local theta rhythm set as $0^{\circ}$ ).

851 (c) LFP signals with spike times for the grid cell during 2 s of active running. Top, unfiltered EEG trace;

852 middle, theta $(6-12 \mathrm{~Hz})$ filtered trace; bottom, individual spikes. Gray dashed lines indicate $0^{\circ}$ of theta

853 phase.

854 (d-g) Theta modulation and theta phase distribution of the same grid cell as in Figure. 2 during bimodal 855 switch of spatial firing patterns in responses to different environmental changes and re-entry into the 856 same familiar environment either from the home cage or from a novel room.

857 (h) Comparison of theta modulation index in the baseline condition (B), after environmental 858 manipulation and back to the baseline condition (B') and after another environmental change and back 859 to the baseline condition again (B'). n.s., not significant.

860 (i) Same as (h) except for theta peak frequency. 

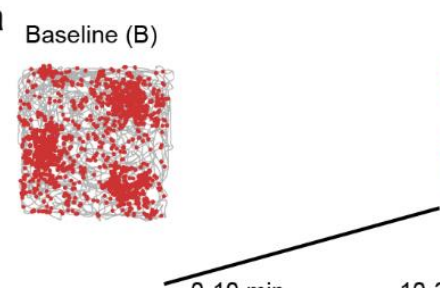

Baseline (B')
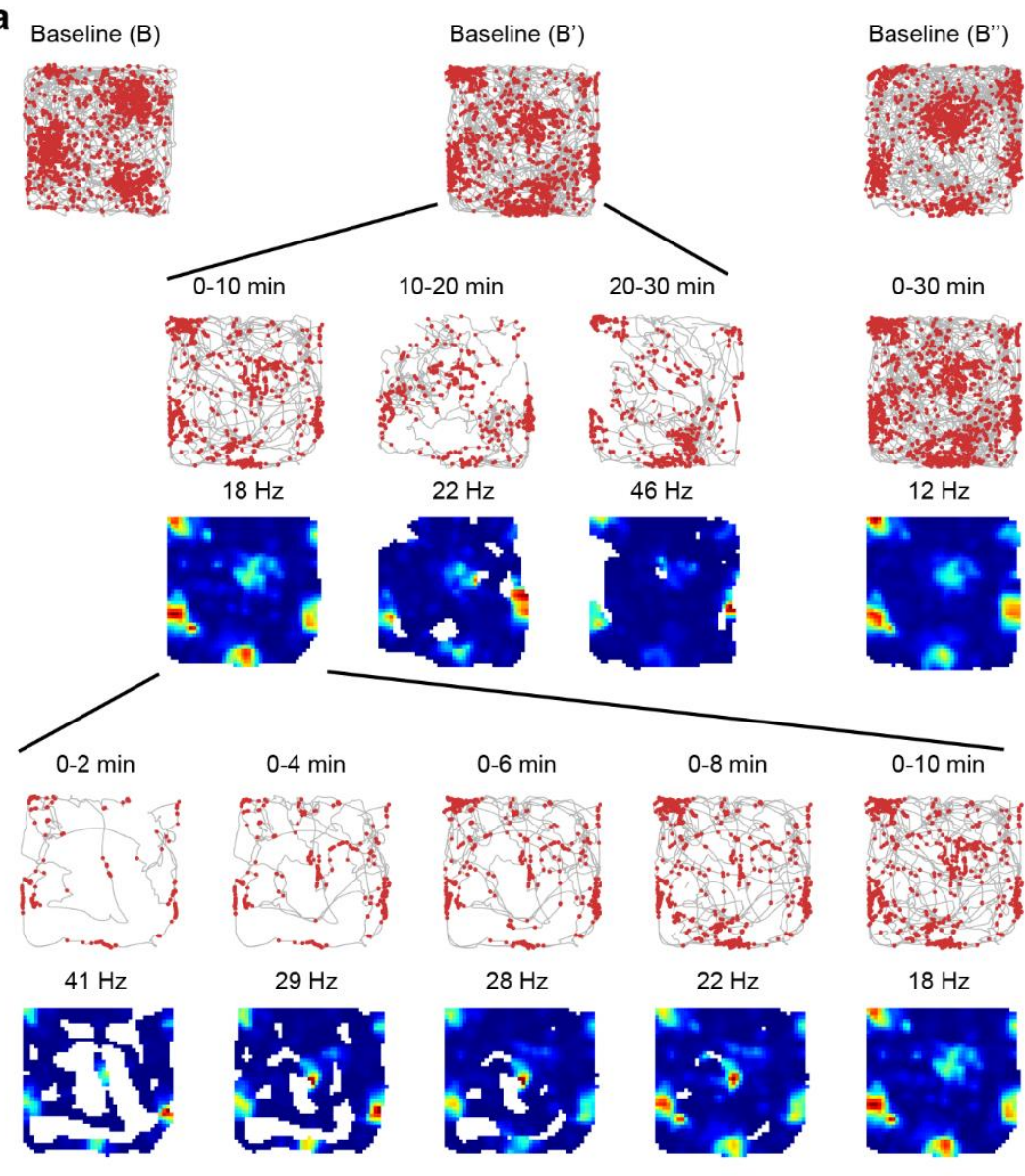

$0-30 \mathrm{~min}$

b

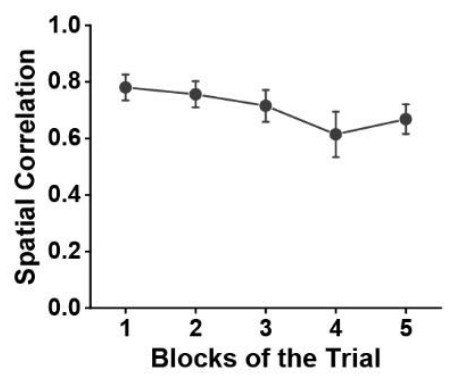

C
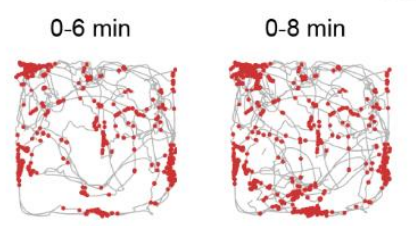

$0-10 \mathrm{~min}$

Fig. S6 Bimodal shift of grid firing pattern is expressed instantly after environmental change.

(a), Trajectory maps for the same grid cell in Fig. 1a in a baseline condition (B), after environmental

864 manipulation and back to the baseline condition (B') and after another environmental change and back

865 to the baseline condition again (B'). The middle trial of the baseline condition (B') is broken into blocks

866 to show the development of grid structure after bimodal shift.

867 (b) Development of grid firing patterns as shown by spatial correlation with the whole session of the

868 firing field of the baseline trial (B') across preceding 5 divided blocks of the same trial $(n=15$, means \pm s.e.m.). 
bioRxiv preprint doi: https://doi.org/10.1101/2021.10.30.466568; this version posted November 2, 2021. The copyright holder for this preprint

(which was not certified by peer review) is the author/funder, who has granted bioRxiv a license to display the preprint in perpetuity. It is made available under aCC-BY-NC-ND 4.0 International license.

870 (c) Stability of mean firing rate across 5 divided blocks, normalized to the mean firing rate for the whole 871 session. 
bioRxiv preprint doi: https://doi.org/10.1101/2021.10.30.466568; this version posted November 2, 2021. The copyright holder for this preprint (which was not certified by peer review) is the author/funder, who has granted bioRxiv a license to display the preprint in perpetuity. It is made available under aCC-BY-NC-ND 4.0 International license.

a Day 1

Light(L) peak $\mathrm{fr}=16.85 \mathrm{~Hz}$ mean $\mathrm{fr}=2.55 \mathrm{~Hz} \quad \mathrm{~g}=0.91 \quad 5.22 \mathrm{~Hz} / 0.39 / 134^{\circ}$
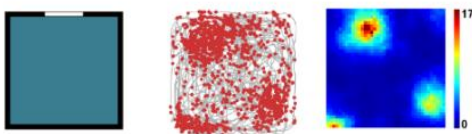

peak $\mathrm{fr}=7.70 \mathrm{~Hz}$

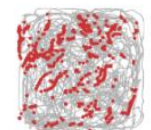

mean $\mathrm{fr}=1.00 \mathrm{~Hz}$

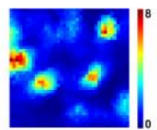

Light(L)
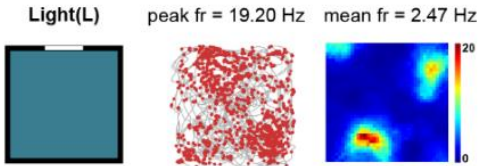

peak $\mathrm{fr}=8.59 \mathrm{~Hz}$
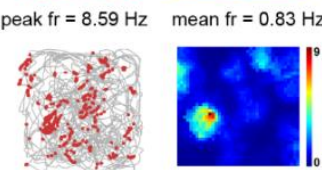

Dark(D)
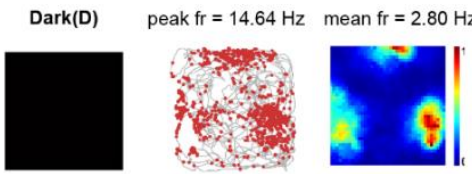

peak $\mathrm{fr}=15.89 \mathrm{~Hz}$ mean $\mathrm{fr}=2.26 \mathrm{~Hz}$

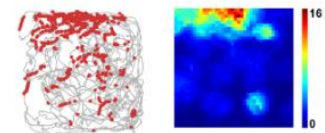

Light(L') peak $\mathrm{fr}=17.38 \mathrm{~Hz}$ mean $\mathrm{fr}=2.30 \mathrm{~Hz}$
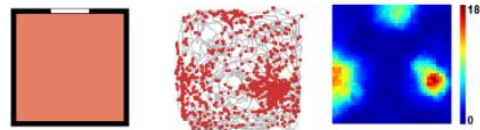

peak $\mathrm{fr}=24.93 \mathrm{H}$
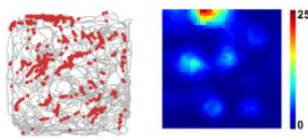

Light(L')
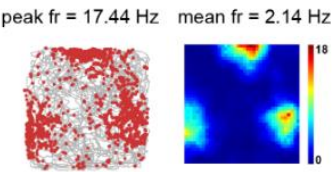

peak $\mathrm{fr}=5.35 \mathrm{H}$
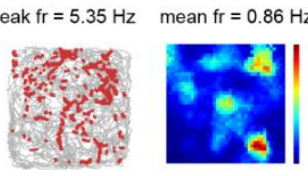

C
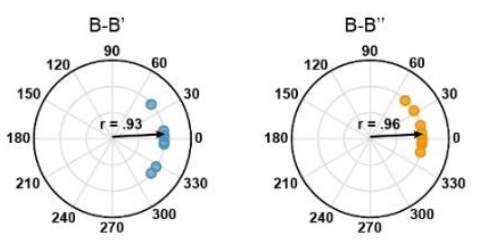

872

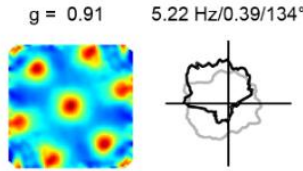

$\mathrm{g}=0.34 \quad 9.01 \mathrm{~Hz} / 0.91 / 208^{\circ}$
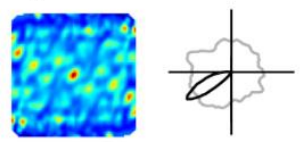

$\mathrm{g}=0.95 \quad 5.81 \mathrm{~Hz} / 0.39 / 140^{\circ}$
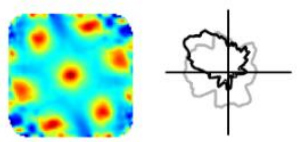

$\mathrm{g}=0.62 \quad 7.75 \mathrm{~Hz} / 0.95 / 202^{\circ}$
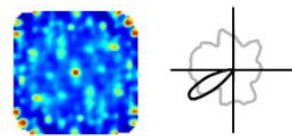

$g=0.10 \quad 5.80 \mathrm{~Hz} / 0.31 / 119^{\circ}$
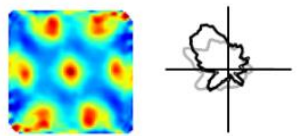

$g=0.16 \quad 11.96 \mathrm{~Hz} / 0.54 / 202^{\circ}$
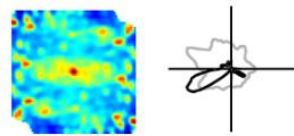

$g=1.10 \quad 4.40 \mathrm{~Hz} / 0.32 / 127^{\circ}$
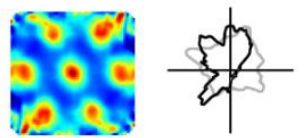

$g=0.27 \quad 12.80 \mathrm{~Hz} / 0.67 / 196^{\circ}$
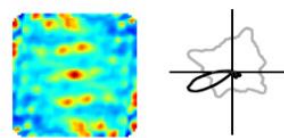

$g=0.92 \quad 5.96 \mathrm{~Hz} / 0.42 / 142^{\circ}$
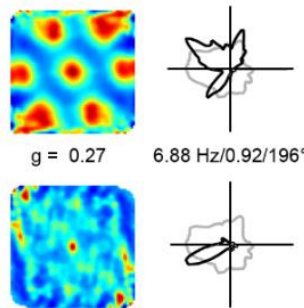

$g=0.27 \quad 6.88 \mathrm{~Hz} / 0.92 / 196^{\circ}$

d

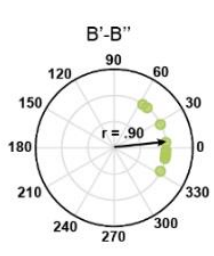

b Day 2

Square(S) peak $\mathrm{fr}=23.97 \mathrm{~Hz}$ mean $\mathrm{fr}=2.68 \mathrm{~Hz} \quad \mathrm{~g}=0.81 \quad 5.23 \mathrm{~Hz} / 0.38 / 145^{\circ}$
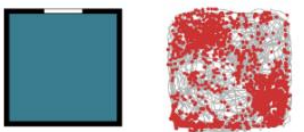

peak $\mathrm{fr}=3.86 \mathrm{~Hz}$
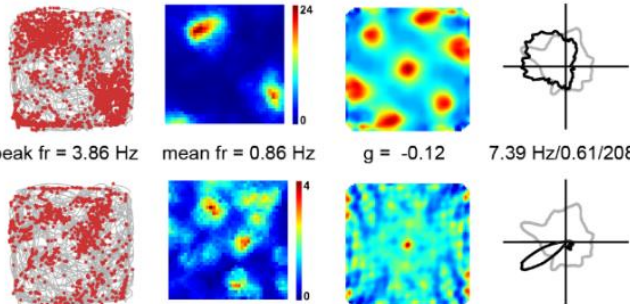

$g=-0.12 \quad 7.39 \mathrm{~Hz} / 0.61 / 208^{\circ}$

Circle(C) peak $\mathrm{fr}=18.87 \mathrm{~Hz}$ mean $\mathrm{fr}=2.85 \mathrm{~Hz}$
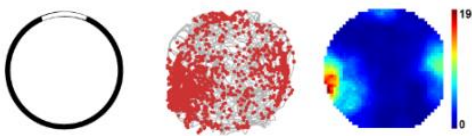

peak $\mathrm{fr}=5.16 \mathrm{H}$
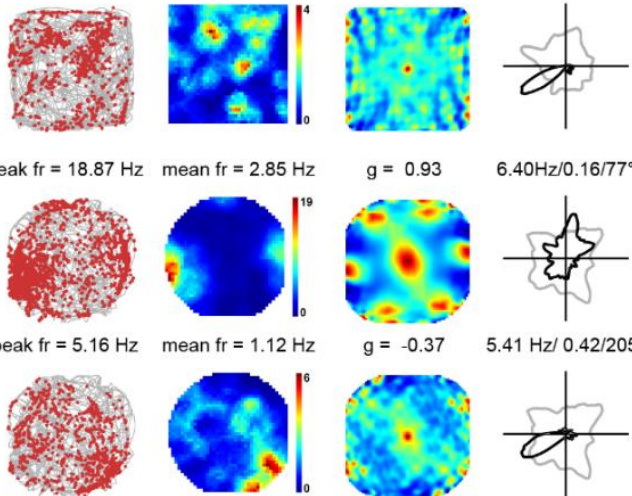

$g=-0.37 \quad 5.41 \mathrm{~Hz} / 0.42 / 205^{\circ}$

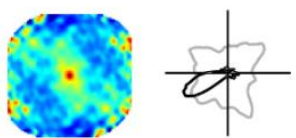

Square(S') peak $\mathrm{fr}=28.41 \mathrm{~Hz}$ mean $\mathrm{fr}=2.55 \mathrm{~Hz}$

$g=0.98 \quad 5.13 \mathrm{~Hz} / 0.34 / 142^{\circ}$
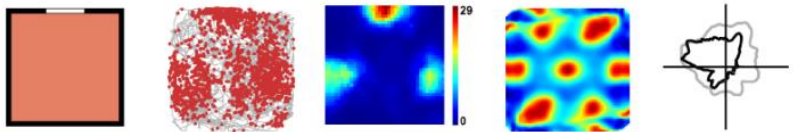

peak $\mathrm{fr}=7.20 \mathrm{~Hz}$

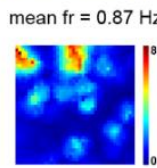

$g=-0.13$

$68 \mathrm{~Hz} / 0.62 / 199^{\circ}$
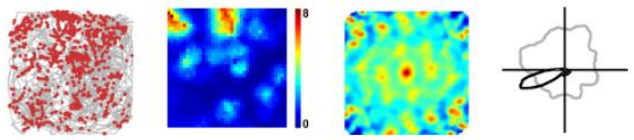

Novel Room peak $\mathrm{fr}=19.38 \mathrm{~Hz}$ mean $\mathrm{fr}=3.18 \mathrm{~Hz}$
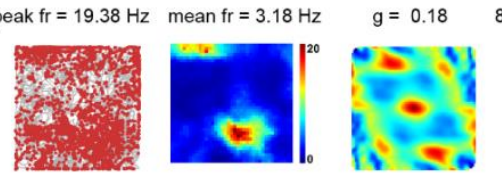

$8.43 \mathrm{~Hz} / 0.36 / 163^{\circ}$

peak $\mathrm{fr}=6.48 \mathrm{~Hz}$

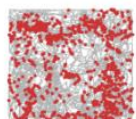

mean $\mathrm{fr}=0.97 \mathrm{~Hz}$

$g=-0.02 \quad 5.43 \mathrm{~Hz} / 0.50 / 211^{\circ}$
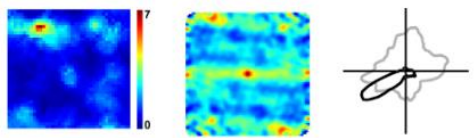

Square(S") $\quad$ peak $\mathrm{fr}=23.45 \mathrm{~Hz}$ mean $\mathrm{fr}=3.18 \mathrm{~Hz}$

$g=0.75 \quad 5.80 \mathrm{~Hz} / 0.32 / 98^{\circ}$
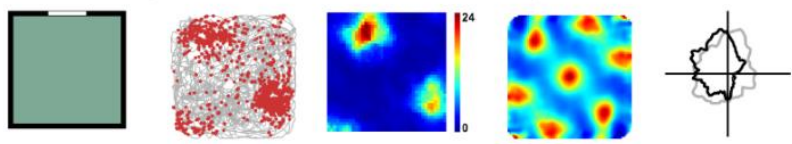

peak $\mathrm{fr}=5.40 \mathrm{~Hz} \quad$ mean $\mathrm{fr}=0.87 \mathrm{~Hz}$

$g=0.55 \quad 6.84 \mathrm{~Hz} / 0.72 / 208^{\circ}$
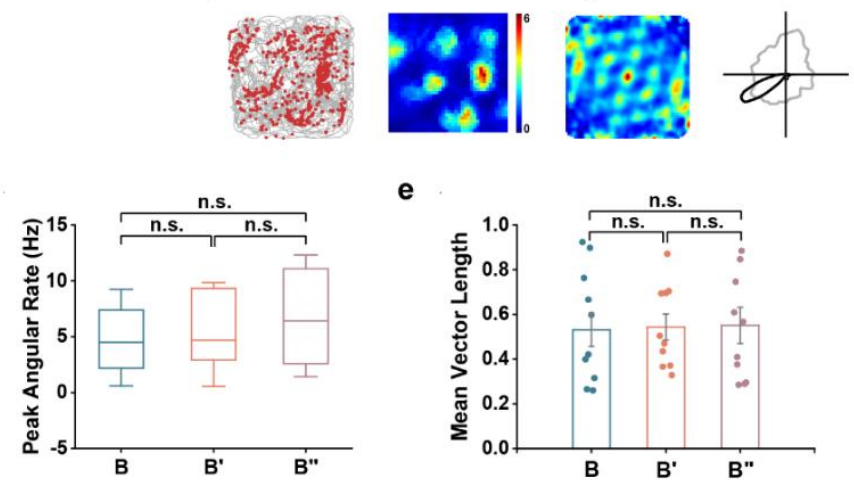

e
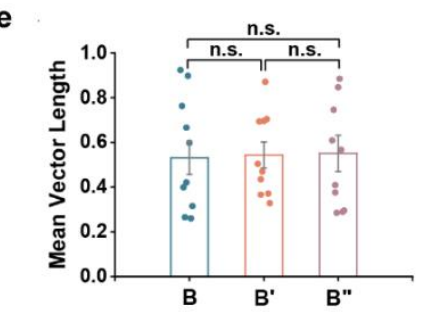


\section{Fig. S7 Head directionality preserved during bimodal shift of grid firing patterns.}

874 (a-b) Co-recorded representative conjunctive grid cell and head-direction cell during bimodal switch of

875 grid firing patterns. The head directionality of one conjunctive V2 grid cell and one V2 head-direction

876 cell preserved while the grid pattern switched between two different spatial firing patterns.

877 (c) Polar plots showing offset of peak angular direction of conjunctive grid cells $(n=4)$ and head-

878 direction cells $(n=6)$ during bimodal switch of grid firing patterns.

879 (d-e) The peak angular rate and mean vector length showed no significant change during bimodal 880 remapping of V2 grid cell firing patterns. 
bioRxiv preprint doi: https://doi.org/10.1101/2021.10.30.466568; this version posted November 2, 2021. The copyright holder for this preprint (which was not certified by peer review) is the author/funder, who has granted bioRxiv a license to display the preprint in perpetuity. It is made available under aCC-BY-NC-ND 4.0 International license.

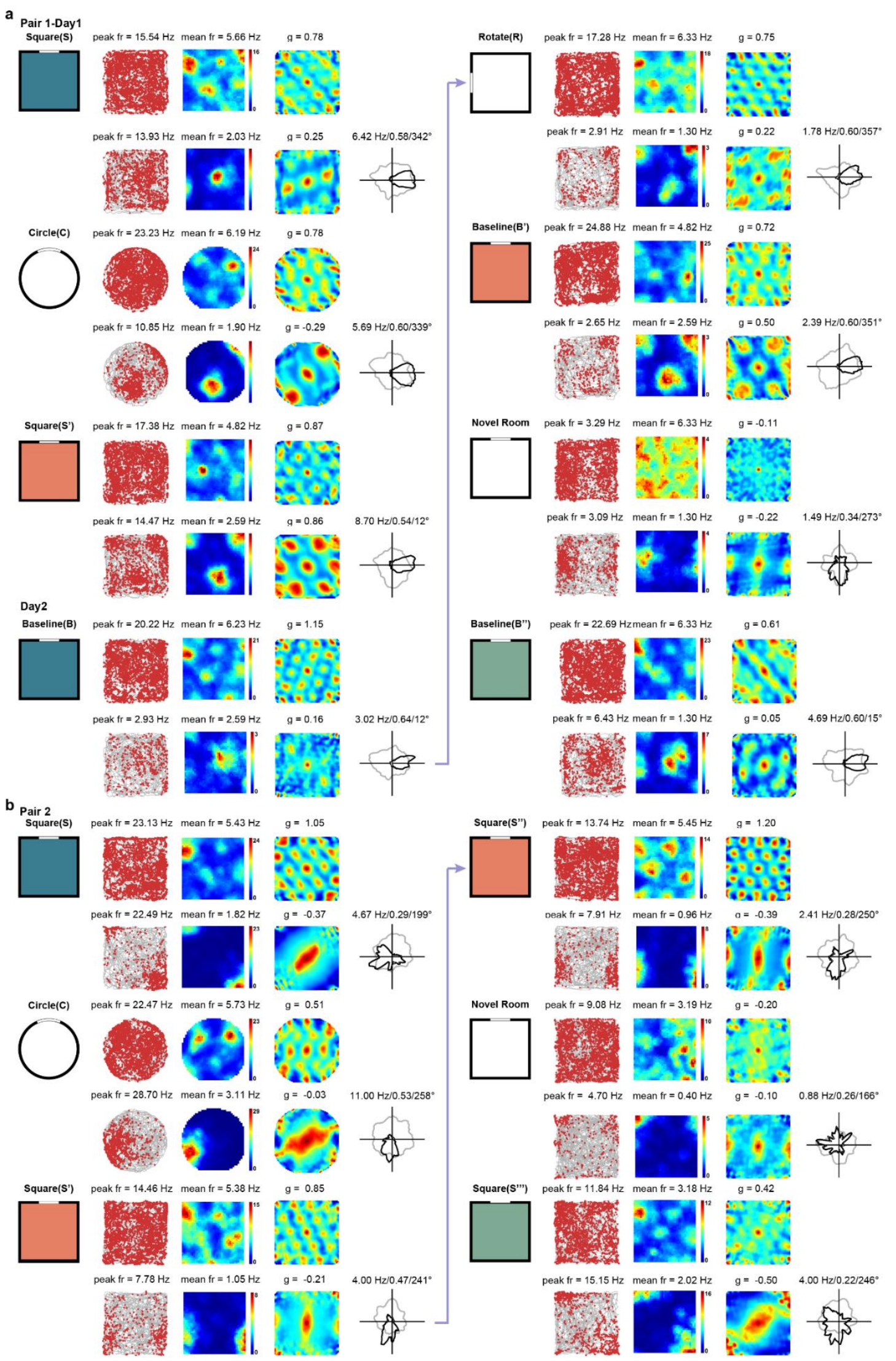


882 Fig. S8 Co-vary and co-restoration of grid firing patterns of two pairs of co-recorded V2 bimodal 883 grid cells.

884 (a) Simultaneously recording of a bimodal grid cell and a conjunctive bimodal grid cell switch their 885 spatial firing pattern when the familiar environment change, and restore the same firing pattern when re886 entry into the same familiar environment from a novel room. Note that the head directionality of the 887 conjunctive bimodal grid cell remained unchanged despite the bimodal switch of spatial firing pattern.

888 (b) Simultaneously recorded a bimodal grid cell and a conjunctive bimodal grid cell switch their spatial 889 firing pattern when the familiar environment changes. 
bioRxiv preprint doi: https://doi.org/10.1101/2021.10.30.466568; this version posted November 2. 2021. The copyright holder for this preprint (which was not certified by peer review) is the author/funder, who has granted bioRxiv a license to display the preprint in perpetuity. It is made available under aCC-BY-NC-ND 4.0 International license.

890

(i)
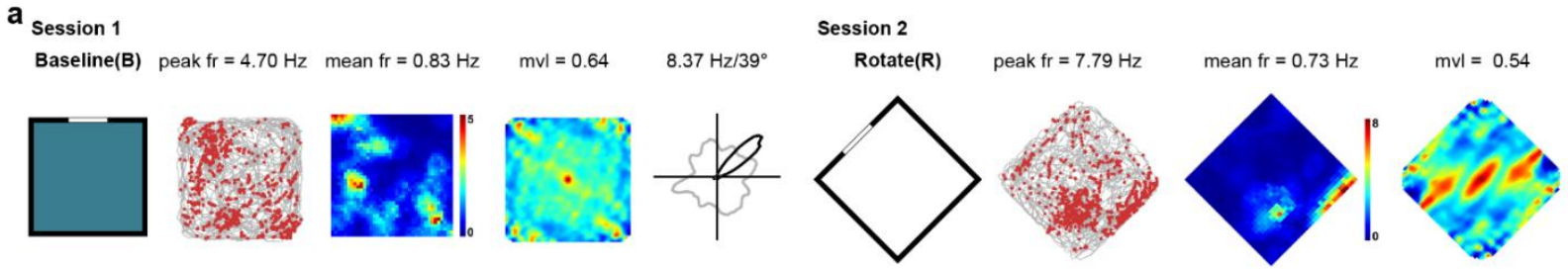

$6.68 \mathrm{~Hz} / 90^{\circ}$

peak $\mathrm{fr}=8.29 \mathrm{~Hz}$ mean $\mathrm{fr}=1.07 \mathrm{~Hz}$

$g=1.20$
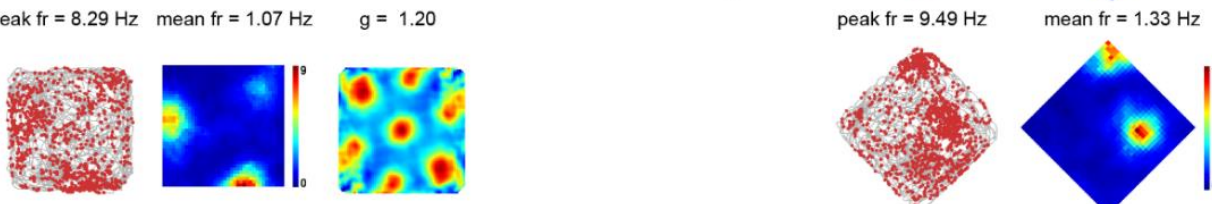

$g=0.42$

peak $\mathrm{fr}=2.35 \mathrm{~Hz}$ mean $\mathrm{fr}=0.32 \mathrm{~Hz}$

$b=0.64$
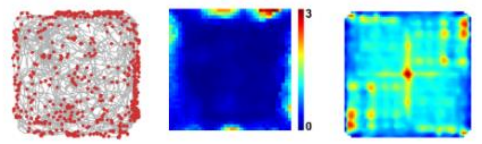

Session 3

Baseline(B') peak fr $=7.22 \mathrm{~Hz}$
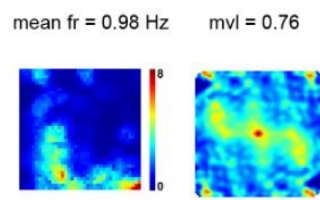

$11.10 \mathrm{~Hz} / 33^{\circ}$
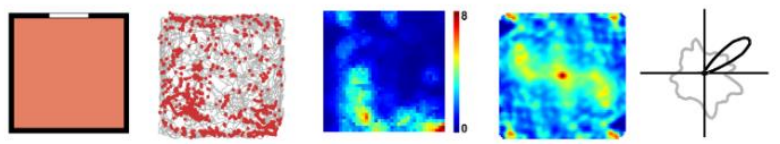

peak $\mathrm{fr}=6.40 \mathrm{~Hz}$

mean $\mathrm{fr}=1.04 \mathrm{~Hz}$

$g=0.82$
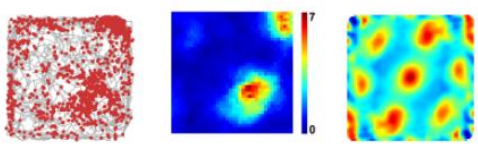

peak $\mathrm{fr}=3.47 \mathrm{~Hz}$ mean $\mathrm{fr}=0.40 \mathrm{~Hz}$

$b=0.84$
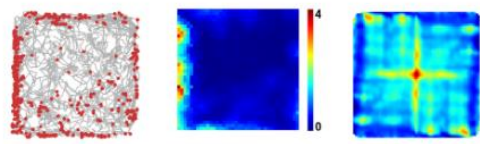

Session 5

Baseline(B") peak $\mathrm{fr}=7.27 \mathrm{~Hz}$ mean $\mathrm{fr}=1.33 \mathrm{~Hz}$
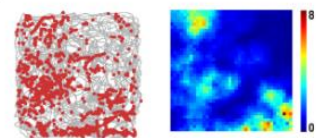

$\mathrm{mvl}=0.76$
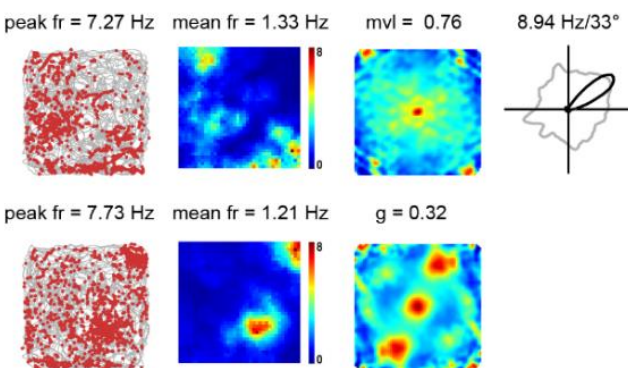

$g=0.32$

peak $\mathrm{fr}=5.09 \mathrm{~Hz}$ mean $\mathrm{fr}=0.77 \mathrm{~Hz}$

$b=0.81$
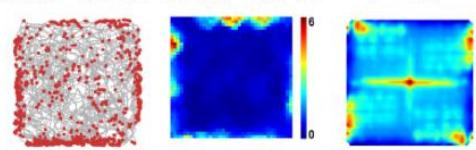
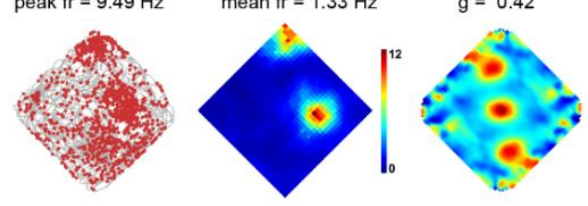

peak $\mathrm{fr}=4.62 \mathrm{~Hz}$
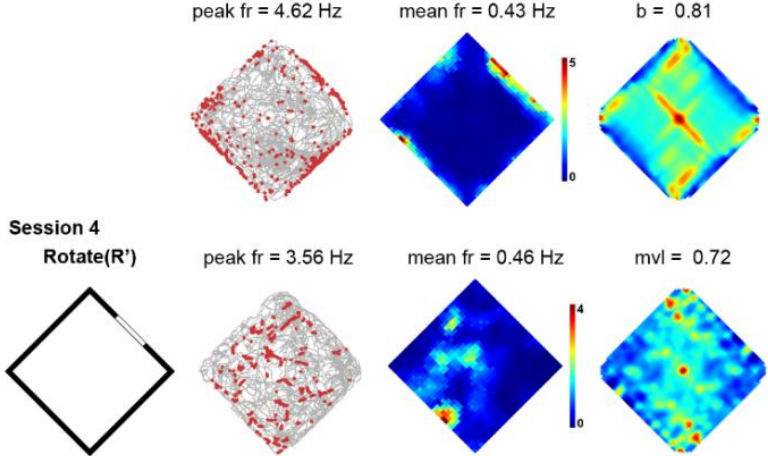

peak $\mathrm{fr}=3.56 \mathrm{~Hz}$
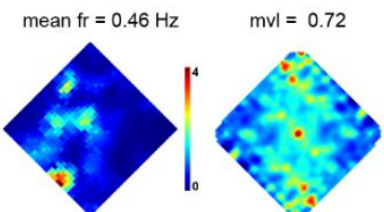

$4.44 \mathrm{~Hz} / 352^{\circ}$

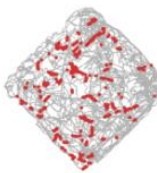

peak $\mathrm{fr}=9.15 \mathrm{~Hz}$

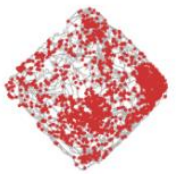

mean $\mathrm{fr}=1.61 \mathrm{~Hz}$

$g=0.07$

peak $\mathrm{fr}=7.33 \mathrm{~Hz}$
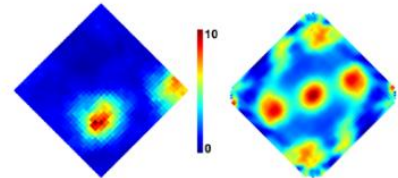

mean $\mathrm{fr}=1.01 \mathrm{~Hz}$

$b=0.79$
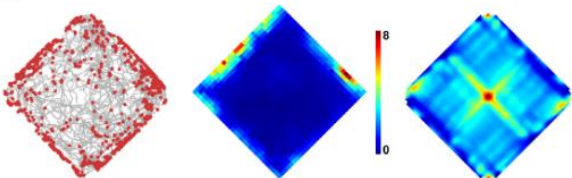
bioRxiv preprint doi: https://doi.org/10.1101/2021.10.30.466568; this version posted November 2, 2021. The copyright holder for this preprint (which was not certified by peer review) is the author/funder, who has granted bioRxiv a license to display the preprint in perpetuity. It is made available under aCC-BY-NC-ND 4.0 International license.

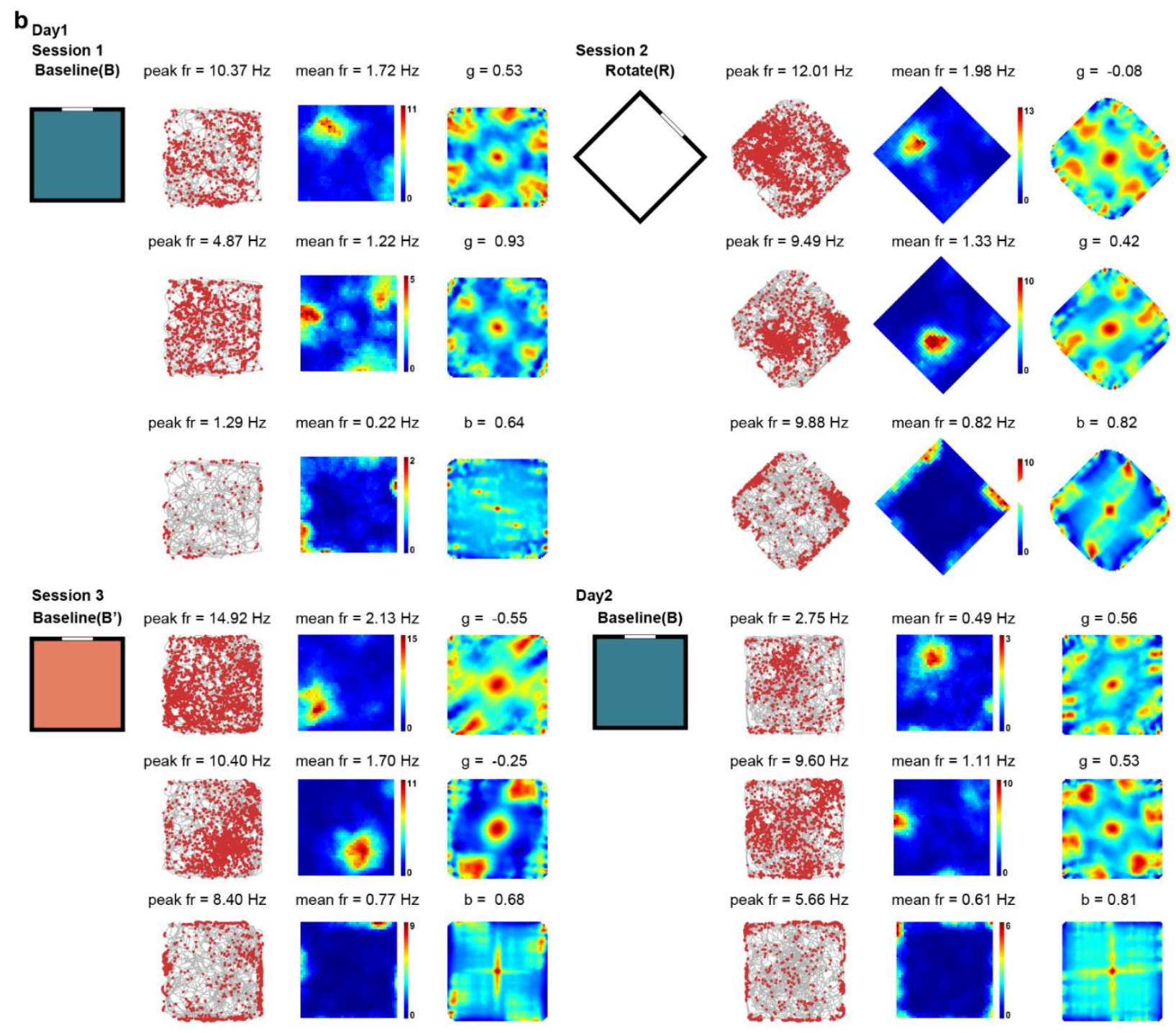

(a) Simultaneously recording of one head-direction cell, one bimodal grid cell and one border cell.

894 (b) Simultaneously recording of two bimodal grid cells and one border cell. 
bioRxiv preprint doi: https://doi.org/10.1101/2021.10.30.466568; this version posted November 2, 2021. The copyright holder for this preprint (which was not certified by peer review) is the author/funder, who has granted bioRxiv a license to display the preprint in perpetuity. It is made available under aCC-BY-NC-ND 4.0 International license.

895 (ii)
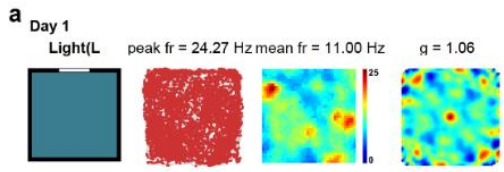

peak $\mathrm{fr}=0.56 \mathrm{~Hz}$ mean $\mathrm{fr}=0.08 \mathrm{~Hz} \quad \mathrm{myl}=0.72$

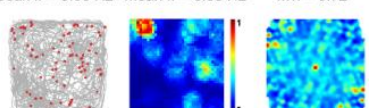
tastare

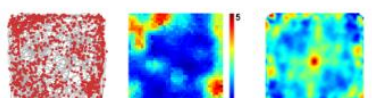

Dark(D) Deak fr $=10.56 \mathrm{~Hz}$ mean $\mathrm{fr}=10.56 \mathrm{~Hz} \quad g=0.76$

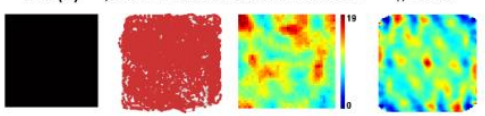

peak $\mathrm{fr}=0.40 \mathrm{~Hz}$ mean $\mathrm{fr}=0.10 \mathrm{~Hz} \quad \mathrm{mvl}=0.72$

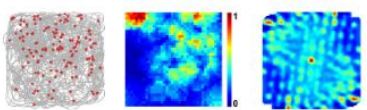
peak $\mathrm{fr}=4.32 \mathrm{~Hz}$ mean $\mathrm{fr}=4.32 \mathrm{~Hz} \quad \mathrm{~b}=0.59$

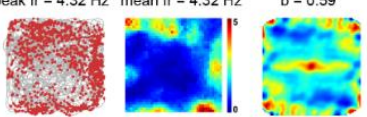

Light( (L') peak fr $=5.00 \mathrm{~Hz}$ mean $\mathrm{fr}=4.99 \mathrm{~Hz}$

$g=1.06$

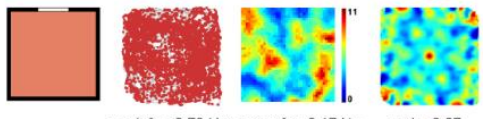

peak $\mathrm{fr}=0.78 \mathrm{~Hz}$ mean $\mathrm{fr}=0.17 \mathrm{~Hz} \quad \mathrm{mvl}=0.67$
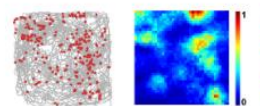

peak $\mathrm{fr}=14.44 \mathrm{~Hz}$ mean $\mathrm{fr}=14.44 \mathrm{~Hz}$

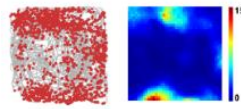

Circle(C) peak $\mathrm{fr}=21.61 \mathrm{~Hz}$ mean $\mathrm{fr}=7.96 \mathrm{~Hz}$
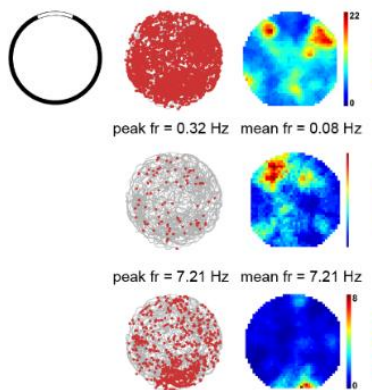

$\left.\right|_{0} ^{1}$

Square(
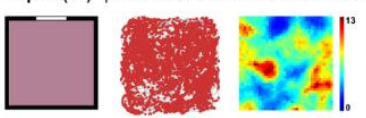

$g=1.25$

peak $\mathrm{fr}=0.35 \mathrm{~Hz}$ mean $\mathrm{fr}_{\mathrm{r}}=0.10 \mathrm{~Hz}$

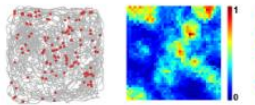

peak $\mathrm{fr}=12.57 \mathrm{~Hz}$ mean $\mathrm{fr}=12.57 \mathrm{~Hz}$

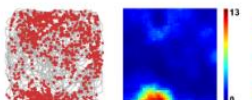

$\mathrm{b}=0.63$

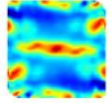

$g=0.49$

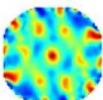

$\mathrm{mvl}=0.43$

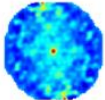

$=0.61$ peak $\mathrm{fr}=0.32 \mathrm{~Hz}$ mean $\mathrm{fr}=0.08 \mathrm{~Hz}$
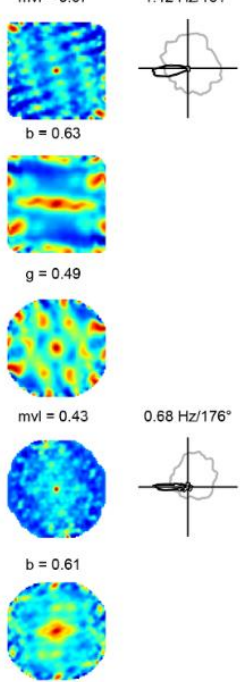

$0.68 \mathrm{~Hz} / 176^{\circ}$
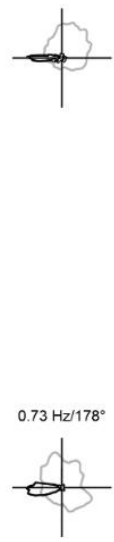

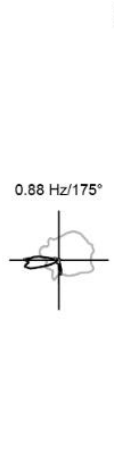

b Day 2

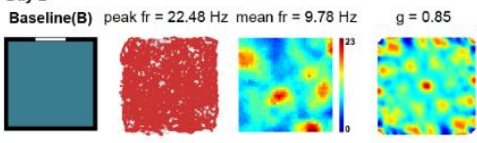

peak $\mathrm{fr}=0.27 \mathrm{~Hz}$ mean $\mathrm{fr}=0.04 \mathrm{~Hz} \quad \mathrm{mvl}=0.85$

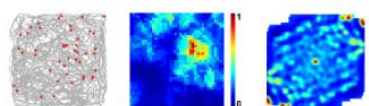

$0.60 \mathrm{~Hz} / 193^{\circ}$

peak $\mathrm{fr}=6.82 \mathrm{~Hz}$ mean fr $=1.56 \mathrm{~Hz} \quad \mathrm{~b}=0.40$

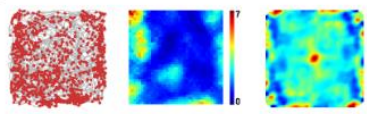

Rotate(R) peak fr $=20.04 \mathrm{~Hz}$ mean $\mathrm{fr}=9.57 \mathrm{~Hz} \quad g=0.67$
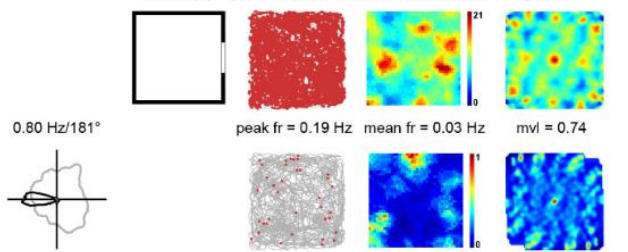

peak $\mathrm{fr}=0.19 \mathrm{~Hz}$
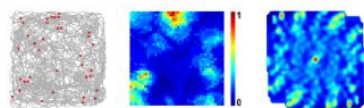

$0.24 \mathrm{~Hz} / 167^{\circ}$

peak $\mathrm{fr}=8.22 \mathrm{~Hz}$ mean $\mathrm{fr}=1.18 \mathrm{~Hz} \quad b=0.83$
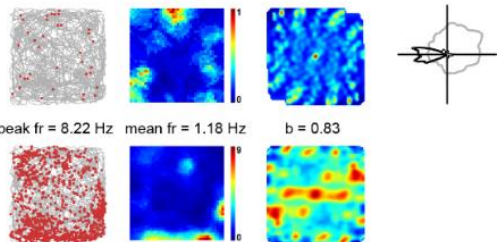

Baseline(B') peak $\mathrm{fr}=21.22 \mathrm{~Hz}$ mean $\mathrm{fr}=8.67 \mathrm{~Hz} \quad g=1.25$

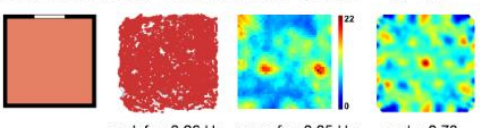

peak $\mathrm{fr}=0.26 \mathrm{~Hz}$ mean $\mathrm{fr}=0.05 \mathrm{~Hz} \quad \mathrm{mvl}=0.70$
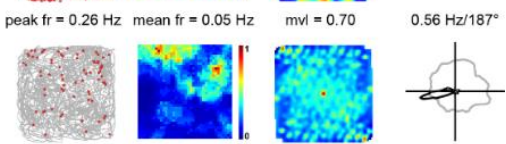

peak $\mathrm{fr}=16.43 \mathrm{~Hz}$ mean $\mathrm{fr}=1.82 \mathrm{~Hz} \quad \mathrm{~b}=0.82$

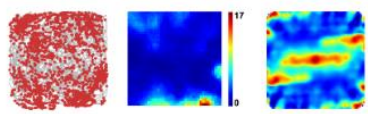

Rotate $\left(R^{\prime}\right)$ peak $\mathrm{fr}=20.88 \mathrm{~Hz}$ mean $\mathrm{fr}=9.62 \mathrm{~Hz} \quad \mathrm{~g}=0.88$
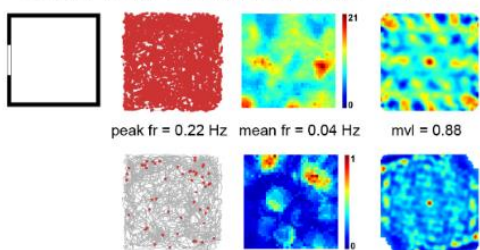

peakfr $=6.97 \mathrm{~Hz}$ mean $\mathrm{fr}=0.99 \mathrm{~Hz} \quad b=0.64$

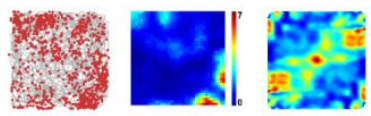

Baseline(B") peak $\mathrm{fr}=20.23 \mathrm{~Hz}$ mean $\mathrm{fr}=9.98 \mathrm{~Hz} \quad \mathrm{~g}=1.27$
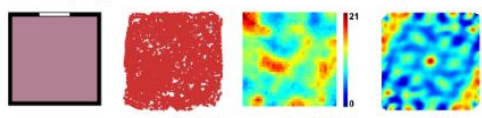

peak $\mathrm{fr}=0.15 \mathrm{~Hz}$ mean $\mathrm{fr}=0.03 \mathrm{~Hz} \quad \mathrm{mvl}=0.75$
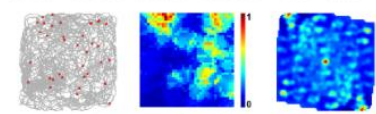

$0.30 \mathrm{~Hz} / 184^{\circ}$

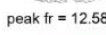

mean $\mathrm{fr}=1.66$
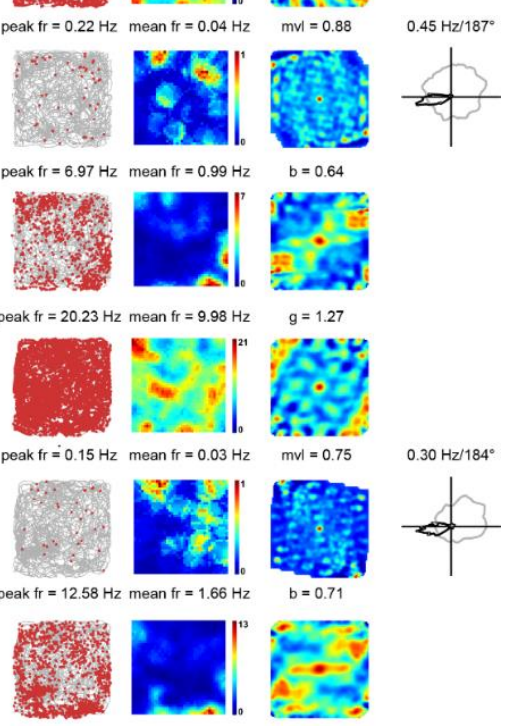
bioRxiv preprint doi: https://doi.org/10.1101/2021.10.30.466568; this version posted November 2, 2021. The copyright holder for this preprint

(which was not certified by peer review) is the author/funder, who has granted bioRxiv a license to display the preprint in perpetuity. It is made available under aCC-BY-NC-ND 4.0 International license.

897 (a) Simultaneously recording of one bimodal grid cell, one head-direction cell and one border cell in 898 V2 on day 1.

899 (b) Simultaneously recording of same three spatial cells on day 2. 
bioRxiv preprint doi: https://doi.org/10.1101/2021.10.30.466568; this version posted November 2. 2021. The copyright holder for this preprint (which was not certified by peer review) is the author/funder, who has granted bioRxiv a license to display the preprint in perpetuity. It is made available under aCC-BY-NC-ND 4.0 International license.

$900 \quad$ (iii)

a

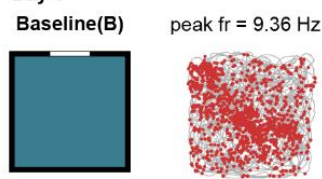

peak $\mathrm{fr}=8.68 \mathrm{~Hz}$
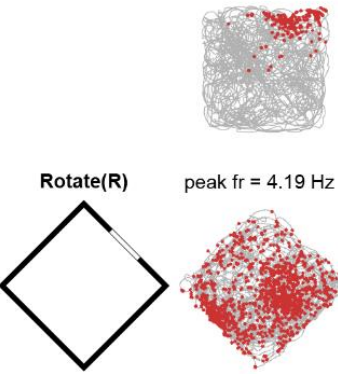

peak $\mathrm{fr}=4.93 \mathrm{~Hz}$
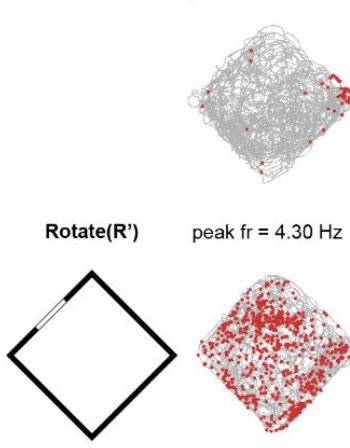

peak $\mathrm{fr}=4.30 \mathrm{~Hz}$

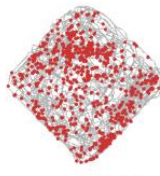

peak $\mathrm{fr}=4.88 \mathrm{~Hz}$

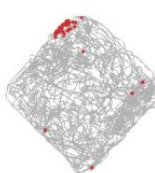

Baseline(B')
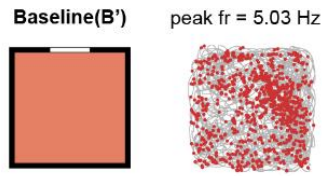

peak $\mathrm{fr}=6.62 \mathrm{~Hz}$

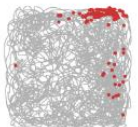

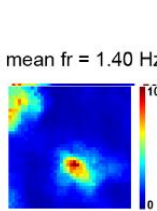

mean $\mathrm{fr}=0.28 \mathrm{~Hz}$
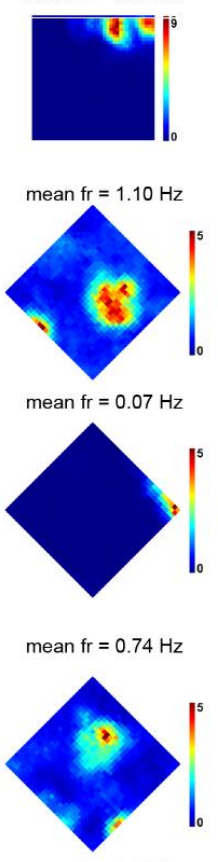

mean $\mathrm{fr}=0.08 \mathrm{~Hz}$
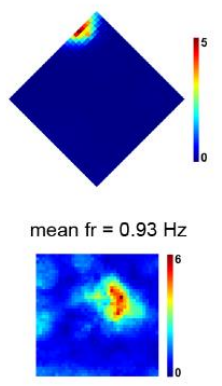

mean $\mathrm{fr}=0.14 \mathrm{~Hz}$

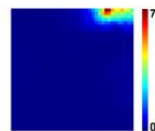

b

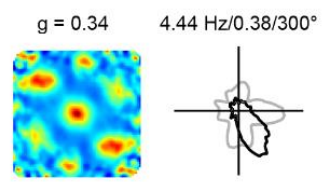

$\mathrm{si}=4.70$
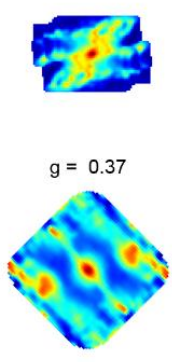

$3.44 \mathrm{~Hz} / 0.31 / 259^{\circ}$
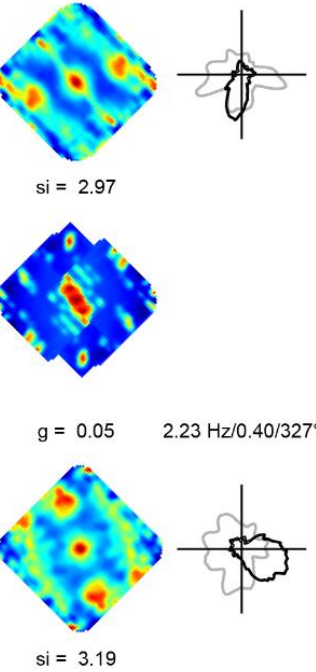

$2.23 \mathrm{~Hz} / 0.40 / 327^{\circ}$
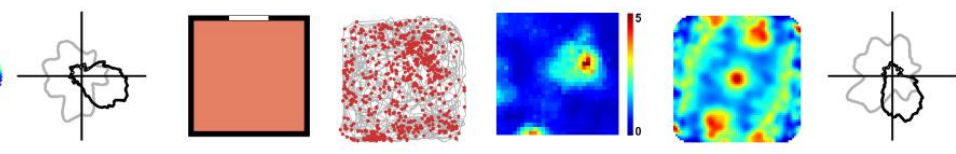

peak $\mathrm{fr}=4.88 \mathrm{~Hz}$ mean $\mathrm{fr}=0.08 \mathrm{~Hz} \quad \mathrm{si}=3.19$
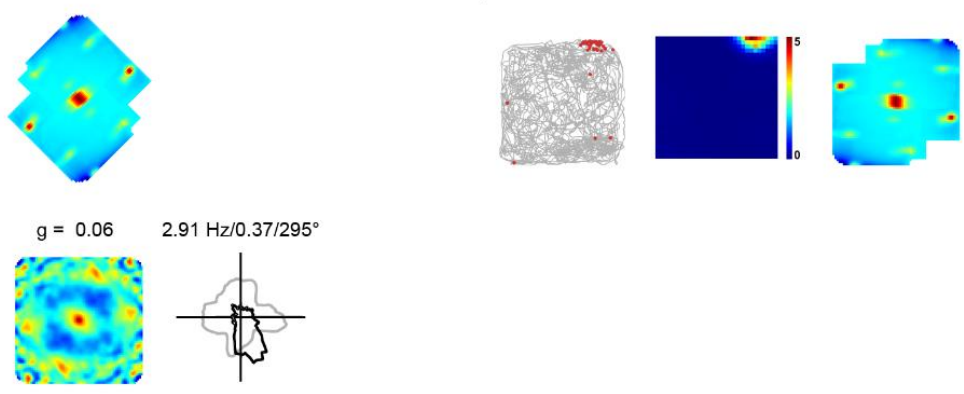

$2.91 \mathrm{~Hz} / 0.37 / 295^{\circ}$
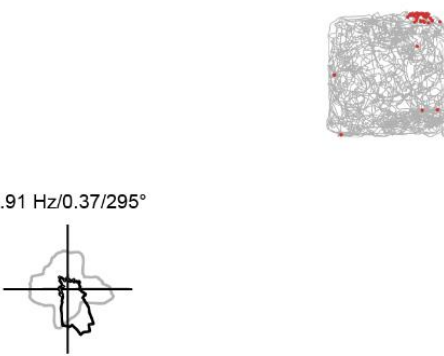

$s i=4.21$

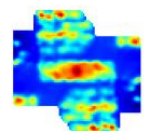

902 (a) Simultaneously recording of one conjunctive bimodal grid cell and one place cell in V2 on day 1.

903 (b) Simultaneously recording of same two spatial cells on day 2. 
bioRxiv preprint doi: https://doi.org/10.1101/2021.10.30.466568; this version posted November 2, 2021. The copyright holder for this preprint (which was not certified by peer review) is the author/funder, who has granted bioRxiv a license to display the preprint in perpetuity. It is made available under aCC-BY-NC-ND 4.0 International license.

904 (iv)

a Day 1

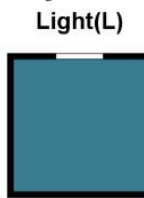

Dark(D)

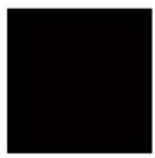

Light(L')

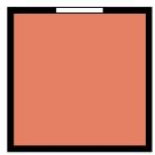

Novel Room

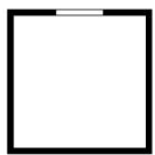

Baseline(B')

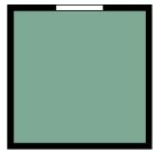

Rotate(R)

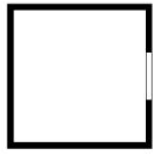

Baseline(B')

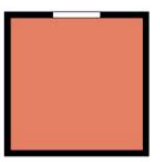

Dark(D')

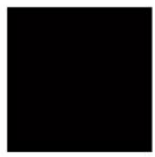

Light(L')

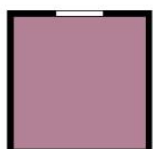

peak $\mathrm{fr}=3.23 \mathrm{~Hz}$

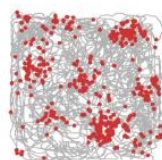

peak $\mathrm{fr}=5.64 \mathrm{~Hz}$

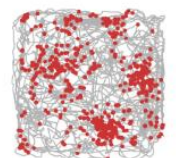

peak $\mathrm{fr}=3.78 \mathrm{~Hz}$

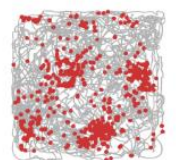

peak $\mathrm{fr}=18.17 \mathrm{~Hz}$

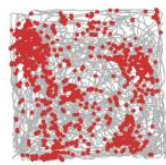

peak $\mathrm{fr}=14.72 \mathrm{~Hz}$

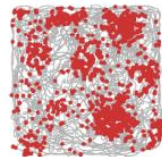

peak $\mathrm{fr}=14.13 \mathrm{~Hz}$

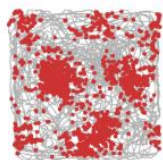

peak $\mathrm{fr}=6.01 \mathrm{~Hz}$

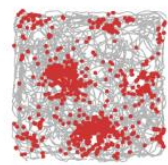

peak $\mathrm{fr}=6.91 \mathrm{~Hz}$

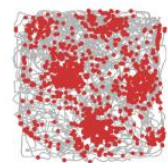

peak $\mathrm{fr}=6.39 \mathrm{~Hz}$

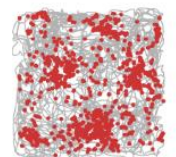

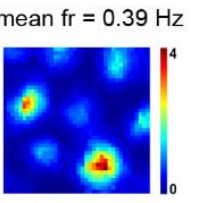

mean $\mathrm{fr}=0.45 \mathrm{~Hz}$

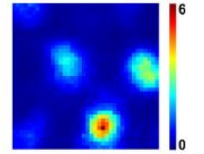

mean $\mathrm{fr}=0.51 \mathrm{~Hz}$

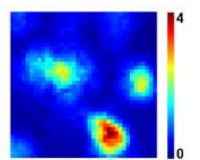

mean $\mathrm{fr}=1.08 \mathrm{~Hz}$

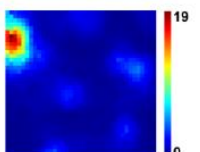

mean $\mathrm{fr}=1.57 \mathrm{~Hz}$

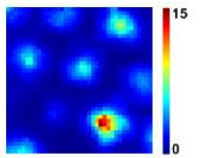

mean $\mathrm{fr}=1.91 \mathrm{~Hz}$

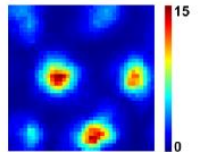

mean $\mathrm{fr}=0.72 \mathrm{~Hz}$

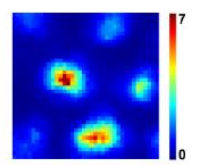

mean $\mathrm{fr}=0.92 \mathrm{~Hz}$

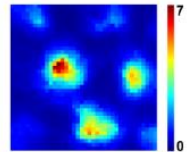

mean $\mathrm{fr}=0.79 \mathrm{~Hz}$

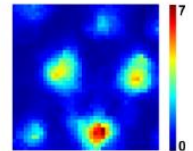

b Day 2
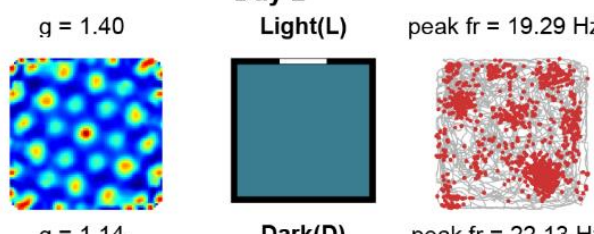

Dark(D)

peak $\mathrm{fr}=22.13 \mathrm{~Hz}$
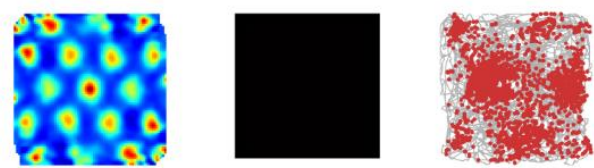

Light(L')

peak $\mathrm{fr}=21.78 \mathrm{~Hz}$
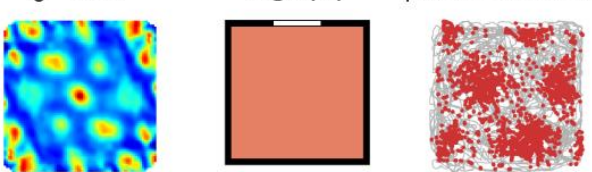

$g=1.08$

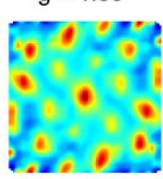

$g=1.21$

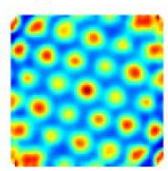

C Day 3

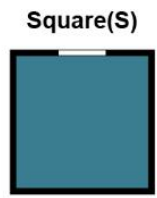

peak $\mathrm{fr}=25.87 \mathrm{~Hz}$

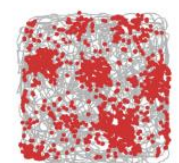

Circle(C) peak fr $=15.19 \mathrm{~Hz}$
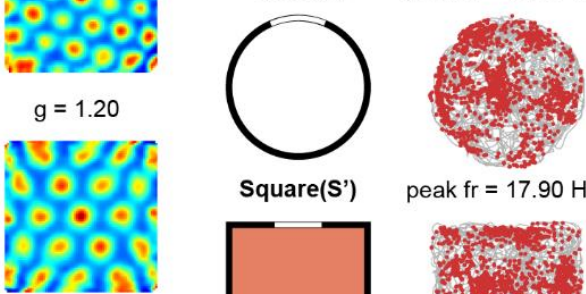

Square(S')

peak $\mathrm{fr}=17.90 \mathrm{~Hz}$

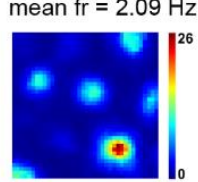

mean $\mathrm{fr}=2.05 \mathrm{~Hz}$

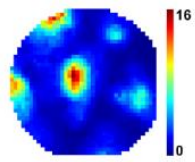

mean $\mathrm{fr}=2.64 \mathrm{~Hz}$
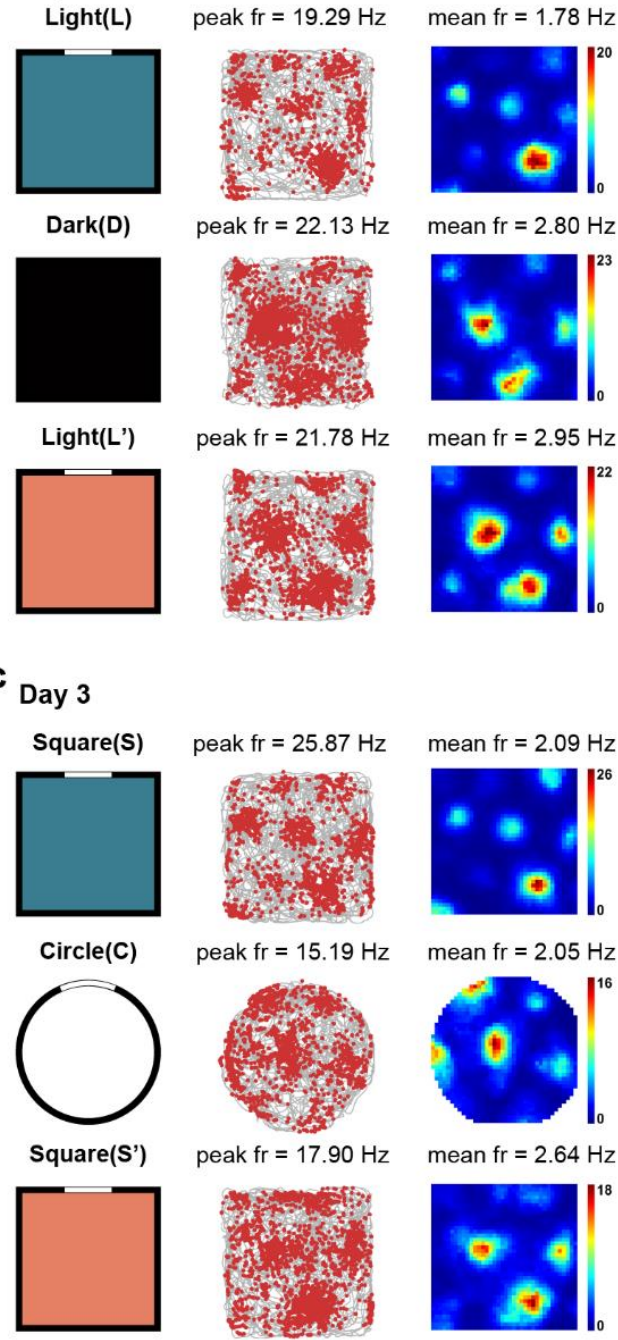

mean $\mathrm{fr}=2.80 \mathrm{~Hz}$

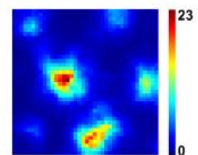

mean $\mathrm{fr}=2.95 \mathrm{~Hz}$

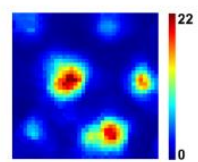

$g=1.10$

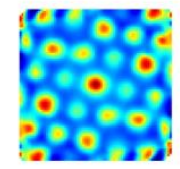

$g=0.50$
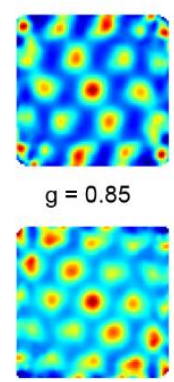

(a) Bimodal switch of a bimodal grid cell in responses to environmental changes and restoration of the

907 original pattern after re-entry into the same familiar environment. 
bioRxiv preprint doi: https://doi.org/10.1101/2021.10.30.466568; this version posted November 2, 2021. The copyright holder for this preprint (which was not certified by peer review) is the author/funder, who has granted bioRxiv a license to display the preprint in perpetuity. It is made available under aCC-BY-NC-ND 4.0 International license.

908 (b) Bimodal switch of grid firing patterns after total darkness.

909 (c) Recording of the same bimodal grid cell across different shapes of running boxes. 
bioRxiv preprint doi: https://doi. org/10.1101/2021.1030.466568. this version posted November 2, 2021. The copyright holder for this preprint (which was not certified by peer review) is the author/funder, who has granted bioRxiv a license to display the preprint in perpetuity. It is made available under aCC-BY-NC-ND 4.0 International license.

$910 \quad(\mathbf{v})$
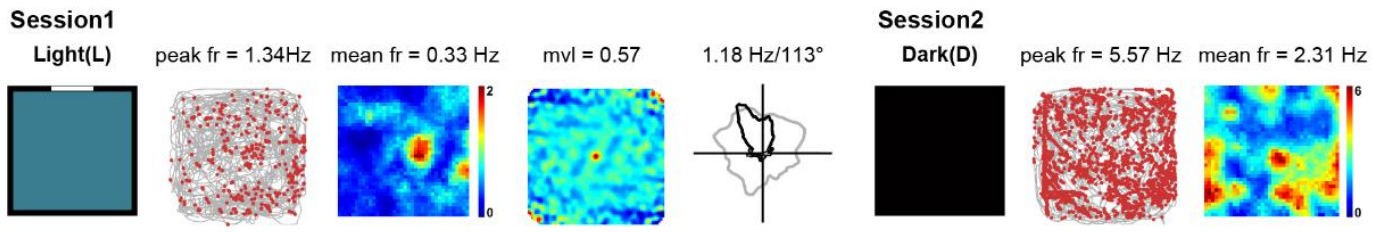

peak $\mathrm{fr}=11.03 \mathrm{~Hz}$ mean $\mathrm{fr}=2.05 \mathrm{~Hz}$

$g=-0.31$

peak $\mathrm{fr}=13.91 \mathrm{~Hz}$ mean $\mathrm{fr}=1.89 \mathrm{~Hz}$
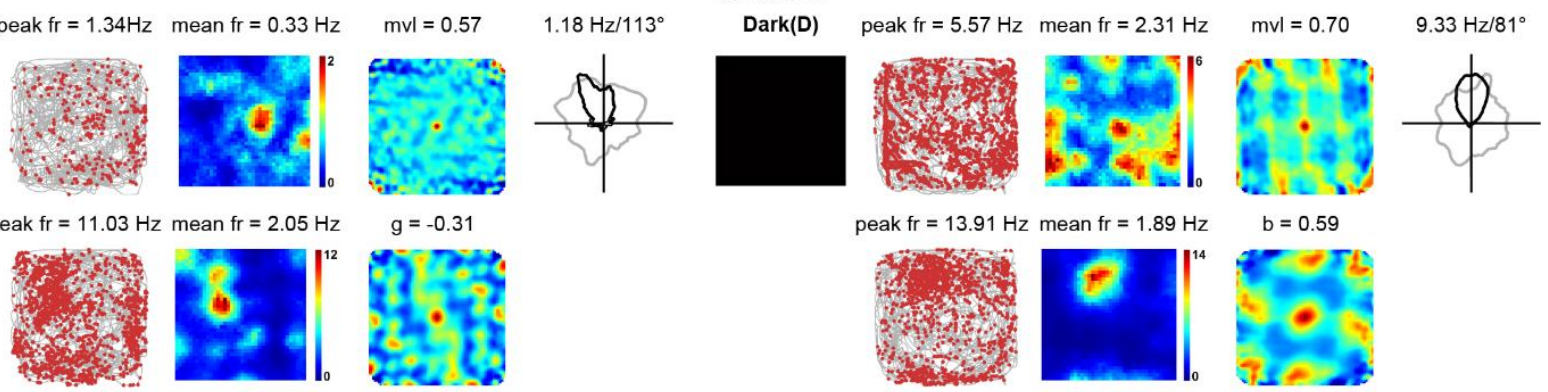

$b=0.59$

Light(L')
Ligsion3

peak $\mathrm{fr}=8.62 \mathrm{~Hz}$ mean $\mathrm{fr}=3.30 \mathrm{~Hz}$

$m v l=0.60 \quad 12.33 \mathrm{~Hz} / 87^{\circ}$

Session4

Light(L”) peak $\mathrm{fr}=6.62 \mathrm{~Hz}$ mean $\mathrm{fr}=2.32 \mathrm{~Hz}$
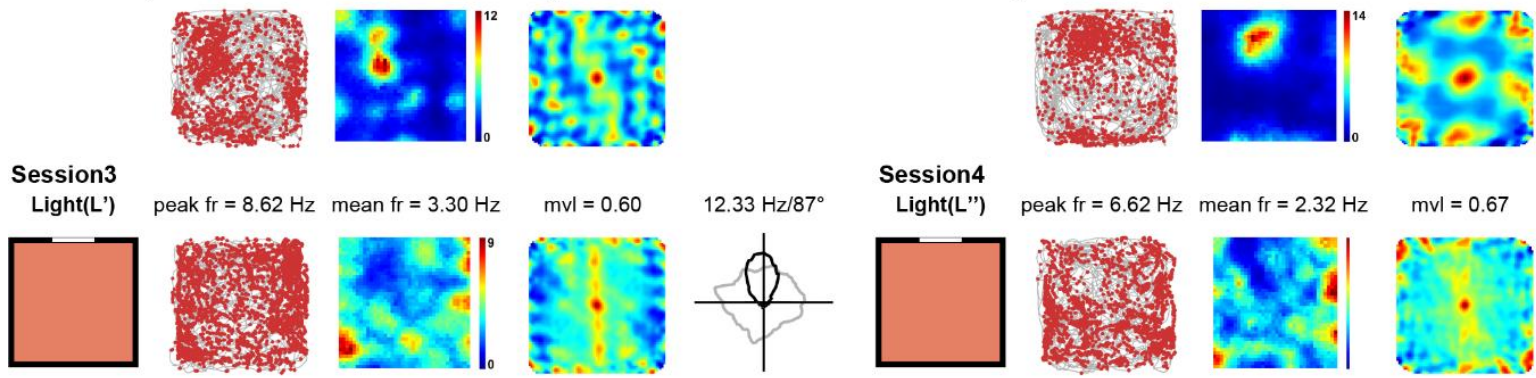

peak $\mathrm{fr}=11.87 \mathrm{~Hz}$ mean $\mathrm{fr}=2.20 \mathrm{~Hz}$

$g=0.54$
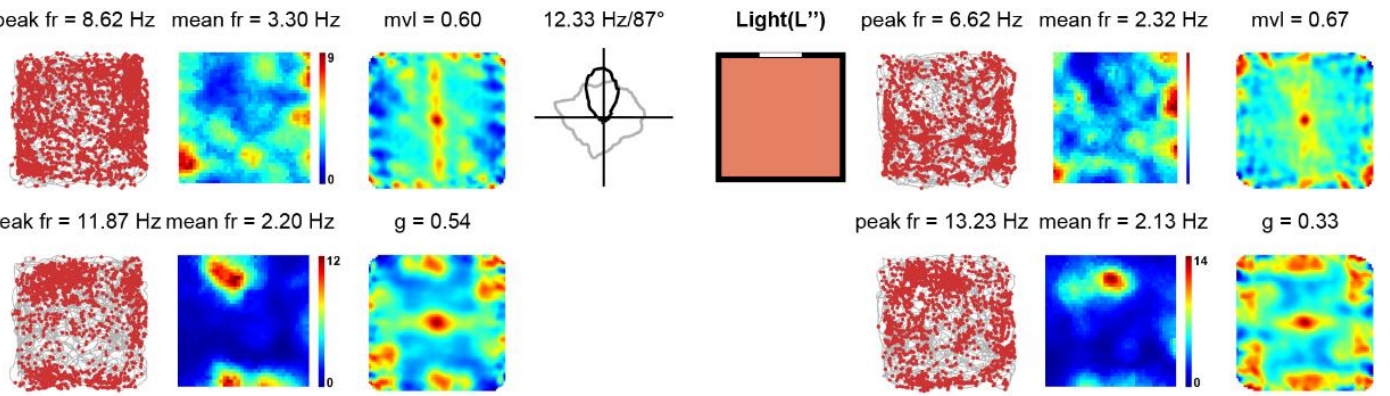

peak $\mathrm{fr}=13.23 \mathrm{~Hz}$ mean $\mathrm{fr}=2.13 \mathrm{~Hz}$
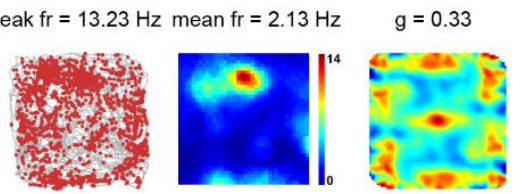

912 Simultaneously recording of one head-direction cell and one bimodal grid cell in V2 across light-light-

913 dark-light sessions. 
(vi)

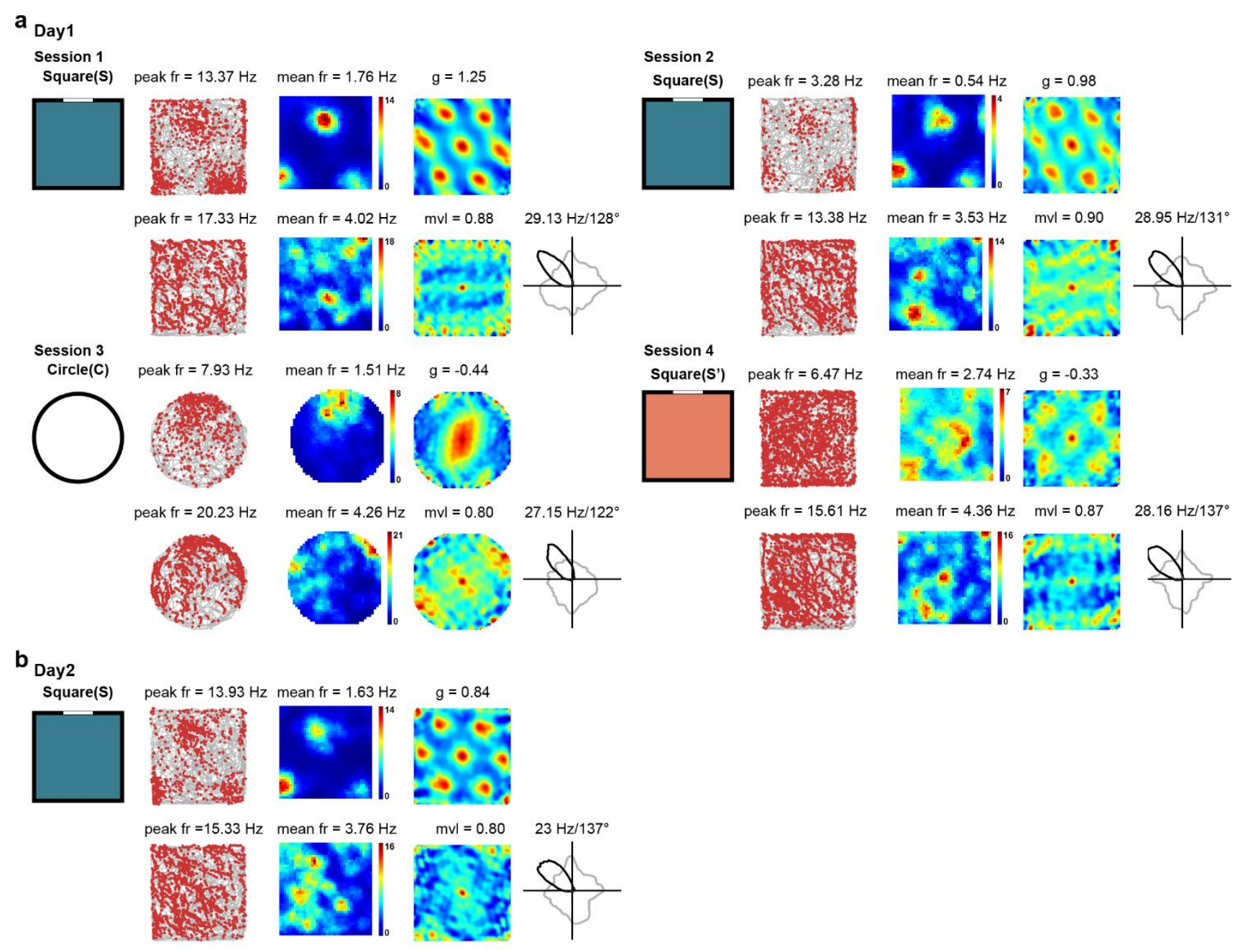

(a) Simultaneously recording of one bimodal grid cell and one head-direction cell.

917 (b) Simultaneously recording of same two spatial cells in (a) on day 2.

918 Fig. S9 Full sample of bimodal grid cells in V2. (i-vi) Switch of grid firing patterns in responses to

919 changes in a familiar environment and restoration of the grid pattern after re-entry into the same 920 environment from a novel room or from animals' home cage. 
bioRxiv preprint doi: https://doi.org/10.1101/2021.10.30.466568. this version posted November 2, 2021. The copyright holder for this preprint (which was not certified by peer review) is the author/funder, who has granted bioRxiv a license to display the preprint in perpetuity. It is made available under aCC-BY-NC-ND 4.0 International license.

a

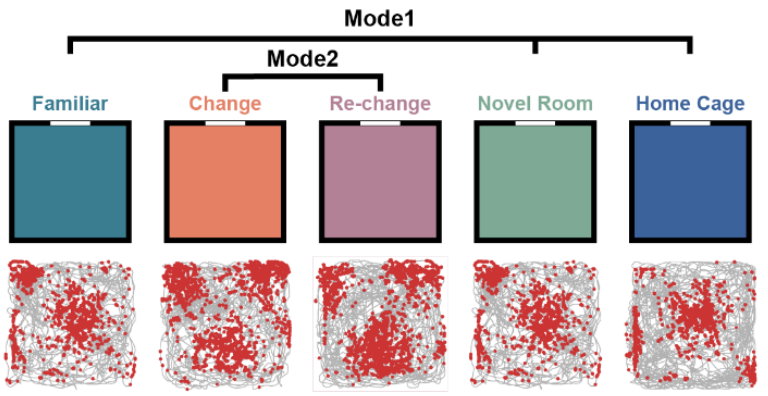

b Familiar

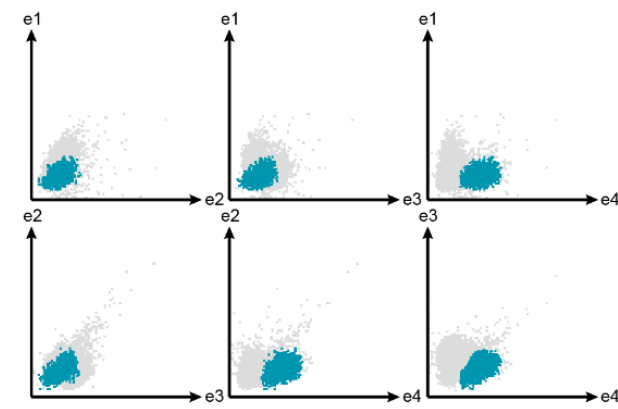

Re-change

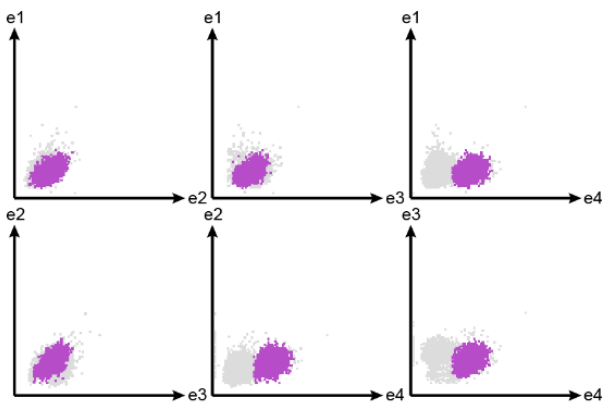

Home Cage

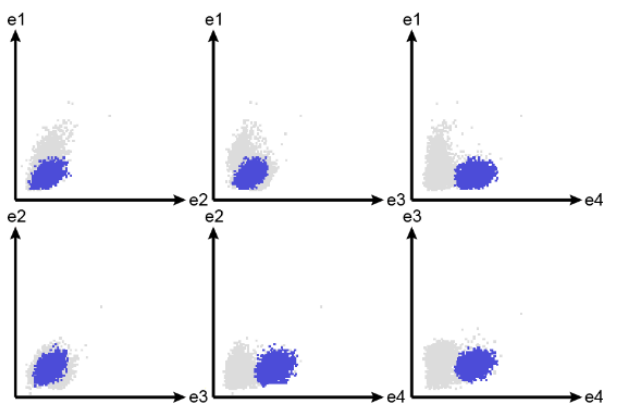

e

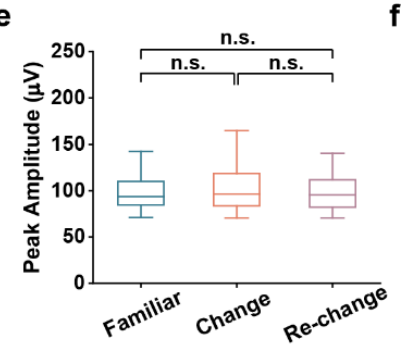

f

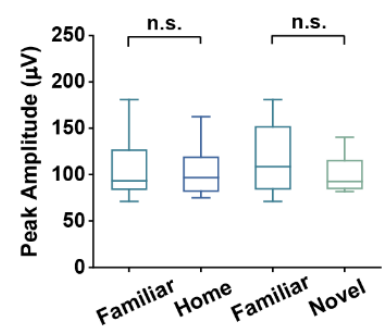

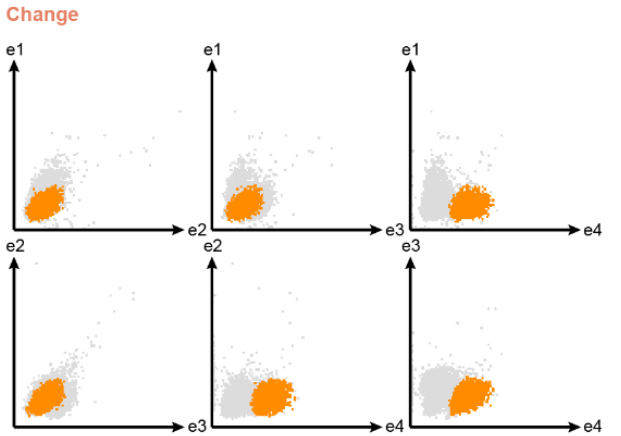

$150 \mu \mathrm{V} \bigsqcup_{300 \mu \mathrm{s}}$

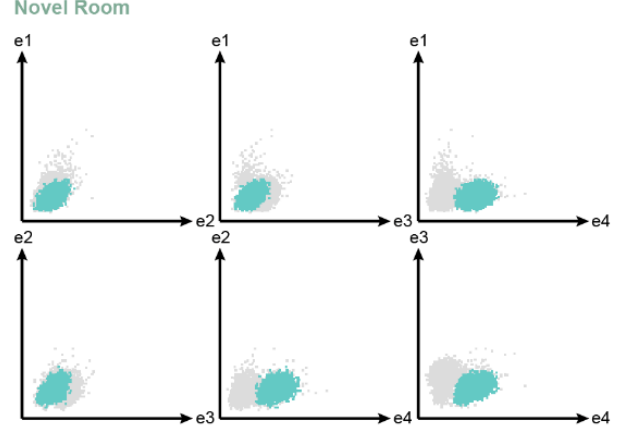

C

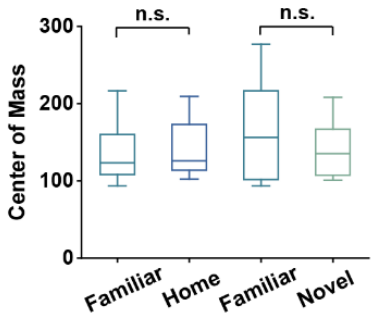

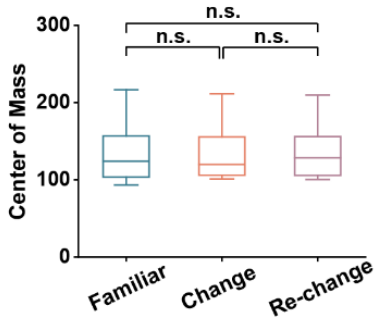

g
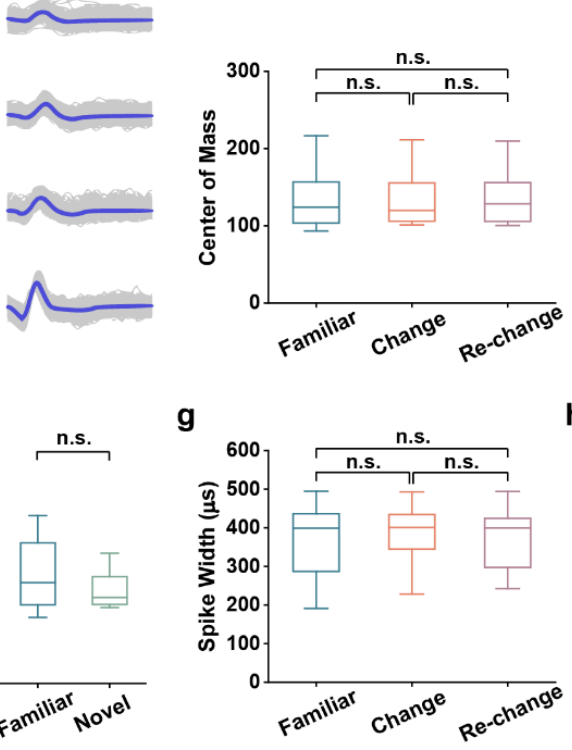
922 Fig. S10 Persistence of cluster diagram and spike waveform during bimodal switch of V2 grid 923 firing patterns.

924 (a) Bimodal firing patterns of the same grid cell in Fig. 2 under familiar environment, after 925 environmental change, re-change, re-entry from a novel room and re-entry from the home cage.

926 (b) Cluster diagram (left panel) showing the peak to trough amplitudes of recorded spikes on each pair 927 of electrodes (e1-e4) on a tetrode. Each dot represents a single spike with the color dots indicating the 928 spike cluster for the grid cell showing in (a). Waveforms on each of the four electrodes for the gird cells 929 are shown on the right panel. Spike clusters and waveforms are preserved during bimodal switch of grid 930 firing patterns.

931 (c-d) Centers of mass for the spike clusters of V2 bimodal grid cells are stable during shift (two-sided 932 Wilcoxon signed-rank test, Familiar-Change: $Z=0.23, P=0.82$; Change-Rechange: $Z=1.36, P=0.17$;

933 Familiar-Rechange, $Z=0.45, P=0.65, n=15$ ) and restoration (Familiar-Home cage: $Z=0.36, P=0.72$, $934 n=12$; Familiar-Novel room: $Z=0.85, P=0.40, n=7$ ) of grid structures.

935 (e-f) Peak amplitudes of V2 bimodal grid cells remain unaltered during shift (Familiar-Change: $Z=0.31$, $936 P=0.76$; Change-Rechange: $Z=1.19, P=0.23$; Familiar-Rechange, $Z=0.43, P=0.67$ ) and restoration 937 (Familiar-Home cage: $Z=0.94, P=0.35$; Familiar-Novel room: $Z=1.01, P=0.31$ ) of grid structures.

938 (g-h) Spike widths of V2 bimodal grid cells maintain during shift (Familiar-Change: $Z=0.82, P=0.41$;

939 Change-Rechange: $Z=1.36, P=0.17$; Familiar-Rechange, $Z=0.51, P=0.61$ ) and restoration (Familiar-

940 Home cage: $Z=0.82, P=0.41$; Familiar-Novel room: $Z=0.85, P=0.40$ ) of grid firing patterns. 